\title{
Synthesis of Protected Amino Hexitol Nucleosides as Building Blocks for Oligonucleotide Synthesis
}

\author{
Swarup De, ${ }^{\dagger}$ Amit M. Jabgunde, ${ }^{\dagger}$ Rahul S. Patil, ${ }^{\dagger}$ Steven De Jonghe, ${ }^{\dagger}$ L Leonid Beigelman, ${ }^{\dagger}$ \\ and Piet Herdewijn $*$,
}

${ }^{\dagger}$ KU Leuven, Rega Institute for Medical Research, Medicinal Chemistry, Herestraat 49, Leuven 3000, Belgium

${ }^{\ddagger}$ Aligos Therapeutics, 1 Corporate Drive, South San Francisco, California 94080, United States

\section{Supporting Information}

ABSTRACT: A new synthesis protocol for the preparation of hitherto unknown 1',5'-anhydro-4'-amino-trityl/MMTr hexitol nucleosides has been developed. Key steps in the synthesis of the pyrimidine analogues ( $\mathrm{U}$ and $\mathrm{C}$ ) include the

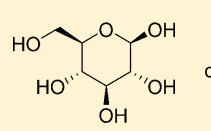

$\beta$-D-glucopyranose

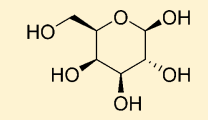

$\beta$-D-galactopyranose
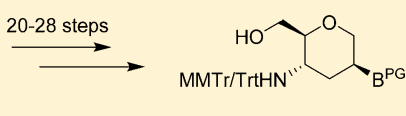

$B=A, U, G, C$ regioselective D-allo-hexitol oxirane and $2^{\prime}, 4^{\prime}$-anhydronucleoside ring opening by uracil and azide, respectively. A different strategy using a regioselective epoxide ring opening of D-gulooxirane, followed by a $S_{N} 2$ type of azidation reaction, has been adopted for the purine analogues (A and G). These compounds can be easily converted to $6^{\prime}$-phosphoramidites for the solid-phase synthesis of $\mathrm{N}^{\prime} \rightarrow \mathrm{P}^{\prime}$ phosphoramidates of amino hexitol nucleic acids (AHNA).

\section{INTRODUCTION}

Since the formulation of the antisense principle, ${ }^{1}$ a wide variety of synthetic oligonucleotides and their conjugates have been investigated, ${ }^{2}$ mainly aimed at the development of conformationally constrained oligomers ${ }^{3,4}$ that can inhibit gene expression by hindering the mRNA translation into proteins. A successful example is Vitravene, a phosphorothioate oligonucleotide that received marketing approval for the treatment of cytomegalovirus retinitis (CMV) infections in immunocompromised patients. ${ }^{5}$ Sugar, base, as well as the phosphodiester linker have been modified in this search for high affinity RNA binders. ${ }^{6}$ Major efforts in our and other laboratories have been devoted to the replacement of the fivemembered furanose moiety with a six-membered hexopyranosyl sugar mimic such as altritol nucleic acid (ANA), $3^{\prime}-O$ Me ANA, mannitol nucleic acid (MNA), ${ }^{7}$ cyclohexa(e)ne ring [cyclohexanyl NA (D-CNA), cyclohexenyl NA (D-CeNA)], and 3'-fluoro hexitol NA (FHNA and Ara-FHNA). ${ }^{8}$ One of the first examples of an oligonucleotide with a six-membered sugar modification that hybridizes with RNA is represented by hexitol nucleic acid (HNA). ${ }^{9}$ Among the natural DNA and RNA phosphodiester linker mimics, a notable example is the $\mathrm{N} 3^{\prime} \rightarrow \mathrm{P5}^{\prime}$ phosphoramidate oligonucleotide (in which the $3^{\prime}$ $\mathrm{O}$-atom of the ribose moiety is replaced by a $3^{\prime}$-amino group) that increases the duplex stability by an average of $2{ }^{\circ} \mathrm{C}$ per base pair versus RNA. ${ }^{10}$

The insertion of HNA units in DNA, as well as the introduction of $\mathrm{N}^{\prime} \rightarrow \mathrm{P}^{\prime}$ phosphoramidate linkages, lead to duplex stabilization with RNA. These observations prompted us to explore the synthesis of hybrid molecules, that is, $1^{\prime}, 5^{\prime}$ anhydro-3'-deoxy-4'-amino hexitol nucleosides (compounds 1-4, Figure 1), and the corresponding oligonucleotides. Here, we describe the synthesis of the amino hexitol nucleosides (AHNA) with the four natural RNA-nucleobases, that is, uracil
(1), cytosine (2), adenine (3), and guanine (4), as precursors, which can be easily converted to their $6^{\prime}$-phosphoramidites that can be used in the solid-phase synthesis of $\mathrm{N}^{\prime} \rightarrow \mathrm{P}^{\prime}$ phosphoramidates of HNA. In oligonucleotide synthesis, both the monomethoxytrityl (MMTr) and the trityl (Trt) can be used as protecting groups for the amino functionality, although trityl protection is easier to handle for stability reasons. These newly developed optimized synthetic strategies are useful to produce gram quantities of aminohexitol monomers that are required to explore the structural, functional, and biological properties of amino hexitol oligonucleotides.

Key transformations in the synthetic sequence are the introductions of the $4^{\prime}$-amino group and the nucleobases with the correct stereochemistry, as well as the regioselective introduction of orthogonal protecting groups.

For the synthesis of $\mathrm{D}$ - and $\mathrm{L}-1^{\prime}, 5^{\prime}$-anhydrohexitol nucleosides, two main strategies have been described in the literature. An appropriate protected 1',5'-anhydro-3'-deoxy-D-gluco-hexitol sugar moiety is synthesized first from D-glucose removing the $1^{\prime}$ - and $3^{\prime}$-hydroxyl groups, which is then coupled in $S_{N} 2$ manner with nucleobases at $2^{\prime}$-position. ${ }^{11}$ Alternatively, the protected $1^{\prime}, 5^{\prime}: 2^{\prime}, 3^{\prime}$-dianhydro-L-allo-hexitol oxirane is prepared and $1^{\prime}, 5^{\prime}$-anhydro-2' -(nucleobase)-2',3' -dideoxy-L-altrohexitol is then obtained by epoxide ring opening with the nucleobases followed by deoxygenation of the $3^{\prime}$-hydroxyl group. ${ }^{12}$ It is apparent that compounds $\mathbf{1 - 4}$ are accessible via two these major routes, as demonstrated in the retrosynthetic analysis (Figure 2). Reduction of a $4^{\prime}$-azido group is considered as an easy transformation to get an amine functionality at $4^{\prime}$-position. However, to introduce a $4^{\prime}$-azido

Received: September 20, 2018

Published: December 7, 2018 


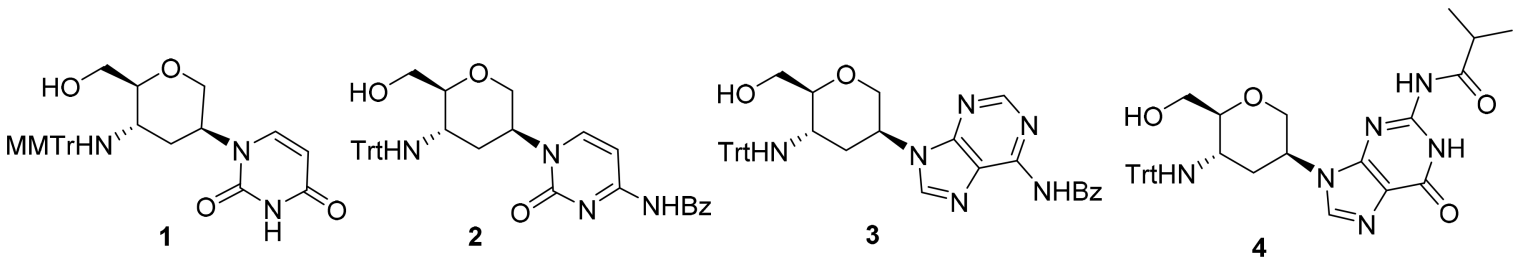

Figure 1. Building blocks of sugar modified $1^{\prime}, 5^{\prime}$-anhydro- $3^{\prime}$-deoxy- $4^{\prime}$-amino hexitol nucleic acids.

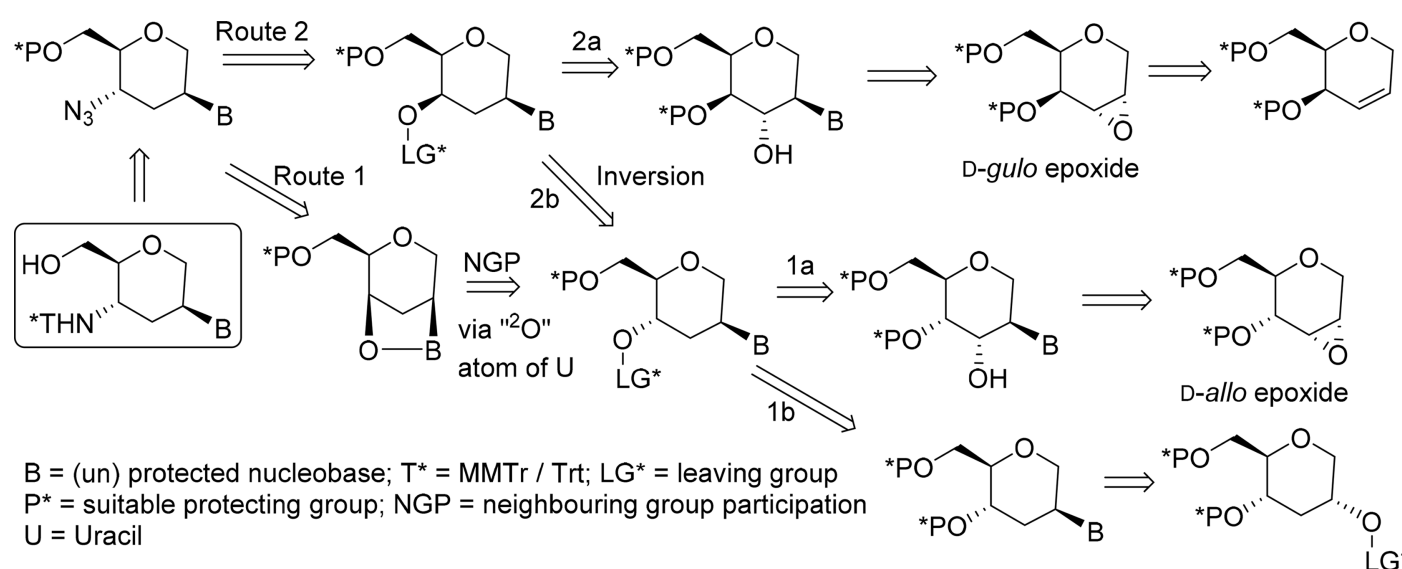

Figure 2. Retrosynthetic analysis of sugar modified dideoxy-D-altro-amino hexitol nucleosides.

\section{Scheme 1. Synthesis of Compound $1^{a}$}<smiles>C[13CH]1CO[C@H]2CO[C@@H](c3ccccc3)O[C@H]2[C@H]2O[C@@H]21</smiles>

5<smiles>O[C@H]1CO[C@@H]2CO[C@H](c3ccccc3)O[C@@H]2[C@H]1O</smiles>

6<smiles>[3H]CCC(C)CC(C)C</smiles>

7<smiles>CC1COC2COC(c3ccccc3)O[C@@H]2C1</smiles><smiles>[R20]C[C@H]1OC[C@@H](O)C[C@H]1[R20]</smiles>

9; $\mathrm{R}_{1}, \mathrm{R}_{2}=\mathrm{H}$

$11 \stackrel{\mathrm{g}}{\longrightarrow}$ 
Scheme 2. Synthesis of Compound $2^{a}$

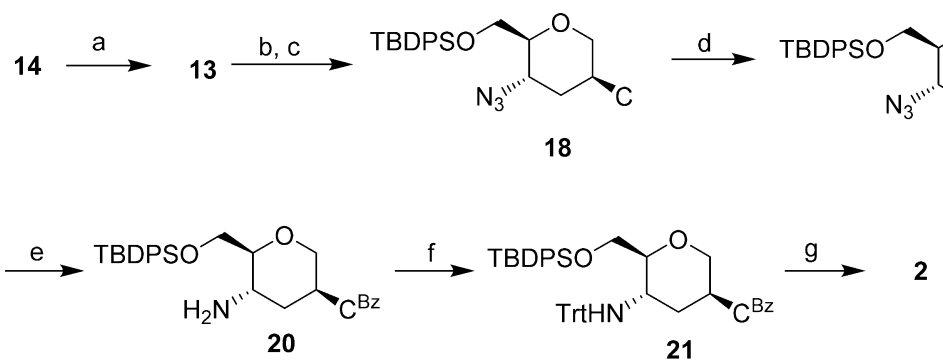

${ }^{a}$ Reagents and conditions: (a) TBDPSCl, dry Py, $50{ }^{\circ} \mathrm{C}, 16 \mathrm{~h}, 96 \%$; (b) $\mathrm{POCl}_{3}, 1,2$,4-triazole, dry ACN, 0 to $35^{\circ} \mathrm{C}, 14 \mathrm{~h}$; (c) aq NH 3 , dioxane, 35 ${ }^{\circ} \mathrm{C}, 16 \mathrm{~h}, 95 \%$ over two steps; (d) BzCl, dry Py, $0{ }^{\circ} \mathrm{C}$ to rt, $30 \mathrm{~h}, 75 \%$; (e) 10\% Pd/C (Degussa type), $\mathrm{H}_{2}$, absolute EtOH, rt, $16 \mathrm{~h}, 84 \%$; (f) TrtCl, DIPEA, dry Py, $55{ }^{\circ} \mathrm{C}, 120 \mathrm{~h}, 88 \%$; (g) Et 3 N.3HF, dry THF, $37{ }^{\circ} \mathrm{C}, 144 \mathrm{~h}, 92 \%$.

functionality, a $\mathrm{S}_{\mathrm{N}} 2$-type displacement of a $4^{\prime}$-axial $(\beta)$ oriented leaving group is necessary.

The first route (route 1 ) involves the nucleophilic $2,4^{\prime}$-sixmembered anhydronucleoside ring opening with an azide nucleophile at the $4^{\prime}$-position. 2,4'-Anhydronucleosides can be derived from a protected $1^{\prime}, 5^{\prime}$-anhydro- $2^{\prime}$-(nucleobase)- $2^{\prime}, 3^{\prime}$ dideoxy-manno-hexitol derivative via $3^{\prime}$-deoxygenation and oxirane ring opening (route $1 \mathrm{a}$ ) or alternatively via $\mathrm{S}_{\mathrm{N}} 2$-type displacement (route $1 \mathrm{~b}$ ) by an appropriate nucleobase. However, anhydronucleoside ring opening strategy is only applicable to pyrimidine nucleosides. For purine (adenine and guanine) analogues, alternative strategies have been adopted (route 2) from an axial $(\beta)$ oriented hydroxyl group at 4 'position, followed by an $\mathrm{S}_{\mathrm{N}}$ 2-type inversion with an azido nucleophile. This D-iodose-sugar derivative can be obtained either from a D-manno-hexitol derivate by inversion of configuration at the $4^{\prime}$-position via an oxidation-reduction method $^{13}$ or via a Mitsunobu reaction ${ }^{14}$ (route $2 b$ ). Alternatively, D-iodose-sugar derivative can be derived via epoxide ring opening of protected $1^{\prime}, 5^{\prime}: 2^{\prime}, 3^{\prime}$-dianhydro-D-gulohexitol followed by Barton-McCombie deoxygenation (route $2 \mathrm{a})$. The advantage of the latter approach is that the $4^{\prime}-\beta-\mathrm{OH}$ functionality can be introduced in a stereoselective way, avoiding tedious and laborious separations in Mitsunobu inversion or the potential formation of epimers in the oxidation-reduction method. Up to now, the synthesis of $1^{\prime}, 5^{\prime}: 2^{\prime}, 3^{\prime}$-dianhydro-D-gulo-hexitol is not described in the literature. However, we presumed that it can be obtained from a (un)protected $1^{\prime}, 5^{\prime}$-anhydro- $2^{\prime}, 3^{\prime}$-dideoxy-D-threo-hex- $2^{\prime}$ enitol via regioselective epoxidation.

\section{RESULTS AND DISCUSSION}

Synthesis of $2^{\prime}$-(Uracil-1-yl)-1', $5^{\prime}$-anhydro-2', $3^{\prime}$-dideoxy-4'-amino Monomethoxytrityl Hexitol Nucleic Acid (U-AHNA) Building Block 1. The synthesis of UAHNA 1 is shown in Scheme 1. $1^{\prime}, 5^{\prime}$-Anhydro-4', $6^{\prime}-O$ benzylidene-2'-deoxy-2'-(uracil-1-yl)-D-altro hexitol 6 is a known compound, ${ }^{15}$ and was obtained in $75 \%$ yield from commercially available oxirane ${ }^{16} \mathbf{5}$, using slightly different reaction conditions (DBU as base in DMF at $90{ }^{\circ} \mathrm{C}$ ). Reductive removal of the $3^{\prime}-\mathrm{OH}$ group of 6 was achieved using slightly modified Barton-McCombie conditions. ${ }^{17}$ Compound 6 was first converted to xanthate 7 , which was, without any purification, immediately treated with tributyltin hydride/ AIBN yielding the corresponding $1^{\prime}, 5^{\prime}$-anhydrohexitol-2', $3^{\prime}$ dideoxy-nucleoside 8 in $78 \%$ yield over two steps. Acidic cleavage of the benzylidene protecting group of the uracil derivative 8 using $80 \% \mathrm{AcOH}$ afforded diol 9 in $79 \%$ yield. The primary hydroxyl group of diol 9 was selectively protected using TBDPSCl in dry pyridine yielding compound $\mathbf{1 0}$ in $\mathbf{8 7 \%}$ yield. The initial plan was to obtain azide $\mathbf{1 3}$ via inversion of the stereochemistry of the $4^{\prime}-\mathrm{OH}$ group of compound 10 by the synthesis of $2^{\prime}$-(uracil-1-yl)-1', $5^{\prime}$-anhydro-2', $3^{\prime}$-dideoxy- $6^{\prime}$ O-TBDPS-iodo-hexose from 10, followed by mesylation and subsequent $\mathrm{S}_{\mathrm{N}} 2$ displacement by an azide nucleophile. Unfortunately, this inversion of the stereochemistry by Mitsonubu reaction was unsuccessful. Inversion of configuration of the $4^{\prime}-\mathrm{OH}$ group by a Dess-Martin periodinane oxidation and $\mathrm{NaBH}_{4}$ reduction sequence afforded a mixture of 4 '-hydroxyl epimers, which were not separable by silica gel flash chromatography ( 6:1 cis:trans). ${ }^{13}$ Therefore, azide 13 was obtained via a $\mathrm{O}^{2}, 4^{\prime}$-anhydronucleoside ring opening. This is equivalent to the $\mathrm{O}^{2}, 3^{\prime}$-anhydronucleoside intermediate for the stereoselective introduction of substituents at the $3^{\prime}$ position of (deoxy)furanose-sugars. ${ }^{18,19}$ The $4^{\prime}$-hydroxyl group of protected nucleoside $\mathbf{1 0}$ was converted to its corresponding $4^{\prime}$-mesyl derivative 11. Alkaline treatment $\left(\mathrm{Et}_{3} \mathrm{~N}\right.$ in EtOH) afforded the $2,4^{\prime}$-anhydro-deoxy-iodo-hexose uracil derivative 12 in excellent yield (97\%). 2,4'-Anhydro ring opening by nucleophilic attack of $\mathrm{LiN}_{3}$ in DMF at $135{ }^{\circ} \mathrm{C}$ yielded the desired 2'-(uracil-1-yl)-1', $5^{\prime}$-anhydro-2', $3^{\prime}$-dideoxy-6'-OTBDPS-manno-hexose 13 as a minor component (19\%), whereas its desilylated derivative $\mathbf{1 4}$ was the major compound (36\%). Earlier research revealed that TBDPS protecting groups are stable under reaction circumstances using $\mathrm{NaN}_{3}$ in DMF at $60{ }^{\circ} \mathrm{C}$ for $48 \mathrm{~h}^{20}$ The exact reason for desilylation using $\mathrm{LiN}_{3}$ is not known, but might be related to the higher temperature used and to the good nucleophilicity of azide anion and thus behaving like a pseudohalide. The 6 '-OTBDPS protecting group of 13 was removed using triethylamine trihydrofluoride and the primary hydroxyl group was protected by a benzoyl group, furnishing azido nucleoside $\mathbf{1 5}$ (90\%). Initial attempts to reduce the $4^{\prime}$-azido moiety of uracil-nucleoside 15 via hydrogenolysis with $10 \% \mathrm{Pd} / \mathrm{C}$ resulted in an intractable mixture of 4 '-amino nucleoside 16 , along with a nucleoside derivative with a dihydrouracil ring. The desired compound 16 was obtained in excellent yield (91\%), when the Degussa-type $10 \% \mathrm{Pd} / \mathrm{C}$ catalyst was used. General reaction conditions that are usually used for trityl protection of amino groups $(\mathrm{MMTrCl} / \mathrm{Py}),{ }^{21}$ even at elevated temperature, resulted only in poor yields of nucleoside 17. However, using a stronger organic base like DIPEA significantly improved the yield (89\%). Finally, removal of the $6^{\prime}$-O-benzoyl protecting groups of nucleoside 17 under modified Zemplen conditions $(7 \mathrm{~N}$ $\mathrm{NH}_{3}$ solution in methanol) afforded the desired 2' (uracil-1- 


\section{Scheme 3. Synthesis of Oxirane $26^{a}$}

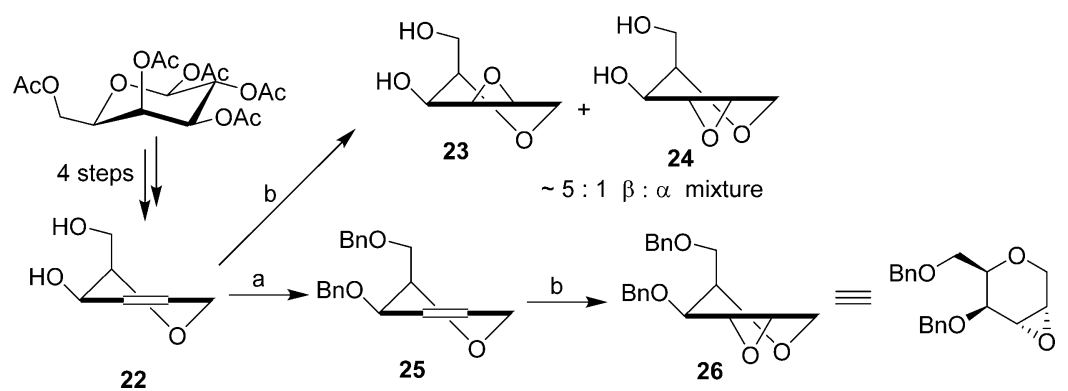

${ }^{a}$ Reagents and conditions: (a) $\mathrm{NaH}, \mathrm{BnBr}$, dry DMF, $-20{ }^{\circ} \mathrm{C}$ to rt, $16 \mathrm{~h}, 90 \%$; (b) $\mathrm{mCPBA}, \mathrm{CH}_{2} \mathrm{Cl}_{2},-50{ }^{\circ} \mathrm{C}$ to rt, $36 \mathrm{~h}, 59 \%$ for 26 and $75 \%$ for $23+24$.

Scheme 4. Synthesis of Compound $3^{a}$

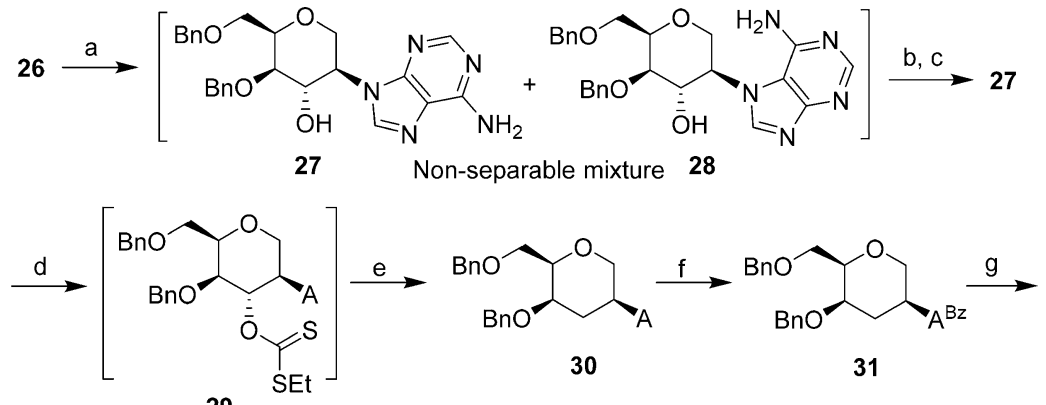

29
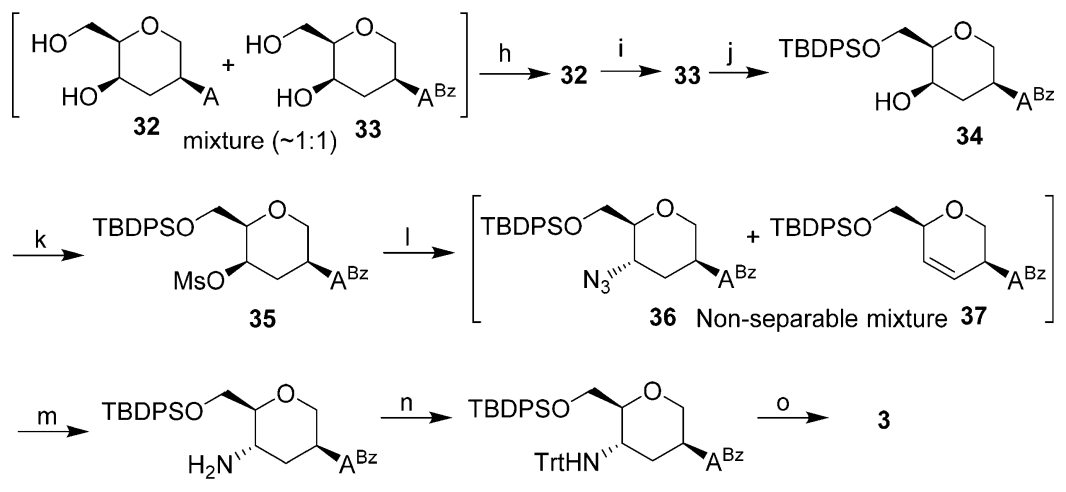

38

39

${ }^{a}$ Reagents and conditions: (a) Adenine, DBU, DMF, $105^{\circ} \mathrm{C}, 20 \mathrm{~h}$; (b) $\mathrm{Ac}_{2} \mathrm{O}$, Py, rt, $24 \mathrm{~h}$; (c) $7 \mathrm{~N} \mathrm{NH}_{3}$ in $\mathrm{MeOH}, \mathrm{rt}, 24 \mathrm{~h}, 68 \%$ over three steps; (d) $\mathrm{CS}_{2}, \mathrm{EtBr}, \mathrm{NaOH}, \mathrm{DMF}, 0{ }^{\circ} \mathrm{C}, 1 \mathrm{~h}$; (e) TBTH, AIBN, toluene, reflux, $3 \mathrm{~h}, 60 \%$ over two steps; (f) $\mathrm{BzCl}, \mathrm{Py}, 40{ }^{\circ} \mathrm{C}, 24 \mathrm{~h}, 95 \%$; (g) $1 \mathrm{M} \mathrm{BCl} 3$ in $\mathrm{CH}_{2} \mathrm{Cl}_{2}$, dry $\mathrm{CH}_{2} \mathrm{Cl}_{2},-78{ }^{\circ} \mathrm{C}$ to rt, $5 \mathrm{~h}$; (h) $7 \mathrm{~N} \mathrm{NH}_{3}$ in $\mathrm{MeOH}$, rt, $24 \mathrm{~h}, 86 \%$ in two steps; (i) (1) TMSCl, dry Py, $0{ }^{\circ} \mathrm{C}$ to rt, $5 \mathrm{~h} ;(2) \mathrm{BzCl}, 0{ }^{\circ} \mathrm{C}$ to rt, $16 \mathrm{~h}$; (3) $\mathrm{Et}_{3} \mathrm{~N} \cdot 3 \mathrm{HF}$, dry THF, rt, $16 \mathrm{~h}$; (4) $2 \mathrm{~N} \mathrm{NH}_{3}$ in EtOH, $0{ }^{\circ} \mathrm{C}, 45 \mathrm{~min}, 67 \%$ in four steps; (j) TBDPSCl, dry Py, $50{ }^{\circ} \mathrm{C}, 24 \mathrm{~h}, 80 \%$; (k) $\mathrm{MsCl}$, dry Py, $0^{\circ} \mathrm{C}$ to rt, 20 h, 85\%; (l) $\mathrm{NaN}_{3}$, dry DMF, $65^{\circ} \mathrm{C}$, $72 \mathrm{~h}$; (m) 10\% Pd/C (Degussa type), $\mathrm{H}_{2}, \mathrm{MeOH}, \mathrm{rt}, 16 \mathrm{~h}, 20 \%$ over two steps; (n) TrtCl, $\mathrm{Et}_{3} \mathrm{~N}$, dry $\mathrm{CH}_{2} \mathrm{Cl}_{2}, 40{ }^{\circ} \mathrm{C}, 16 \mathrm{~h}, 80 \%$; (o) $\mathrm{Et}_{3} \mathrm{~N} \cdot 3 \mathrm{HF}$, dry THF, $46{ }^{\circ} \mathrm{C}, 72 \mathrm{~h}, 87 \%$.

yl)-1',5'-anhydro-2', $3^{\prime}$-dideoxy-4' -amino monomethoxytrityl hexitol nucleic acid (U-AHNA) 1 in excellent yield (85\%).

Synthesis of 2'-(N4-Benzoyl-cytosin-1-yl)-1',5'-anhydro-2', $3^{\prime}$-dideoxy-4'-amino Monomethoxytrityl Hexitol Nucleic Acid (C-AHNA) Building Block 2. Synthesis of CAHNA 2 was accomplished as shown in Scheme 2. The primary hydroxyl group of compound $\mathbf{1 4}$ was protected as a TBDPS ether, yielding uridine derivative 13. The uracil ring of intermediate $\mathbf{1 3}$ was converted to its corresponding cytosine derivative $\mathbf{1 8}$ in excellent yield (95\%) following Reese's method ${ }^{22}$ using $\mathrm{POCl}_{3} / 1,2,4$-triazole and $\mathrm{NH}_{3}$. Protection of the 4- $\mathrm{NH}_{2}$ group of cytosine with a benzoyl group furnished 19 in $75 \%$ yield. The azide functionality of 19 was catalytically hydrogenated in the presence of $10 \% \mathrm{Pd} / \mathrm{C}$ (Degussa type) to yield the $4^{\prime}$-amino $N^{4}$-benzoyl-cytosine analogue 20 (84\%).
The primary 4 '-amino group of cytosine nucleoside $\mathbf{2 0}$ was protected using $\mathrm{TrtCl} / \mathrm{Py} / \mathrm{DIPEA}$ at slightly elevated temperatures $\left(55{ }^{\circ} \mathrm{C}\right)$ and prolonged reaction times affording tritylated $21(88 \%)$. Finally, desilylation of the $6^{\prime}$-OTBDPS group using the classical TBAF reaction conditions resulted in the formation of the desired compound 2, along with debenzoylated cytosine analogue as a side product. This method required cumbersome and tedious purifications to remove the tetrabutylammonium salt. When other reagents for the desilylaton were used (e.g., Py.HF), low yields were obtained. When a mild desilylating reagent, such as $\mathrm{Et}_{3} \mathrm{~N} \cdot 3 \mathrm{HF}$, was applied, the desired $2^{\prime}$-( $N^{4}$-benzoyl-cytosin-1-yl $)-1^{\prime}, 5^{\prime}$ anhydro-2', $3^{\prime}$-dideoxy-4'-amino monomethoxytrityl hexitol nucleic acid 2 (U-AHNA) was isolated in excellent yield 
Scheme 5. Synthesis of Compound $4^{a}$

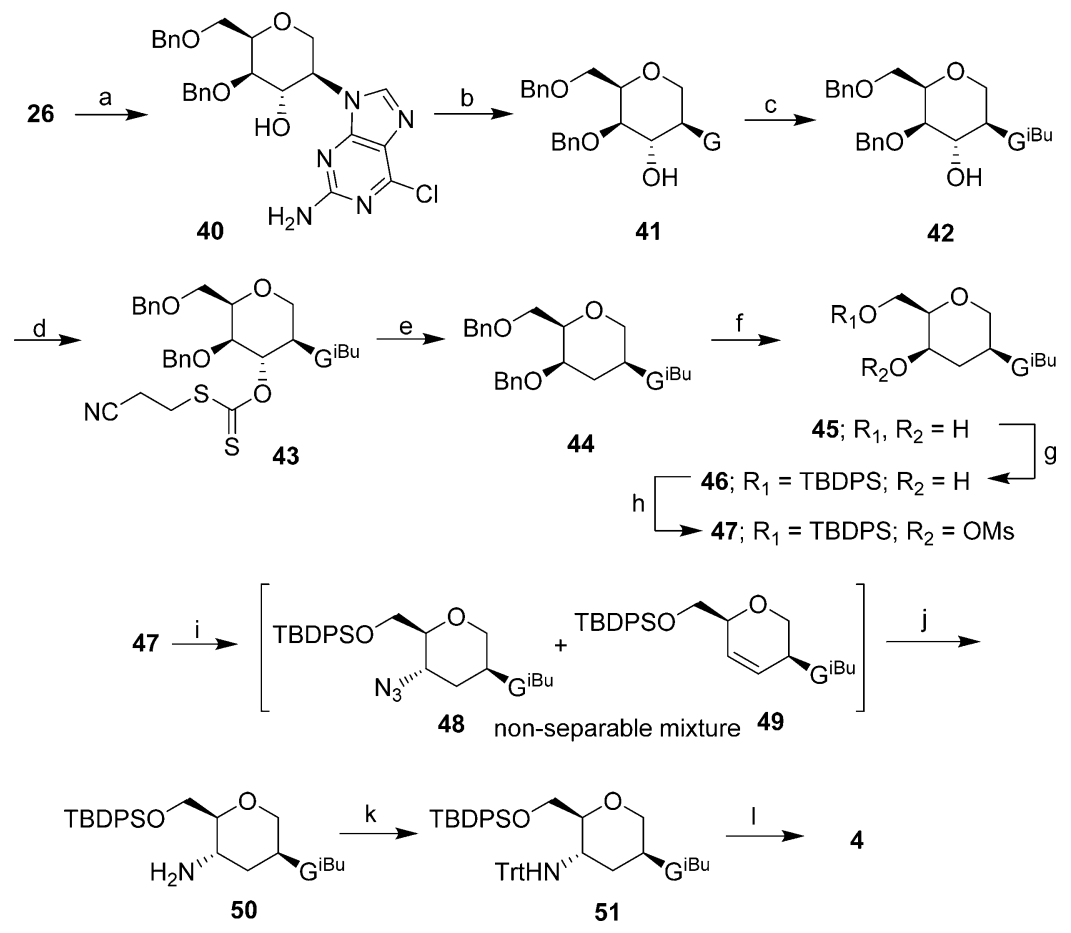

${ }^{a}$ Reagents and conditions: (a) 2-Amino-6-chloro purine, DBU, DMSO, $88^{\circ} \mathrm{C}, 36 \mathrm{~h}, 60 \%$; (b) $2 \mathrm{~N} \mathrm{NaOH}, \mathrm{DABCO}$, dioxane, $90{ }^{\circ} \mathrm{C}, 16 \mathrm{~h}, 83 \%$; $(\mathrm{c})$ (1) TMSCl, dry Py, $0{ }^{\circ} \mathrm{C}$ to rt, $7 \mathrm{~h}$; (2) isobutyric anhydride, $35^{\circ} \mathrm{C}, 16 \mathrm{~h}$; (3) Et $3 \mathrm{~N} \cdot 3 \mathrm{HF}$, dry THF, rt, $6 \mathrm{~h}$; (4) $2 \mathrm{~N} \mathrm{NH}{ }_{3}$ in EtOH, $0{ }^{\circ} \mathrm{C}, 2 \mathrm{~h}, 84 \%$ in four steps; (d) $\mathrm{CS}_{2}$, 3-bromo propionitrile, $50 \% \mathrm{NaOH}$, DMSO, $0{ }^{\circ} \mathrm{C}, 2 \mathrm{~h}, 80 \%$; (e) TBTH, AIBN, toluene, reflux, $3 \mathrm{~h}, 82 \%$; (f) $1 \mathrm{M} \mathrm{BCl}{ }_{3}$ in $\mathrm{CH}_{2} \mathrm{Cl}_{2}$, dry $\mathrm{CH}_{2} \mathrm{Cl}_{2},-78{ }^{\circ} \mathrm{C}$ to rt, $7 \mathrm{~h}, 89 \%$; (g) TBDPSCl, dry Py, $50{ }^{\circ} \mathrm{C}, 16 \mathrm{~h}, 75 \%$; (h) MsCl, dry Py, $0{ }^{\circ} \mathrm{C}$ to rt, $24 \mathrm{~h}, 83 \%$; (i) $\mathrm{NaN}$, dry DMF, $65{ }^{\circ} \mathrm{C}, 72 \mathrm{~h}$; (j) 10\% Pd/C (Degussa type), $\mathrm{H}_{2}, \mathrm{MeOH}, \mathrm{rt}, 16 \mathrm{~h}, 30 \%$ over two steps; (k) TrtCl, Et ${ }_{3} \mathrm{~N}, \mathrm{dry}_{\mathrm{CH}} \mathrm{Cl}_{2}, 40{ }^{\circ} \mathrm{C}, 16 \mathrm{~h}, 98 \%$; $(1)$ $\mathrm{Et}_{3} \mathrm{~N} \cdot 3 \mathrm{HF}$, dry THF, $46^{\circ} \mathrm{C}, 60 \mathrm{~h}, 85 \%$.

(92\%), although the reaction proceeded rather sluggish (reaction time of $144 \mathrm{~h}$, as monitored by TLC).

Synthesis of $2^{\prime}-\left(N^{6}\right.$-Benzoyladenin-9-yl)-1', $5^{\prime}$-anhydro-2', $3^{\prime}$-dideoxy-4'-amino Trityl Hexitol Nucleic Acid (A-AHNA) Building Block 3. Azide-mediated 2,4'-anhydro ring opening, as used for the pyrimidine nucleosides (Scheme 1 ), cannot be applied for the synthesis of the purine nucleoside analogues A-AHNA (3) and G-AHNA (4). In contrast, the key step here is the introduction of the $4^{\prime}$-azido group onto a $3^{\prime}$ deoxy-iodo-hexose nucleoside. As inversion of configuration of the $4^{\prime}$-hydroxyl group of 3 '-deoxy-iodo-hexose nucleoside was cumbersome in the uridine series (Scheme 1), an alternative synthetic road was established, starting from a dibenzyl protected $1^{\prime}, 5^{\prime}: 2^{\prime}, 3^{\prime}$-dianhydro-D-gulo-hexitol 26.

The synthesis of D-gulo-oxirane $\mathbf{2 6}$ is depicted in Scheme 3. $1^{\prime}, 5^{\prime}$-Anhydro-2',3'-dideoxy-D-threo-hex-2-enitol 22 was accessible from $\beta$-D-galactose pentaacetate in four steps according to known procedures. $^{23,24}$ Initial attempts in the epoxidation of unprotected 2',3'-dideoxy-2',3'-unsaturated pyranoside 22 with mCPBA resulted in a mixture of $\sim 5: 1$; syn 23:anti (desired) 24 oxirane. This result arises presumably due to Henbest-type directivity of the allylic $4^{\prime}-\mathrm{OH}$ function, which promotes syn epoxidation. ${ }^{25}$ Simultaneous protection of the $4^{\prime}$ and $6^{\prime}-\mathrm{OH}$ as benzylethers afforded the pyranoside 25 . Epoxidation with $\mathrm{mCPBA}$ provided the desired anti oxirane 26 stereoselectively in 59\% yield. A coupling constant between $\mathrm{H}-1^{\prime}$ eq and $\mathrm{H}-2^{\prime}$ ax of $3.4 \mathrm{~Hz}$ is indicative for an $\alpha$-oxirane in compound 26.

The synthesis of A-AHNA 3 from benzyl protected D-gulooxirane 26 is shown in Scheme 4. Treatment of oxirane 26 with adenine under basic conditions (DBU in DMF) at $105^{\circ} \mathrm{C}$ selectively introduces the adenine base at the $2^{\prime}$-position according to the Fürst-Plattner rule, ${ }^{26}$ yielding a nonseparable mixture (column chromatography) of $N^{9}$-substituted hexitol nucleoside analogue 27, along with its undesired $N^{7}$ adduct 28 ( $\sim 3: 1$ ratio). The mixture of 27 and 28 was treated with acetic anhydride. At this stage of the synthesis, the acetylated derivatives of $\mathbf{2 7}$ and $\mathbf{2 8}$ were separated by flash chromatography. The acetylated analogue of 27 was treated with $7 \mathrm{~N}$ $\mathrm{NH}_{3}$ in $\mathrm{MeOH}$ furnishing pure 27 in a $68 \%$ yield over three steps. Unlike uracil xanthate 7 , a careful handling of metastable adenine xanthate 29 was required for $3^{\prime}$-deoxygenation of 27 under modified Barton-McCombie conditions, ${ }^{17}$ furnishing the corresponding $3^{\prime}$-deoxynucleoside 30 in $60 \%$ yield in two steps. A wide variety of hydrogenation conditions were explored for removal of the benzyl groups, using different Pd-catalysts like $10 \% \mathrm{Pd} / \mathrm{C}, 20 \% \mathrm{Pd}(\mathrm{OH})_{2} / \mathrm{C}$, Pd-black, or $\mathrm{Pd}(\mathrm{OAc})_{2}$. This resulted either in the recovery of unreacted starting material (mild condition) or in the formation of undesired side products (not isolated, harsh condition), probably due to catalyst poisoning arising from traces of tinor sulfur-byproducts transmitting from earlier step. Lewis acidmediated debenzylation (using boron trichloride) of $\mathbf{3 0}$ resulted only in $6^{\prime}$-mono debenzylated product, probably due to the poor solubility of the mono debenzylated intermediate in dichloromethane. To increase the solubility in organic solvents, the exocyclic amino group of adenine of compound 30 was benzoyl protected furnishing intermediate 31. Boron trichloride-mediated didebenzylation of 31 afforded a $\sim 1: 1$ mixture of diol 33 , along with debenzoylated diol 32, formed 


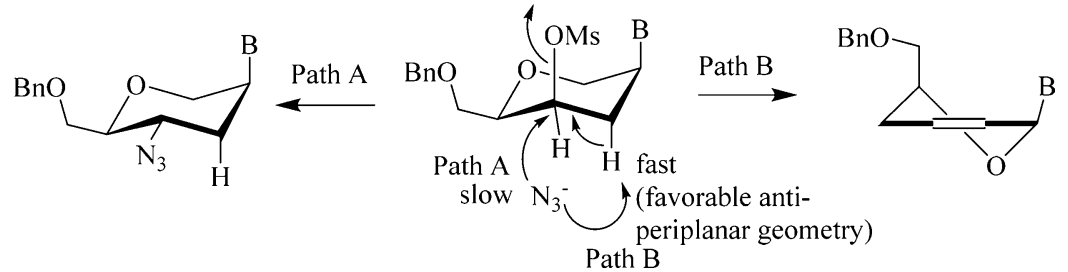

Figure 3. Plausible pathways of dihydropyran and azido nucleoside mixture formation.

due to acidic deprotection by $\mathrm{HCl}$ that was formed during workup (quenching $\mathrm{BCl}_{3}$ with methanol). As separation of 32 and 33 by silica gel flash chromatography was difficult, the mixture was treated with $7 \mathrm{~N} \mathrm{NH}_{3}$ in $\mathrm{MeOH}$ to obtain the completely deacetylated analogue $\mathbf{3 2}$ as a single compound, which could be conveniently purified. At this stage of the synthesis, the formation of the desired N-9 regioisomer was confirmed by the observation of a clear HMBC correlation between $\mathrm{H}-2^{\prime}$ and C-4 (see HMBC spectrum of compound 32 in the Supporting Information). Transient protection of $4^{\prime}$ and $6^{\prime}-\mathrm{OH}$ of 32 with $\mathrm{TMSCl}$ and reprotection of the amino group with a benzoyl group gave derivative 33 in $67 \%$ yield over four steps. Selective protection of the 6 '-primary hydroxyl group of adenine nucleoside 33 was achieved using tertbutyldiphenylsilyl chloride in pyridine, furnished compound 34. All methods to convert the $4^{\prime}$-hydroxyl group into a $4^{\prime}$-Otriflate were unsuccessful, providing either a pyridine-adduct or an eliminated side product. Therefore, a $4^{\prime}$-O-mesyl group was installed in $85 \%$ yield, along with a small amount of eliminated product (12\%). Several reaction conditions and reagents, that is, $\mathrm{TMSN}_{3} / \mathrm{LiF} / \mathrm{TMEDA} / \mathrm{DMF}, \mathrm{LiN}_{3} / \mathrm{DMF}, \mathrm{DPPA} / \mathrm{DBU} /$ $\mathrm{THF}^{27}$ DPPA/DIAD/ $\mathrm{PPh}_{3} / \mathrm{THF}^{14}{ }^{14}$ and $\mathrm{NaN}_{3} / \mathrm{DMF}$, at variable temperature were screened for a selective $S_{N} 2$-type nucleophilic $4^{\prime}$-azido displacement of mesyl analogue 35 . When DPPA was used as azide source, no desired product was formed at ambient temperature, whereas at elevated temperature only undesired side compounds were formed (not isolated). When $\mathrm{TMSN}_{3}, \mathrm{LiN}_{3}$, and $\mathrm{NaN}_{3}$ were applied mostly unreacted starting material was recovered at ambient temperature, and at elevated temperature $\left(>100{ }^{\circ} \mathrm{C}\right)$, a complex reaction mixture was formed, with the undesired dihydropyran (37) as a major product, along with the desired azido nucleoside 36 and a mixture of the desilylated counterparts of 36 and 37, as well as a small fraction of the debenzoylated product. Using crown ethers to increase the nucleophilicity of the azide ion did not improve the reaction yields. Ultimately, $\mathrm{NaN}_{3}$ in DMF at moderate temperature $\left(65{ }^{\circ} \mathrm{C}\right)$ for a prolonged reaction time $(72 \mathrm{~h})$ was found to be the optimal condition, reducing the formation of eliminated, desilylated, and debenzoylated side products. After workup, the crude reaction mixture was treated with $\mathrm{TBDPSCl} / \mathrm{Py}$ for resilylation. Having the same $R_{f}$, the separation of azido nucleoside 36 and dihydropyran 37 was not possible via column chromatography. The mixture of 36 and 37 was subjected to hydrogenation under $10 \% \mathrm{Pd} / \mathrm{C}$ (Degussa type), and the resulting $4^{\prime}$-amino nucleoside was purified at this stage to furnishing desired $\mathbf{3 8}$ in $20 \%$ yield over two steps. Tritylation ( $\mathrm{TrtCl} / \mathrm{Et}_{3} \mathrm{~N} / \mathrm{CH}_{2} \mathrm{Cl}_{2}$ ) yielded the $4^{\prime}$-amino trityl nucleoside 39. Finally, desilylation with $\mathrm{Et}_{3} \mathrm{~N} \cdot 3 \mathrm{HF}$ afforded target compound A-AHNA 3 in excellent yield (87\%). The axial orientation of the adenine nucleobase of compound 3 was derived from the ${ }^{3} \mathrm{~J}$ coupling constant of $3.1 \mathrm{~Hz}$ between $\mathrm{H}$ $1^{\prime}$ ax and $\mathrm{H}-2^{\prime}$ eq.
Synthesis of 2'-( $N^{2}$-Isobutyrylguanin-9-yl)-1', $5^{\prime}$-anhydro-2', $\mathbf{3}^{\prime}$-dideoxy-4'-amino Trityl Hexitol Nucleic Acid (G-AHNA) Building Block 4. Similar as for the preparation of A-AHNA, the synthesis of G-AHNA 4 started from benzyl protected D-gulo-oxirane $\mathbf{2 6}$ as shown in Scheme 5. Different methods have been described in the literature to obtain guanine nucleosides via the epoxide opening of oxirane D-allitol 5 using the lithium salt of $N^{2}$-acetyl-2-amino-6-[2(trimethylsilyl)ethoxy] purine ${ }^{15}(45 \%)$ or using the sodium salt of 2-amino-6-chloropurine/Aliquat $336 / \mathrm{K}_{2} \mathrm{CO}_{3}{ }^{28}$ to improve the yield (70\%). Unfortunately, these methods proved to be low yielding for epoxide opening of D-gulo-oxirane 26 . Using DBU (2.3 equiv) as base and 2-amino-6-chloropurine as nucleophile (1.2 equiv) in DMF at $108{ }^{\circ} \mathrm{C}$ resulted in only $41 \%$ of the desired compound 40 , accompanied by typical side products, such as the N-9-substituted regioisomer, chlorosubstituted $\mathrm{N}$-dimer, and $\mathrm{N}, \mathrm{N}$-dimethyl adducts. By switching to DMSO as solvent, reducing the DBU amount (1.3 equiv), and lowering the reaction temperature to $90{ }^{\circ} \mathrm{C}$, the formation of side products was minimalized and the desired compound 40 was obtained in $60 \%$ yield. The isolation of the desired N-9 isomer was confirmed by a clear HMBC correlation between H-2' and C-4 (see Supporting Information for compound 40). The 6-chloro-2-aminopurine base was converted into the guanine base by $\mathrm{NaOH}$ treatment, followed by the transient protection of $3^{\prime}-\mathrm{OH}$ of 41 with TMSCl and protection of the 2 -amino group as an isobutyryl group to furnish $\mathbf{4 2}$ in excellent yield. Barton-McCombie-mediated deoxygenation of 42, via xanthate 43, furnished compound 44 (82\%) along with recovered starting material 42 (14\%). Lewis acid-mediated cleavage of both benzyl groups, followed by selective $6^{\prime}-O$ silylation with TBDPSCl and 4'-O-mesylation, provided compound 47 in excellent yield.

Azidation yielded a nonseparable mixture of the desired azido nucleoside $\mathbf{4 8}$ as minor component, whereas the major compound was dihydropyran 49. Hydrogenolytic azide reduction of the mixture furnished the $4^{\prime}$-amino guanine nucleoside $\mathbf{5 0}$ in $30 \%$ yield over two steps. The plausible formation of dihydropyran as a major product over azido analogue (minor) is described in Figure 3. Because of the good leaving group ability of OMs group, the transition state exhibits two possibilities: either a $\mathrm{S}_{\mathrm{N}}$ 2-type nucleophilic attack of $\mathrm{N}_{3}{ }^{-}$ ion or an $\mathrm{E}_{2}$-type elimination. $\mathrm{N}_{3}^{-}$ion is also known for good nucleophilicity, but an $\mathrm{S}_{\mathrm{N}}$ 2-type $\mathrm{N}_{3}^{-}$attack on secondary carbon $\left(4^{\prime}-\right)$ is less favored probably due to steric hindrance. Although the azide ion is a weak base, at elevated temperature it might advocate for the $\mathrm{E}_{2}$-type elimination in a perfectly oriented trans antiperiplanar geometry of TS. Tritylation of the 4 '-amino group and subsequent desilylation of the TBDPS group gave access to the desired G-AHNA 4 in excellent yield. The small coupling constant ${ }^{3} J$ of $2.9 \mathrm{~Hz}$ between $\mathrm{H}-1^{\prime}$ ax and $\mathrm{H}-2^{\prime}$ eq of compound 4 confirmed the axial position of the nucleobase. 


\section{CONCLUSIONS}

In this Article, an accessible and optimized protocol for the synthesis of the hitherto unknown $1^{\prime}, 5^{\prime}$-anhydro-4'-aminotrityl/MMTr hexitol nucleosides $\mathbf{1 - 4}$ has been developed. The synthesis of the pyrimidine nucleoside U-AHNA 1 was accomplished via a regioselective epoxide and a $2^{\prime}, 4^{\prime}$ anhydronucleoside ring opening by uracil and an azide anion, respectively, with an overall yield of $11 \%$ over 13 linear steps starting from D-allo-hexitol oxirane 5. The other pyrimidine nucleoside C-AHNA 2 was obtained via conversion of the uracil base of compound $\mathbf{1}$ in the cytosine base yielding compound 2 with an overall yield of $8.3 \%$ over 15 linear steps starting from oxirane 5 . The purine nucleosides were prepared via a different strategy. Epoxide ring opening of $\mathrm{D}$-gulo-oxirane 26 (accessible from $\beta$-D-galactose pentaacetate), followed by an $\mathrm{S}_{\mathrm{N}}$ 2-type azidation, afforded A-AHNA 3 with an overall yield of $0.8 \%$ over 28 linear steps and G-AHNA 4 with an overall yield of $1.4 \%$ over 21 linear steps, respectively. Compounds 1-4 are the immediate precursors of AHNA phosphoramidite building blocks. Hence, access to gram-scale quantities of $1^{\prime}, 5^{\prime}$-anhydro-4'-amino-trityl/MMTr hexitol nucleosides monomers paves the way for constructing $\mathrm{N}^{\prime}$ $\rightarrow \mathrm{P}^{\prime}$ phosphoramidate oligonucleotide of AHNA.

\section{EXPERIMENTAL SECTION}

General Information. For all reactions, either analytical grade or anhydrous solvents were used. All moisture-sensitive reactions were performed using oven-dried glassware $\left(115^{\circ} \mathrm{C}\right)$ under a nitrogen or an argon atmosphere. All heating reactions were performed in silicon oil bath, and reaction temperatures are reported as bath temperatures. Precoated aluminum sheets with silica $(254 \mathrm{~nm})$ were used for TLC. Compounds were visualized with UV light $(\lambda=254 \mathrm{~nm})$. Products were purified by flash chromatography on ICN silica gel $40-60 \mu, 60$ Å. Melting points were recorded with a Stuart SMP20 melting point apparatus. ${ }^{1} \mathrm{H}$ and ${ }^{13} \mathrm{C}$ spectra were recorded on either Bruker Avance 300,500 , or $600 \mathrm{MHz}$ spectrometers. Compounds were characterized using 2D NMR (H-COSY, HSQC, HMBC, ROESY, and NOESY) techniques. For structural assignments, NMR signals of protons and carbons for sugar and base moieties are designated with and without a prime, respectively. Chemical shifts were referenced to residual solvent signals at $\delta \mathrm{H} / \mathrm{C} 7.26 / 77.16\left(\mathrm{CDCl}_{3}\right), 3.31 / 49.00\left(\mathrm{CD}_{3} \mathrm{OD}\right)$, $4.79\left(\mathrm{D}_{2} \mathrm{O}\right)$, and $2.50 / 39.52$ (DMSO- $\left.d_{6}\right)$ relative to TMS as internal standard wherever applied. Coupling constants are stated in hertz $(\mathrm{Hz})$ and were directly obtained from the spectra. NMR splitting patterns are designated as s (singlet), d (doublet), dd (doublet of doublet), $\mathrm{t}$ (triplet), $\mathrm{q}$ (quartet), $\mathrm{m}$ (multiplet), br (broad), and apparent (app). High-resolution mass spectra (HRMS) were obtained on a quadruple orthogonal acceleration time-of-flight mass spectrometer (Synapt G2 HDMS, Waters, Milford, MA). Samples were infused at $3 \mu \mathrm{L} / \mathrm{min}$, and spectra were obtained in positive (or negative) ionization mode with a resolution of 15000 (fwhm) using leucine enkephalin as lock mass.

$1^{\prime}, 5^{\prime}$-Anhydro-4',6'-0-benzylidene-2' -deoxy-2' -(uracil-1yl)-D-altro-hexitol (6). To a stirred mixture of oxirane 5 (30.5 g, 130 $\mathrm{mmol})$ and uracil $(33.6 \mathrm{~g}, 300 \mathrm{mmol})$ in dry DMF $(500 \mathrm{~mL})$ was added DBU $(58.2 \mathrm{~mL}, 390 \mathrm{mmol})$, and the resulting mixture was heated at $90{ }^{\circ} \mathrm{C}$ under inert atmosphere for $4 \mathrm{~h}$. The reaction was monitored with TLC; upon completion, the reaction mixture was cooled and the volatiles were removed under reduced pressure. The residue was diluted with ice-water $(800 \mathrm{~mL})$ and neutralized with 1 $\mathrm{N} \mathrm{HCl}$ at $0{ }^{\circ} \mathrm{C}$. The aq layer was extracted with $\mathrm{CH}_{2} \mathrm{Cl}_{2}(3 \times 600$ $\mathrm{mL}$ ). The combined organic layer was dried over $\mathrm{Na}_{2} \mathrm{SO}_{4}$, filtered, and concentrated in vacuo, and the resulting crude residue was purified by column chromatography on silica gel $\left(R_{f}=0.41 ; 10 \%\right.$ $\mathrm{MeOH}$ in $\mathrm{CH}_{2} \mathrm{Cl}_{2}$, gradient $\mathrm{CH}_{2} \mathrm{Cl}_{2} / \mathrm{MeOH}, 99: 1, \mathrm{v} / \mathrm{v} ; 49: 1, \mathrm{v} / \mathrm{v}$; $97: 3, \mathrm{v} / \mathrm{v})$ to afford $6(33.7 \mathrm{~g}, 75 \%)$ as a white semisolid. The NMR spectral data are in accord with the literature. ${ }^{15}$ HRMS (ESI-TOF) $m / z:[\mathrm{M}+\mathrm{H}]^{+}$calcd for $\mathrm{C}_{17} \mathrm{H}_{18} \mathrm{~N}_{2} \mathrm{O}_{6}, 347.1237$; found, 347.1238.

$1^{\prime}, 5^{\prime}$-Anhydro-4', 6'-O-benzylidene-2', 3'-dideoxy-2' -(uracil1-yl)-D-altro-hexitol (8). To a stirred solution of compound 6 (30 g, $86.67 \mathrm{mmol})$ in DMSO $(350 \mathrm{~mL})$ were added aq. $\mathrm{NaOH}(5 \mathrm{~N}$; 91.5 $\mathrm{mL})$ followed by $\mathrm{CS}_{2}(91.5 \mathrm{~mL})$ at $0{ }^{\circ} \mathrm{C}$. The resulting dark brown mixture was stirred for $20 \mathrm{~min}$, and then 3-bromopropionitrile (219 $\mathrm{mL}$ ) was added slowly to the reaction mixture. After being stirred for $45 \mathrm{~min}$, the volatiles were evaporated in reduced pressure, and the crude residue was diluted with ice cold water $(1.6 \mathrm{~L})$. The aqueous layer was extracted with $\mathrm{CH}_{2} \mathrm{Cl}_{2}(3 \times 600 \mathrm{~mL})$, and the combined organic layer was washed with saturated $\mathrm{NH}_{4} \mathrm{Cl}$ solution $(3 \times)$, dried over $\mathrm{Na}_{2} \mathrm{SO}_{4}$, and concentrated in vacuo to give crude 7 , which was used for the next step without further purification. HRMS (ESI-TOF) $m / z:[\mathrm{M}+\mathrm{H}]^{+}$calcd for $\mathrm{C}_{21} \mathrm{H}_{21} \mathrm{~N}_{3} \mathrm{O}_{6} \mathrm{~S}_{2}, 476.0944$; found, 476.0941.

To a stirred refluxing solution of 7 in anhydrous toluene $(700 \mathrm{~mL})$ under argon atmosphere were added $\mathrm{nBu}_{3} \mathrm{SnH}(58.3 \mathrm{~mL}, 216.7$ mmol) and a solution of AIBN (2.13 g, $13 \mathrm{mmol}$ ) in anhydrous toluene $(100 \mathrm{~mL})$ dropwise over $2.5 \mathrm{~h}$. After the addition was over, the reaction mixture was refluxed for an additional $30 \mathrm{~min}$. The reaction mixture was then cooled, concentrated under reduced pressure, and crude residue was purified by column chromatography on silica gel $\left(R_{f}=0.49 ; 10 \% \mathrm{MeOH}\right.$ in $\mathrm{CH}_{2} \mathrm{Cl}_{2}$; gradient $\mathrm{CH}_{2} \mathrm{Cl}_{2}$ / $\mathrm{MeOH}, 199: 1, \mathrm{v} / \mathrm{v} ; 99: 1, \mathrm{v} / \mathrm{v} ; 19.7: 0.3, \mathrm{v} / \mathrm{v})$ to provide $8(22.3 \mathrm{~g}, 78 \%$ over two steps) as a white solid. Mp $196{ }^{\circ} \mathrm{C} .{ }^{1} \mathrm{H}$ NMR $(600 \mathrm{MHz}$, DMSO- $\left.d_{6}\right) \delta 11.33$ (br s, $\left.1 \mathrm{H}, \mathrm{NH}-3\right), 7.93(\mathrm{~d}, J=8.1 \mathrm{~Hz}, 1 \mathrm{H}, \mathrm{H}-6)$, 7.41-7.34 (m, 5H, Ar- $\mathrm{H} \mathrm{Ph}), 5.66-5.64(\mathrm{~m}, 2 \mathrm{H}, \mathrm{H}-5$ and $\mathrm{CH}-$ benzylidine), $4.56-4.54\left(\mathrm{~m}, 1 \mathrm{H}, \mathrm{H}-2^{\prime}\right), 4.21-4.18\left(\mathrm{~m}, 2 \mathrm{H}, \mathrm{H}-6^{\prime}\right.$ and $\mathrm{H}-1^{\prime}{ }_{\text {eq }}$ ), 3.99 (dd, $\left.J=13.6,3.6 \mathrm{~Hz}, 1 \mathrm{H}, \mathrm{H}-1^{\prime}{ }_{\mathrm{ax}}\right), 3.79-3.73(\mathrm{~m}, 2 \mathrm{H}, \mathrm{H}-$ $4^{\prime}$ and $\left.\mathrm{H}-6^{\prime \prime}\right), 3.47-3.43\left(\mathrm{~m}, 1 \mathrm{H}, \mathrm{H}-5^{\prime}\right), 2.20-2.16\left(\mathrm{~m}, 1 \mathrm{H}, \mathrm{H}-3^{\prime}{ }_{\mathrm{eq}}\right)$, 2.02-1.97 (m, $\left.1 \mathrm{H}, \mathrm{H}-3^{\prime}{ }_{\mathrm{ax}}\right) ;{ }^{13} \mathrm{C}$ NMR $\left(150 \mathrm{MHz}, \mathrm{DMSO}-d_{6}\right) \delta 163.3$ (C-4), 150.9 (C-2), 142.7 (C-6), 137.7 (ipso C-Ph), 128.8 ( $p \mathrm{C}-\mathrm{Ph}$ ), $128.0(\mathrm{mC}-\mathrm{Ph}), 126.2(o \mathrm{C}-\mathrm{Ph}), 101.1(\mathrm{C}-5), 100.9$ (CH-benzylidine), $73.3\left(\mathrm{C}-5^{\prime}\right), 73.1$ (C-4'), $68.0\left(\mathrm{C}-1^{\prime}\right), 67.9\left(\mathrm{C}-6^{\prime}\right), 51.0\left(\mathrm{C}-2^{\prime}\right)$, $31.9\left(\mathrm{C}-3^{\prime}\right)$; HRMS (ESI-TOF) $m / z:[\mathrm{M}+\mathrm{H}]^{+}$calcd for $\mathrm{C}_{17} \mathrm{H}_{18} \mathrm{~N}_{2} \mathrm{O}_{5}, 331.1288$; found, 331.1288.

1',5'-Anhydro-2', 3'-dideoxy-2'-(uracil-1-yl)-D-altro-hexitol (9). A stirred solution of compound $8(22 \mathrm{~g}, 66.6 \mathrm{mmol})$ in $80 \%$ $\mathrm{AcOH}(500 \mathrm{~mL})$ was heated at $85{ }^{\circ} \mathrm{C}$ for $4 \mathrm{~h}$. The reaction mixture was then cooled and concentrated to dryness in vacuo, and the residue was coevaporated with a mixture of toluene and EtOH $(1: 1 \mathrm{v} /$ $\mathrm{v}, 3 \times 100 \mathrm{~mL}$ ). The resulting crude residue was purified by column chromatography on silica gel $\left(R_{f}=0.16 ; 15 \% \mathrm{MeOH}\right.$ in $\mathrm{CH}_{2} \mathrm{Cl}_{2}$; gradient $\left.\mathrm{CH}_{2} \mathrm{Cl}_{2} / \mathrm{MeOH}, 19: 1, \mathrm{v} / \mathrm{v} ; 9: 1, \mathrm{v} / \mathrm{v} ; 17: 3, \mathrm{v} / \mathrm{v}\right)$ to yield 9 $(12.7 \mathrm{~g}, 79 \%)$ as a white solid. ${ }^{1} \mathrm{H}$ NMR $\left(500 \mathrm{MHz}\right.$, DMSO- $\left.d_{6}\right) \delta$ 11.26 (br s, $1 \mathrm{H}, \mathrm{NH}-3$ ), 8.01 (d, $J=8.1 \mathrm{~Hz}, 1 \mathrm{H}, \mathrm{H}-6), 5.54$ (dd, $J=$ 8.1, $3.4 \mathrm{~Hz}, 1 \mathrm{H}, \mathrm{H}-5), 4.91,4.59\left(2 \times\right.$ br s, $2 \times 1 \mathrm{H}, \mathrm{OH}-6^{\prime}$ and $\mathrm{OH}-$ $\left.4^{\prime}\right), 4.48$ (br s, $\left.1 \mathrm{H}, \mathrm{H}-2^{\prime}\right), 4.02\left(\mathrm{~d}, J=13.2 \mathrm{~Hz}, 1 \mathrm{H}, \mathrm{H}-1^{\prime}{ }_{\mathrm{eq}}\right), 3.75$ (dd, $\left.J=13.1,3.5 \mathrm{~Hz}, 1 \mathrm{H}, \mathrm{H}-1^{\prime}{ }_{\mathrm{ax}}\right), 3.66$ (dd, $\left.J=11.9,2.4 \mathrm{~Hz}, 1 \mathrm{H}, \mathrm{H}-6^{\prime}\right)$, $3.56-3.51\left(\mathrm{~m}, 2 \mathrm{H}, \mathrm{H}-6^{\prime \prime}\right.$ and $\left.\mathrm{H}-4^{\prime}\right), 3.14-3.11\left(\mathrm{~m}, 1 \mathrm{H}, \mathrm{H}-5^{\prime}\right), 2.08$ $\left(\mathrm{d}, J=13.9 \mathrm{~Hz}, 1 \mathrm{H}, \mathrm{H}_{-} 3^{\prime}{ }_{\mathrm{eq}}\right), 1.76-1.70\left(\mathrm{~m}, 1 \mathrm{H}, \mathrm{H}-3^{\prime}{ }_{\mathrm{ax}}\right) ;{ }^{13} \mathrm{C}$ NMR $\left(125 \mathrm{MHz}, \mathrm{DMSO}-d_{6}\right) \delta 163.2(\mathrm{C}-4), 150.9(\mathrm{C}-2), 143.2(\mathrm{C}-6)$, $100.7(\mathrm{C}-5), 82.6\left(\mathrm{C}-5^{\prime}\right), 67.0\left(\mathrm{C}-1^{\prime}\right), 60.7\left(\mathrm{C}-4^{\prime}\right), 60.5\left(\mathrm{C}-6^{\prime}\right), 50.5$ $\left(\mathrm{C}-2^{\prime}\right), 35.2\left(\mathrm{C}-3^{\prime}\right)$; HRMS (ESI-TOF) $\mathrm{m} / z:[\mathrm{M}+\mathrm{H}]^{+}$calcd for $\mathrm{C}_{10} \mathrm{H}_{14} \mathrm{~N}_{2} \mathrm{O}_{5}, 243.0975$; found, 243.0974.

1',5'-Anhydro-6'-O-tert-butyldiphenylsilyl-2', 3'-dideoxy-2'(uracil-1-yl)-D-altro-hexitol (10). TBDPSCl (27.3 mL, 104.9 $\mathrm{mmol})$ was added slowly to a stirred solution of compound 9 (12.7 $\mathrm{g}, 52.4 \mathrm{mmol})$ in anhydrous pyridine $(250 \mathrm{~mL})$, and the resulting reaction mixture was heated at $50{ }^{\circ} \mathrm{C}$ for $16 \mathrm{~h}$. The reaction mixture was then cooled to $0{ }^{\circ} \mathrm{C}$ and neutralized with $5 \% \mathrm{NaHCO}_{3}$ solution. The aq layer was extracted with $\mathrm{CH}_{2} \mathrm{Cl}_{2}(3 \times 500 \mathrm{~mL})$. The combined organic layer was dried over $\mathrm{Na}_{2} \mathrm{SO}_{4}$, filtered, and concentrated under reduced pressure, and the resulting crude residue was purified by column chromatography on silica gel $\left(R_{f}=0.58 ; 10 \%\right.$ $\mathrm{MeOH}$ in $\mathrm{CH}_{2} \mathrm{Cl}_{2} ;$ gradient $\mathrm{CH}_{2} \mathrm{Cl}_{2} / \mathrm{MeOH}, 99: 1, \mathrm{v} / \mathrm{v} ; 49: 1, \mathrm{v} / \mathrm{v}$; $97: 3, \mathrm{v} / \mathrm{v})$ to give $10(21.9 \mathrm{~g}, 75 \%)$ as a white foam. Mp $109{ }^{\circ} \mathrm{C} .{ }^{1} \mathrm{H}$ NMR $\left(500 \mathrm{MHz}, \mathrm{CDCl}_{3}\right) \delta 9.38$ (br s, $\left.1 \mathrm{H}, \mathrm{NH}-3\right), 8.08$ (d, $J=8.1$ $\mathrm{Hz}, 1 \mathrm{H}, \mathrm{H}-6), 7.69-7.38$ (m, 10H, Ar-H TBDPS), 5.60 (d, $J=8.1$ $\mathrm{Hz}, 1 \mathrm{H}, \mathrm{H}-5), 4.68$ (br s, $\left.1 \mathrm{H}, \mathrm{H}-2^{\prime}\right), 4.11$ (d, $J=13.4 \mathrm{~Hz}, 1 \mathrm{H}, \mathrm{H}-1^{\prime}{ }_{\mathrm{eq}}$ ), 
3.99-3.94 (m, 2H, H-6 $6^{\prime}$ and $\left.\mathrm{H}-4^{\prime}\right), 3.89(\mathrm{dd}, J=11.0,4.3 \mathrm{~Hz}, 1 \mathrm{H}, \mathrm{H}-$ $6^{\prime \prime}$ ), 3.83 (dd, $J=13.5,3.2 \mathrm{~Hz}, 1 \mathrm{H}, \mathrm{H}-1^{\prime}{ }_{\mathrm{ax}}$ ), 3.29-3.25 (m, $\left.1 \mathrm{H}, \mathrm{H}-5^{\prime}\right)$, $2.51\left(\right.$ br s, $\left.1 \mathrm{H}, \mathrm{OH}-4^{\prime}\right), 2.40-2.36\left(\mathrm{~m}, 1 \mathrm{H}, \mathrm{H}-3^{\prime}{ }_{\mathrm{eq}}\right), 1.88-1.82(\mathrm{~m}$, $\left.1 \mathrm{H}, \mathrm{H}-3^{\prime}{ }_{\mathrm{ax}}\right), 1.07\left(\mathrm{~s}, 9 \mathrm{H}, 3 \times \mathrm{CH}_{3}-{ }^{t} \mathrm{Bu}\right) ;{ }^{13} \mathrm{C}$ NMR $(125 \mathrm{MHz}$, $\mathrm{CDCl}_{3}$ ) $\delta 163.3$ (C-4), 151.0 (C-2), 142.9 (C-6), 135.5, 135.5 (Ar CTBDPS), 132.7, 132.6 (ipso C-TBDPS), 130.1, 130.0, 127.9, 127.8 (Ar C-TBDPS), 102.0 (C-5), 81.2 (C-5'), 68.3 (C-1'), 63.9 (C-6'), $62.9\left(\mathrm{C}-4^{\prime}\right), 51.1\left(\mathrm{C}-2^{\prime}\right), 35.5\left(\mathrm{C}-3^{\prime}\right), 26.8\left(3 \times \mathrm{CH}_{3}-{ }^{t} \mathrm{Bu}\right), 19.2$ $\left(1 \mathrm{C}-{ }^{t} \mathrm{Bu}\right)$; HRMS (ESI-TOF) $\mathrm{m} / z:[\mathrm{M}+\mathrm{H}]^{+}$calcd for $\mathrm{C}_{26} \mathrm{H}_{32} \mathrm{~N}_{2} \mathrm{O}_{5} \mathrm{Si}$, 481.2153; found, 481.2155.

$1^{\prime}, 5^{\prime}$-Anhydro-6'-O-tert-butyldiphenylsilyl-4' -O-mesyl$2^{\prime}, 3^{\prime}$-dideoxy-2'-(uracil-1-yl)-D-altro-hexitol (11). Mesyl chloride $(8.5 \mathrm{~mL}, 109.7 \mathrm{mmol})$ was added slowly to a stirred solution of compound $10(21.1 \mathrm{~g}, 43.9 \mathrm{mmol})$ in anhydrous pyridine $(250 \mathrm{~mL})$ at $0{ }^{\circ} \mathrm{C}$, and the resulting reaction mixture was slowly warmed to room temperature over $4 \mathrm{~h}$ and stirred at the same temperature for 12 $\mathrm{h}$. The reaction mixture was then cooled to $-20^{\circ} \mathrm{C}$ and neutralized with $5 \% \mathrm{NaHCO}_{3}$ solution. The aqueous layer was extracted with $\mathrm{CH}_{2} \mathrm{Cl}_{2}(3 \times 400 \mathrm{~mL})$. The combined organic layer was dried over $\mathrm{Na}_{2} \mathrm{SO}_{4}$, filtered, and concentrated under reduced pressure, and the resulting crude residue was purified by column chromatography on silica gel $\left(R_{f}=0.68 ; 10 \% \mathrm{MeOH}\right.$ in $\mathrm{CH}_{2} \mathrm{Cl}_{2}$; gradient $\mathrm{CH}_{2} \mathrm{Cl}_{2} /$ $\mathrm{MeOH}, 199: 1, \mathrm{v} / \mathrm{v} ; 99: 1, \mathrm{v} / \mathrm{v} ; 19.7: 0.3, \mathrm{v} / \mathrm{v})$ to give $11(24 \mathrm{~g}, 98 \%)$ as an off-white foam. $\mathrm{Mp} 88^{\circ} \mathrm{C} .{ }^{1} \mathrm{H}$ NMR $\left(300 \mathrm{MHz}, \mathrm{CDCl}_{3}\right) \delta 9.94(\mathrm{br}$ s, $1 \mathrm{H}, \mathrm{NH}-3), 8.00$ (d, $J=8.1 \mathrm{~Hz}, 1 \mathrm{H}, \mathrm{H}-6), 7.71-7.36(\mathrm{~m}, 10 \mathrm{H}, \mathrm{Ar}-$ $H$ TBDPS), 5.58 (d, $J=8.1 \mathrm{~Hz}, 1 \mathrm{H}, \mathrm{H}-5), 5.10-5.02\left(\mathrm{~m}, 1 \mathrm{H}, \mathrm{H}-4^{\prime}\right)$, 4.83-4.79 (m, 1H, H-2'), 4.15 (d, J = $\left.13.5 \mathrm{~Hz}, 1 \mathrm{H}, \mathrm{H}-\mathrm{1}^{\prime}{ }_{\mathrm{eq}}\right), 3.97$ (dd, $\left.J=11.8,2.2 \mathrm{~Hz}, 1 \mathrm{H}, \mathrm{H}-6^{\prime}\right), 3.92-3.84\left(\mathrm{~m}, 2 \mathrm{H}, \mathrm{H}-6^{\prime \prime}\right.$ and $\left.\mathrm{H}-1^{\prime}{ }_{\mathrm{ax}}\right)$, 3.51-3.46 (m, 1H, H-5'), 2.88 (s, 3H, $\left.\mathrm{CH}_{3}-\mathrm{OMs}\right), 2.70-2.62(\mathrm{~m}$, $\left.1 \mathrm{H}, \mathrm{H}-3^{\prime}{ }_{\mathrm{eq}}\right), 2.24-2.14\left(\mathrm{~m}, 1 \mathrm{H}, \mathrm{H}-3^{\prime}{ }_{\mathrm{ax}}\right), 1.09\left(\mathrm{~s}, 9 \mathrm{H}, 3 \times \mathrm{CH}_{3}-{ }^{t} \mathrm{Bu}\right)$; ${ }^{13} \mathrm{C} \mathrm{NMR}\left(75 \mathrm{MHz}, \mathrm{CDCl}_{3}\right) \delta 163.4$ (C-4), $151.2(\mathrm{C}-2), 142.1(\mathrm{C}-$ 6), 135.7 (Ar C-TBDPS), 132.8, 132.7 (ipso C-TBDPS), 130.1, 130.0, 127.9, 127.8 (Ar C-TBDPS), 102.9 (C-5), $79.2\left(\mathrm{C}^{\prime} 5^{\prime}\right), 70.7$ (C-4'), $68.4\left(\mathrm{C}-1^{\prime}\right), 61.9\left(\mathrm{C}-6^{\prime}\right), 50.3\left(\mathrm{C}-2^{\prime}\right), 38.7\left(\mathrm{CH}_{3}-\mathrm{OMs}\right), 33.9\left(\mathrm{C}-3^{\prime}\right)$, $26.9\left(3 \times \mathrm{CH}_{3}-{ }^{t} \mathrm{Bu}\right), 19.3\left(1 \mathrm{C}-{ }^{t} \mathrm{Bu}\right)$; HRMS (ESI-TOF) $m / z:[\mathrm{M}+$ $\mathrm{H}]^{+}$calcd for $\mathrm{C}_{27} \mathrm{H}_{34} \mathrm{~N}_{2} \mathrm{O}_{7} \mathrm{SSi}$, 559.1929; found, 559.1919.

$1^{\prime}, 5^{\prime}$-Anhydro-4',2-anhydro-6'-O-tert-butyldiphenylsilyl$2^{\prime}, 3^{\prime}$-dideoxy-2'-(uracil-1-yl)-D-iodo-hexitol (12). Triethylamine $(6.5 \mathrm{~mL}, 46.9 \mathrm{mmol})$ was added to a stirred solution of compound $\mathbf{1 1}$ $(23.8 \mathrm{~g}, 42.6 \mathrm{mmol})$ in absolute ethanol $(300 \mathrm{~mL})$, and the resulting reaction mixture was heated at $90{ }^{\circ} \mathrm{C}$ for $16 \mathrm{~h}$. The reaction mixture was then cooled, and volatiles were removed under reduced pressure. The crude residue was diluted with $5 \% \mathrm{NaHCO}_{3}$ solution $(500 \mathrm{~mL})$, and the aqueous layer was extracted with $\mathrm{CH}_{2} \mathrm{Cl}_{2}(3 \times 400 \mathrm{~mL})$. The combined organic layer was dried over $\mathrm{Na}_{2} \mathrm{SO}_{4}$, filtered, and concentrated under reduced pressure, and the resulting crude residue was purified by column chromatography on silica gel $\left(R_{f}=0.35 ; 10 \%\right.$ $\mathrm{MeOH}$ in $\mathrm{CH}_{2} \mathrm{Cl}_{2}$; gradient $\mathrm{CH}_{2} \mathrm{Cl}_{2} / \mathrm{MeOH}, 99: 1, \mathrm{v} / \mathrm{v} ; 97: 3, \mathrm{v} / \mathrm{v}$; $47: 3, \mathrm{v} / \mathrm{v})$ to yield $12(19.3 \mathrm{~g}, 98 \%)$ as a white foam. Mp $110{ }^{\circ} \mathrm{C} .{ }^{1} \mathrm{H}$ NMR $\left(300 \mathrm{MHz}, \mathrm{CDCl}_{3}\right) \delta$ 7.67-7.28 $(\mathrm{m}, 11 \mathrm{H}, \mathrm{H}-6$ and $\mathrm{Ar}-\mathrm{H}$ TBDPS), 5.98 (d, $J=7.3 \mathrm{~Hz}, 1 \mathrm{H}, \mathrm{H}-5), 4.83$ (br s, $1 \mathrm{H}, \mathrm{H}-4^{\prime}$ ), 4.38 (br s, $\left.1 \mathrm{H}, \mathrm{H}-2^{\prime}\right), 3.89$ (d, $J=12.1 \mathrm{~Hz}, 1 \mathrm{H}, \mathrm{H}_{-1}{ }^{\prime}{ }_{\mathrm{eq}}$ ), 3.81 (dd, $J=8.8$, $\left.7.5 \mathrm{~Hz}, 1 \mathrm{H}, \mathrm{H}-6^{\prime}\right), 3.77-3.63\left(\mathrm{~m}, 3 \mathrm{H}, \mathrm{H}-6^{\prime \prime}, \mathrm{H}-1^{\prime}{ }_{\text {ax }}\right.$ and H-5'), $2.49-$ $2.42\left(\mathrm{~m}, 1 \mathrm{H}, \mathrm{H}-3^{\prime}{ }_{\mathrm{eq}}\right), 2.26-2.19\left(\mathrm{~m}, 1 \mathrm{H}, \mathrm{H}-3^{\prime}{ }_{\mathrm{ax}}\right), 1.05(\mathrm{~s}, 9 \mathrm{H}, 3 \times$ $\left.\mathrm{CH}_{3}-{ }^{t} \mathrm{Bu}\right) ;{ }^{13} \mathrm{C} \mathrm{NMR}\left(75 \mathrm{MHz}, \mathrm{CDCl}_{3}\right) \delta 171.7(\mathrm{C}-4), 155.9(\mathrm{C}-2)$, 141.2 (C-6), 135.5, 135.4 (Ar C-TBDPS), 133.1, 132.8 (ipso CTBDPS), 129.9, 127.9, 127.8 (Ar C-TBDPS), 110.7 (C-5), 79.6 (C5'), $70.0\left(\mathrm{C}-4^{\prime}\right), 69.9\left(\mathrm{C}-1^{\prime}\right), 62.1\left(\mathrm{C}-6^{\prime}\right), 53.4\left(\mathrm{C}-2^{\prime}\right), 26.8(3 \times$ $\left.\mathrm{CH}_{3}-{ }^{t} \mathrm{Bu}\right), 26.4\left(\mathrm{C}-3^{\prime}\right), 19.2\left(1 \mathrm{C}-{ }^{t} \mathrm{Bu}\right)$; HRMS (ESI-TOF) $m / z$ : $[\mathrm{M}$ $+\mathrm{H}]^{+}$calcd for $\mathrm{C}_{26} \mathrm{H}_{30} \mathrm{~N}_{2} \mathrm{O}_{4} \mathrm{Si}, 463.2047$; found, 463.2044.

$1^{\prime}, 5^{\prime}$-Anhydro-6'-O-tert-butyldiphenylsilyl-4' -azido-2', $3^{\prime}$-dideoxy-2'-(uracil-1-yl)-D-altro-hexitol (13). To a stirred solution of compound $12(19 \mathrm{~g}, 41.1 \mathrm{mmol})$ in dry DMF $(300 \mathrm{~mL})$ was added lithium azide $(13.1 \mathrm{~g}, 267.1 \mathrm{mmol})$, and the resulting reaction mixture was heated at $135{ }^{\circ} \mathrm{C}$ for $48 \mathrm{~h}$. The progress of reaction was monitored by TLC, and, after completion, the reaction mixture was cooled and volatiles were removed under reduced pressure. The crude residue was purified by column chromatography on silica gel to provide $13\left(R_{f}=0.86 ; 10 \% \mathrm{MeOH}\right.$ in $\mathrm{CH}_{2} \mathrm{Cl}_{2}$; gradient $\mathrm{CH}_{2} \mathrm{Cl}_{2} /$ $\mathrm{MeOH}, 100: 0$, v/v; 199:1, v/v; 99:1, v/v; $3.95 \mathrm{~g}, 19 \%$ ) as an off-white foam and $14\left(R_{f}=0.27 ; 10 \% \mathrm{MeOH}\right.$ in $\mathrm{CH}_{2} \mathrm{Cl}_{2}$; gradient $\mathrm{CH}_{2} \mathrm{Cl}_{2}$ / $\mathrm{MeOH}, 99: 1, \mathrm{v} / \mathrm{v} ; 49: 1, \mathrm{v} / \mathrm{v} ; 24: 1, \mathrm{v} / \mathrm{v} ; 3.95 \mathrm{~g}, 36 \%)$ as an off-white solid. Spectral data for 13: ${ }^{1} \mathrm{H}$ NMR $\left(300 \mathrm{MHz}, \mathrm{CDCl}_{3}\right) \delta 9.62$ (br s, $1 \mathrm{H}, \mathrm{NH}-3$ ), 8.20 (d, $J=8.2 \mathrm{~Hz}, 1 \mathrm{H}, \mathrm{H}-6), 7.72-7.36$ (m, 10H, Ar- $\mathrm{H}$ TBDPS), $5.58(\mathrm{~d}, J=8.1 \mathrm{~Hz}, 1 \mathrm{H}, \mathrm{H}-5), 4.73-4.69\left(\mathrm{~m}, 1 \mathrm{H}, \mathrm{H}-2^{\prime}\right)$, 4.19 (dd, $J=13.4,1.8 \mathrm{~Hz}, 1 \mathrm{H}, \mathrm{H}-1^{\prime}{ }_{\mathrm{eq}}$ ), 3.99-3.83 (m, 4H, H-6', H6", $\mathrm{H}-4^{\prime}$, and $\left.\mathrm{H}-1^{\prime}{ }_{\mathrm{ax}}\right), 3.24-3.19\left(\mathrm{~m}, 1 \mathrm{H}, \mathrm{H}-5^{\prime}\right), 2.57-2.49(\mathrm{~m}, 1 \mathrm{H}$, $\left.\mathrm{H}-3^{\prime}{ }_{\text {eq }}\right), 1.99-1.89\left(\mathrm{~m}, 1 \mathrm{H}, \mathrm{H}-3^{\prime}{ }_{\mathrm{ax}}\right), 1.07\left(\mathrm{~s}, 9 \mathrm{H}, 3 \times \mathrm{CH}_{3}-{ }^{t} \mathrm{Bu}\right) ;{ }^{13} \mathrm{C}$ NMR $\left(75 \mathrm{MHz}, \mathrm{CDCl}_{3}\right) \delta 163.4$ (C-4), 151.3 (C-2), 142.9 (C-6), 135.7, 135.6 (Ar C-TBDPS), 133.0, 132.9 (ipso C-TBDPS), 130.1, 130.0, 127.9 (Ar C-TBDPS), 102.6 (C-5), 80.8 (C-5'), 68.5 (C-1'), $62.9\left(\mathrm{C}-6^{\prime}\right), 51.7\left(\mathrm{C}-4^{\prime}\right), 50.1\left(\mathrm{C}-2^{\prime}\right), 33.3\left(\mathrm{C}-3^{\prime}\right), 26.9(3 \times$ $\left.\mathrm{CH}_{3}-{ }^{t} \mathrm{Bu}\right), 19.4\left(1 \mathrm{C}-{ }^{t} \mathrm{Bu}\right.$ ); HRMS (ESI-TOF) $\mathrm{m} / z:[\mathrm{M}+\mathrm{H}]^{+}$calcd for $\mathrm{C}_{26} \mathrm{H}_{31} \mathrm{~N}_{5} \mathrm{O}_{4} \mathrm{Si}$, 506.2218; found, 506.2208.

Spectral data for 14: ${ }^{1} \mathrm{H}$ NMR (500 MHz, DMSO- $\left.d_{6}\right) \delta 11.26(\mathrm{br}$ s, $1 \mathrm{H}, \mathrm{NH}-3), 8.00(\mathrm{~d}, J=8.1 \mathrm{~Hz}, 1 \mathrm{H}, \mathrm{H}-6), 5.53(\mathrm{~d}, J=8.1 \mathrm{~Hz}, 1 \mathrm{H}$, $\mathrm{H}-5), 4.86\left(\mathrm{~m}, 1 \mathrm{H}, \mathrm{OH}-6^{\prime}\right), 4.48-4.46\left(\mathrm{~m}, 1 \mathrm{H}, \mathrm{H}-2^{\prime}\right), 4.09-4.06(\mathrm{~m}$, $\left.1 \mathrm{H}, \mathrm{H}-1^{\prime}{ }_{\mathrm{eq}}\right), 3.83-3.77\left(\mathrm{~m}, 2 \mathrm{H}, \mathrm{H}-4^{\prime}\right.$ and $\left.\mathrm{H}^{\prime}{ }^{\prime}{ }_{\mathrm{ax}}\right), 3.65-3.55(\mathrm{~m}, 2 \mathrm{H}$, $\mathrm{H}-6^{\prime}$ and $\left.\mathrm{H}-6^{\prime \prime}\right), 3.25-3.21\left(\mathrm{~m}, 1 \mathrm{H}, \mathrm{H}-5^{\prime}\right), 2.37-2.32(\mathrm{~m}, 1 \mathrm{H}, \mathrm{H}-$ $\left.3^{\prime}{ }_{\text {eq }}\right), 1.92-1.86\left(\mathrm{~m}, 1 \mathrm{H}, \mathrm{H}-3^{\prime}{ }_{\mathrm{ax}}\right) ;{ }^{13} \mathrm{C}$ NMR $\left(125 \mathrm{MHz}\right.$, DMSO- $\left.d_{6}\right) \delta$ 163.4 (C-4), 151.1 (C-2), 143.1 (C-6), 100.9 (C-5), 79.7 (C-5'), 67.0 (C-1'), 60.5 (C-6'), $52.4\left(\mathrm{C}-4^{\prime}\right), 49.5\left(\mathrm{C}-2^{\prime}\right), 31.4\left(\mathrm{C}-3^{\prime}\right)$; HRMS (ESI-TOF) $m / z$ : $[\mathrm{M}+\mathrm{H}]^{+}$calcd for $\mathrm{C}_{10} \mathrm{H}_{13} \mathrm{~N}_{5} \mathrm{O}_{4}, 268.1040$; found, 268.1037.

Compound 13 was also synthesized (96\%) starting from 14, following a procedure similar to that used for the synthesis of $\mathbf{1 0}$.

$1^{\prime}, 5^{\prime}$-Anhydro-4' -azido-2', 3'-dideoxy-2' -(uracil-1-yl)-Daltro-hexitol (14). To a stirred solution of compound $13(0.9 \mathrm{~g}, 1.78$ $\mathrm{mmol})$ in dry THF $(30 \mathrm{~mL})$ in a plastic vessel was added triethylamine trihydrofluoride $(1.16 \mathrm{~mL}, 7.12 \mathrm{mmol})$, and the resulting reaction mixture was heated at $50{ }^{\circ} \mathrm{C}$ for $60 \mathrm{~h}$. The progress of the reaction was monitored by TLC, and after completion the reaction mixture was then cooled, and volatiles were removed under reduced pressure. Remaining hydrofluoride was quenched by addition of excess of silica gel, and the crude residue was purified by column chromatography on silica gel $\left(R_{f}=0.27 ; 10 \% \mathrm{MeOH}\right.$ in $\mathrm{CH}_{2} \mathrm{Cl}_{2}$; gradient $\mathrm{CH}_{2} \mathrm{Cl}_{2} / \mathrm{MeOH}, 99: 1, \mathrm{v} / \mathrm{v} ; 49: 1, \mathrm{v} / \mathrm{v} ; 24: 1, \mathrm{v} / \mathrm{v}$ ) to provide $14(0.4 \mathrm{~g}, 85 \%)$ as an off-white solid. Mp $199{ }^{\circ} \mathrm{C}$.

$1^{\prime}, 5^{\prime}$-Anhydro-6'-O-benzoyl-4' -azido-2', 3'-dideoxy-2' -(uracil-1-yl)-D-altro-hexitol (15). To a stirred solution of compound 14 $(1.90 \mathrm{~g}, 7.11 \mathrm{mmol})$ in anhydrous pyridine $(40 \mathrm{~mL})$ was added benzoyl chloride $(0.84 \mathrm{~mL}, 7.25 \mathrm{mmol})$ at $0{ }^{\circ} \mathrm{C}$, and the resulting reaction mixture was slowly warmed to room temperature and stirred at the same temperature for $16 \mathrm{~h}$. The reaction mixture was then cooled to $0{ }^{\circ} \mathrm{C}$, and the $\mathrm{pH}$ was adjusted to $\sim 8$ with the addition of $5 \% \mathrm{NaHCO}_{3}$ solution. The aq layer was extracted with $\mathrm{CH}_{2} \mathrm{Cl}_{2}(3 \times$ $200 \mathrm{~mL}$ ). The combined organic layer was dried over $\mathrm{Na}_{2} \mathrm{SO}_{4}$, filtered, and concentrated under reduced pressure, and the resulting crude residue was purified by column chromatography on silica gel $\left(R_{f}\right.$ $=0.63 ; 10 \% \mathrm{MeOH}$ in $\mathrm{CH}_{2} \mathrm{Cl}_{2}$; gradient $\mathrm{CH}_{2} \mathrm{Cl}_{2} / \mathrm{MeOH}, 199: 1$, v/v; 99:1, v/v; 66:1, v/v) to give $15(2.37 \mathrm{~g}, 90 \%)$ as a white semisolid. Mp $91{ }^{\circ} \mathrm{C} .{ }^{1} \mathrm{H}$ NMR $\left(300 \mathrm{MHz}, \mathrm{CDCl}_{3}\right) \delta 9.76$ (br s, $1 \mathrm{H}, \mathrm{NH}-3$ ), $8.07-8.01(\mathrm{~m}, 3 \mathrm{H}, \mathrm{H}-6$ and $o-\mathrm{H} \mathrm{Bz}), 7.61(\mathrm{t}, 1 \mathrm{H}, J=7.4 \mathrm{~Hz}, p-\mathrm{H} \mathrm{Bz})$, $7.47(\mathrm{t}, 2 \mathrm{H}, J=7.7 \mathrm{~Hz}, m-\mathrm{H} \mathrm{Bz}), 5.52(\mathrm{~d}, J=8.2 \mathrm{~Hz}, 1 \mathrm{H}, \mathrm{H}-5), 4.75-$ $4.68\left(\mathrm{~m}, 2 \mathrm{H}, \mathrm{H}-6^{\prime}\right.$ and $\left.\mathrm{H}-2^{\prime}\right), 4.52\left(\mathrm{dd}, J=12.3,3.6 \mathrm{~Hz}, 1 \mathrm{H}, \mathrm{H}-6^{\prime \prime}\right)$, $4.25\left(\mathrm{~d}, J=13.9 \mathrm{~Hz}, 1 \mathrm{H}, \mathrm{H}-1^{\prime}{ }_{\mathrm{eq}}\right), 3.95(\mathrm{dd}, J=13.7,3.2 \mathrm{~Hz}, 1 \mathrm{H}, \mathrm{H}-$ $\left.1^{\prime}{ }_{\mathrm{ax}}\right), 3.77-3.69\left(\mathrm{~m}, 1 \mathrm{H}, \mathrm{H}-4^{\prime}\right), 3.59-3.54\left(\mathrm{~m}, 1 \mathrm{H}, \mathrm{H}-5^{\prime}\right), 2.66-2.58$ $\left(\mathrm{m}, 1 \mathrm{H}, \mathrm{H}-3^{\prime}{ }_{\mathrm{eq}}\right), 2.06-1.96\left(\mathrm{~m}, 1 \mathrm{H}, \mathrm{H}-3^{\prime}{ }_{\mathrm{ax}}\right) ;{ }^{13} \mathrm{C} \mathrm{NMR}(75 \mathrm{MHz}$, $\left.\mathrm{CDCl}_{3}\right) \delta 166.0$ (CO-Bz), 163.3 (C-4), 151.2 (C-2), 142.4 (C-6), 133.7 (pC-Bz), 129.6 (oC-Bz), 129.5 (ipso C-Bz), 128.7 ( $m \mathrm{C}-\mathrm{Bz})$, 102.4 (C-5), $78.4\left(\mathrm{C}-5^{\prime}\right), 68.3\left(\mathrm{C}-1^{\prime}\right), 63.3\left(\mathrm{C}-6^{\prime}\right), 52.4\left(\mathrm{C}-4^{\prime}\right), 50.3$ $\left(\mathrm{C}-2^{\prime}\right), 33.0\left(\mathrm{C}-3^{\prime}\right)$; HRMS (ESI-TOF) $\mathrm{m} / z:[\mathrm{M}+\mathrm{H}]^{+}$calcd for $\mathrm{C}_{17} \mathrm{H}_{17} \mathrm{~N}_{5} \mathrm{O}_{5}, 372.1302$; found, 372.1318 .

1',5'-Anhydro-6'-O-benzoyl-4'-amino-2', 3'-dideoxy-2' -(uracil-1-yl)-D-altro-hexitol (16). To a stirred solution of 15 (2.3 g, $6.19 \mathrm{mmol}, 1$ equiv) in absolute $\mathrm{EtOH}(130 \mathrm{~mL}$, degaussed with argon) were added two drops of glacial $\mathrm{AcOH}$ followed by $10 \% \mathrm{Pd} / \mathrm{C}$ (Degussa type, $0.345 \mathrm{~g}, 0.15$ equiv $\mathrm{w} / \mathrm{w}$ ), and evacuation was then carried out with hydrogen atmosphere replacements $(3 \times)$. The reaction mixture was stirred at room temperature for $16 \mathrm{~h}$ under an 
atmospheric pressure of hydrogen. After completion of the reaction, the catalyst was removed by filtration through a Celite pad, and the pad was thoroughly washed with EtOH. The combined filtrate was concentrated under reduced pressure, and the crude residue was purified by column chromatography on silica gel $\left(R_{f}=0.29 ; 10 \%\right.$ $\mathrm{MeOH}$ in $\mathrm{CH}_{2} \mathrm{Cl}_{2}$; gradient $\mathrm{CH}_{2} \mathrm{Cl}_{2} / \mathrm{MeOH}, 99: 1, \mathrm{v} / \mathrm{v} ; 24: 1, \mathrm{v} / \mathrm{v}$; 93:7, v/v) to afford $16(1.94 \mathrm{~g}, 91 \%)$ as a white semisolid. Mp $128^{\circ} \mathrm{C}$. ${ }^{1} \mathrm{H}$ NMR $\left(300 \mathrm{MHz}, \mathrm{CDCl}_{3}\right) \delta 8.14(\mathrm{~d}, J=8.1 \mathrm{~Hz}, 1 \mathrm{H}, \mathrm{H}-6), 8.04-$ $8.02(\mathrm{~m}, 2 \mathrm{H}, o-\mathrm{H} \mathrm{Bz}), 7.63-7.57(\mathrm{~m}, 1 \mathrm{H}, p-\mathrm{H} \mathrm{Bz}), 7.46(\mathrm{t}, 2 \mathrm{H}, J=$ $7.8 \mathrm{~Hz}, m-\mathrm{H} \mathrm{Bz}), 5.46(\mathrm{~d}, J=8.1 \mathrm{~Hz}, 1 \mathrm{H}, \mathrm{H}-5), 4.79(\mathrm{dd}, 1 \mathrm{H}, J=$ $\left.12.2,3.3 \mathrm{~Hz}, \mathrm{H}-6^{\prime}\right), 4.61$ (br s, $\left.1 \mathrm{H}, \mathrm{H}-2^{\prime}\right), 4.56(\mathrm{dd}, J=12.2,2.2 \mathrm{~Hz}$, $\left.1 \mathrm{H}, \mathrm{H}-6^{\prime \prime}\right), 4.21$ (dd, $J=13.4,1.4 \mathrm{~Hz}, 1 \mathrm{H}, \mathrm{H}-1^{\prime}{ }_{\mathrm{eq}}$ ), 3.93 (dd, $J=13.6$, $\left.3.2 \mathrm{~Hz}, 1 \mathrm{H}, \mathrm{H}-1^{\prime}{ }_{\mathrm{ax}}\right), 3.46-3.41\left(\mathrm{~m}, 1 \mathrm{H}, \mathrm{H}-5^{\prime}\right), 3.06-2.98(\mathrm{~m}, 1 \mathrm{H}, \mathrm{H}-$ $\left.4^{\prime}\right), 2.35-2.27\left(\mathrm{~m}, 1 \mathrm{H}, \mathrm{H}-3^{\prime}{ }_{\mathrm{eq}}\right), 1.81-1.71\left(\mathrm{~m}, 1 \mathrm{H}, \mathrm{H}-3^{\prime}{ }_{\mathrm{ax}}\right) ;{ }^{13} \mathrm{C}$ NMR $\left(75 \mathrm{MHz}, \mathrm{CDCl}_{3}\right) \delta 166.5$ (CO-Bz), 163.6 (C-4), 151.3 (C-2), 143.1 (C-6), 133.6 ( $p \mathrm{C}-\mathrm{Bz}$ ), 129.7 (oC-Bz), 129.6 (ipso C-Bz), 128.6 $(m \mathrm{C}-\mathrm{Bz}), 101.8(\mathrm{C}-5), 82.0\left(\mathrm{C}-5^{\prime}\right), 68.4\left(\mathrm{C}-1^{\prime}\right), 63.5\left(\mathrm{C}-6^{\prime}\right), 50.8(\mathrm{C}-$ $\left.2^{\prime}\right), 42.7$ (C-4'), 36.5 (C-3'); HRMS (ESI-TOF) $m / z$ : $[\mathrm{M}+\mathrm{H}]^{+}$ calcd for $\mathrm{C}_{17} \mathrm{H}_{19} \mathrm{~N}_{3} \mathrm{O}_{5}, 346.1397$; found, 346.1402 .

$1^{\prime}, 5^{\prime}$-Anhydro-6'-O-benzoyl-4' -amino(monomethoxytrityl)$2^{\prime}, 3^{\prime}$-dideoxy-2'-(uracil-1-yl)-D-altro-hexitol (17). To a stirred solution of compound $16(1.9 \mathrm{~g}, 5.5 \mathrm{mmol})$ in dry pyridine $(60 \mathrm{~mL})$ were added $N, N$-diisopropylethylamine $(9.6 \mathrm{~mL}, 55 \mathrm{mmol})$ followed by 4-methoxytrityl chloride $(5.09 \mathrm{~g}, 16.5 \mathrm{mmol})$, and the resulting reaction mixture was stirred at room temperature for $24 \mathrm{~h}$. The progress of the reaction was monitored by TLC, and, after completion, the reaction mixture was quenched with $5 \% \mathrm{NaHCO}_{3}$ solution. The aq layer was extracted with $\mathrm{CH}_{2} \mathrm{Cl}_{2}(3 \times 200 \mathrm{~mL})$. The combined organic layer was dried over $\mathrm{Na}_{2} \mathrm{SO}_{4}$, filtered, and concentrated under reduced pressure, and the resulting crude residue was purified by column chromatography on silica gel $\left(R_{f}=0.52 ; 80 \%\right.$ EtOAc in hexane; gradient hexane/EtOAc, 4:1, v/v; 3:2, v/v; 2:3, v/ v) to give $17(3.02 \mathrm{~g}, 89 \%)$ as a white solid. ${ }^{1} \mathrm{H}$ NMR $(600 \mathrm{MHz}$, $\left.\mathrm{CDCl}_{3}\right) \delta 7.83-7.81(\mathrm{~m}, 2 \mathrm{H}, o \mathrm{H}-\mathrm{Bz}), 7.75(\mathrm{~d}, J=8.1 \mathrm{~Hz}, 1 \mathrm{H}, \mathrm{H}-6)$, 7.61-7.58 (m, 1H, pH-Bz), 7.45-6.68 (m, 16H, Ar-H MMTr and $m \mathrm{H}-\mathrm{Bz}), 5.33$ (d, $J=8.1 \mathrm{~Hz}, 1 \mathrm{H}, \mathrm{H}-5), 4.70(\mathrm{dd}, J=12.1,3.5 \mathrm{~Hz}, 1 \mathrm{H}$, $\left.\mathrm{H}-6^{\prime}\right), 4.58\left(\mathrm{dd}, J=12.0,2.7 \mathrm{~Hz}, 1 \mathrm{H}, \mathrm{H}-6^{\prime \prime}\right), 4.36-4.34(\mathrm{~m}, 1 \mathrm{H}, \mathrm{H}-$ $\left.2^{\prime}\right), 4.01-3.98\left(\mathrm{~m}, 1 \mathrm{H}, \mathrm{H}-1^{\prime}{ }_{\mathrm{eq}}\right), 3.86\left(\mathrm{dd}, J=13.3,3.5 \mathrm{~Hz}, \mathrm{H}-1^{\prime}{ }_{\mathrm{ax}}\right)$, $3.70\left(\mathrm{~s}, 3 \mathrm{H}, \mathrm{OCH}_{3}\right), 3.66-3.64\left(\mathrm{~m}, 1 \mathrm{H}, \mathrm{H}-5^{\prime}\right), 2.75-2.70(\mathrm{~m}, 1 \mathrm{H}, \mathrm{H}-$ $\left.4^{\prime}\right), 1.97\left(\mathrm{~d}, J=6.5 \mathrm{~Hz}, 1 \mathrm{H}, \mathrm{NH}-4^{\prime}\right), 1.61-1.57\left(\mathrm{~m}, 1 \mathrm{H}, \mathrm{H}-3^{\prime}{ }_{\mathrm{eq}}\right)$, $1.53-1.48\left(\mathrm{~m}, 1 \mathrm{H}, \mathrm{H}-3^{\prime}{ }_{\mathrm{ax}}\right) ;{ }^{13} \mathrm{C}$ NMR $\left(150 \mathrm{MHz}, \mathrm{CDCl}_{3}\right) \delta 166.1$ (CO-Bz), 162.6 (C-4), 158.1 ( $p$ C-anisyl), 150.2 (C-2), 146.4, 146.3 (ipso C-Ph), 142.8 (C-6), 137.7 (ipso C-anisyl), 133.3, 129.8, 129.6, 128.4, 128.4, 128.3, 127.9, 126.6, 126.5 (Ar C-anisyl and $\mathrm{Ph}$ ), 113.2 (mC-anisyl), 101.2 (C-5), 79.9 (C-5'), 70.0 (1C-MMTr), 67.9 (C$\left.1^{\prime}\right), 63.3\left(\mathrm{C}-6^{\prime}\right), 55.1\left(\mathrm{OCH}_{3}\right.$-anisyl), $50.3\left(\mathrm{C}-2^{\prime}\right), 46.4\left(\mathrm{C}-4^{\prime}\right), 35.0$ $\left(\mathrm{C}-3^{\prime}\right)$; HRMS (ESI-TOF) $m / z$ : $[\mathrm{M}+\mathrm{Na}]^{+}$calcd for $\mathrm{C}_{37} \mathrm{H}_{35} \mathrm{~N}_{3} \mathrm{O}_{6}$, 640.2418; found, 640.2412 .

$1^{\prime}, 5^{\prime}$-Anhydro-4' -amino(monomethoxytrityl)-2', 3' -dideoxy-2'-(uracil-1-yl)-D-altro-hexitol (1). A stirred solution of compound 17 (2.63 g, $4.26 \mathrm{mmol})$ in $7 \mathrm{~N} \mathrm{NH}_{3}$ in $\mathrm{MeOH}(30 \mathrm{~mL})$ in a sealed vessel was heated at $55{ }^{\circ} \mathrm{C}$ for $48 \mathrm{~h}$. After completion, the reaction mixture was cooled, and volatiles were removed under reduced pressure. The resulting crude residue was purified by column chromatography on silica gel $\left(R_{f}=0.28\right.$; EtOAc; gradient hexane/ EtOAc, 3:2, v/v; 2:3, v/v; 0:100, v/v) to afford $1(1.86 \mathrm{~g}, 85 \%)$ as a white semisolid. ${ }^{1} \mathrm{H}$ NMR (500 MHz, DMSO- $\left.d_{6}\right) \delta 11.2$ (br s, $1 \mathrm{H}$, $\mathrm{NH}-3$ ), 7.55 (d, $J=8.1 \mathrm{~Hz}, 1 \mathrm{H}, \mathrm{H}-6), 7.44-6.77$ (m, 14H, Ar- $H$ Trt), $5.34(\mathrm{~d}, J=8.0 \mathrm{~Hz}, 1 \mathrm{H}, \mathrm{H}-5), 4.72\left(\mathrm{t}, J=5.5 \mathrm{~Hz}, 1 \mathrm{H}, \mathrm{OH}-6^{\prime}\right), 4.20-$ $4.17\left(\mathrm{~m}, 1 \mathrm{H}, \mathrm{H}-2^{\prime} 3.86\left(\mathrm{~d}, J=13.2 \mathrm{~Hz}, 1 \mathrm{H}, \mathrm{H}-1^{\prime}{ }_{\mathrm{eq}}\right), 3.71-3.68(\mathrm{~m}\right.$, $4 \mathrm{H}, \mathrm{OCH}_{3}$ and $\left.\mathrm{H}-\mathrm{1}^{\prime}{ }_{\mathrm{ax}}\right), 3.52-3.38\left(\mathrm{~m}, 2 \mathrm{H}, \mathrm{H}-6^{\prime}\right.$ and $\left.\mathrm{H}-6^{\prime \prime}\right), 3.30-$ $3.27\left(\mathrm{~m}, 1 \mathrm{H}, \mathrm{H}-5^{\prime}\right), 3.09$ (d, J = 5.6 Hz, 1H, NH-4'), 2.23-2.17 (m, $\left.1 \mathrm{H}, \mathrm{H}-4^{\prime}\right), 1.65-1.61\left(\mathrm{~m}, 1 \mathrm{H}, \mathrm{H}-3^{\prime}{ }_{\mathrm{eq}}\right), 1.54-1.49$ (m, $\left.1 \mathrm{H}, \mathrm{H}-3^{\prime}{ }_{\mathrm{ax}}\right)$; ${ }^{13} \mathrm{C}$ NMR (125 MHz, DMSO- $\left.d_{6}\right) \delta 163.2$ (C-4), 157.5 ( $p$ C-anisyl), 150.7 (C-2), 147.3, 147.2 (ipso C-Ph), 142.8 (C-6), 138.2 (ipso Canisyl), 129.7, 128.9, 128.3, 128.2, 127.6, 126.1, 125.4 (Ar C-anisyl and $\mathrm{Ph}), 112.9\left(\mathrm{mC}\right.$-anisyl), $100.5(\mathrm{C}-5), 80.2\left(\mathrm{C}-5^{\prime}\right), 69.7$ (1CMMTr), $66.2\left(\mathrm{C}-1^{\prime}\right), 62.3\left(\mathrm{C}-6^{\prime}\right), 54.9\left(\mathrm{OCH}_{3}\right.$-anisyl), $49.8\left(\mathrm{C}-2^{\prime}\right)$, $48.7\left(\mathrm{C}-4^{\prime}\right)$, $33.4\left(\mathrm{C}-3^{\prime}\right)$; HRMS (ESI-TOF) $m / z:[\mathrm{M}+\mathrm{Na}]^{+}$calcd for $\mathrm{C}_{30} \mathrm{H}_{31} \mathrm{~N}_{3} \mathrm{O}_{5}, 536.2156$; found, 536.2137.
1',5'-Anhydro-6'-O-tert-butyldiphenylsilyl-4'-azido-2', 3'-dideoxy-2'-(cytosine-1-yl)-D-altro-hexitol (18). To a stirred suspension of 1,2,4-triazole $(21.04 \mathrm{~g}, 304.6 \mathrm{mmol})$ in dry ACN $(400 \mathrm{~mL})$ was added $\mathrm{POCl}_{3}$ dropwise $(6.6 \mathrm{~mL}, 69.6 \mathrm{mmol})$ at $0{ }^{\circ} \mathrm{C}$. After being stirred for $15 \mathrm{~min}$ at the same temperature, dry triethylamine $(48.4 \mathrm{~mL}, 348 \mathrm{mmol})$ was added to the reaction mixture, and stirring was continued for an additional $30 \mathrm{~min}$. Nucleoside 13 (4.4 g, $8.70 \mathrm{mmol})$ dissolved in dry ACN $(100 \mathrm{~mL})$ was then added to the reaction mixture and stirred at $35{ }^{\circ} \mathrm{C}$ for $13 \mathrm{~h}$. After completion, the reaction mixture was diluted with ethyl acetate, and organic layer was washed with water followed by $5 \% \mathrm{NaHCO}_{3}$ solution and brine. Organic layer was dried over $\mathrm{Na}_{2} \mathrm{SO}_{4}$, filtered, and concentrated under reduced pressure to give crude triazolide, which was used for the next reaction without purification.

Crude triazolide was dissolved in 1,4 dioxane $(100 \mathrm{~mL}), 25 \%$ aq ammonia solution $(40 \mathrm{~mL})$ was added to the solution, and the reaction mixture was stirred at $35^{\circ} \mathrm{C}$ for $16 \mathrm{~h}$. The reaction mixture was concentrated under reduced pressure, coevaporated with toluene $(2 \times)$, and crude residue was purified by column chromatography on silica gel $\left(R_{f}=0.28 ; 10 \% \mathrm{MeOH}\right.$ in $\mathrm{CH}_{2} \mathrm{Cl}_{2}$; gradient $\mathrm{CH}_{2} \mathrm{Cl}_{2} /$ $\mathrm{MeOH}, 99: 1, \mathrm{v} / \mathrm{v} ; 49: 1, \mathrm{v} / \mathrm{v} ; 24: 1, \mathrm{v} / \mathrm{v})$ to give $\mathbf{1 8}$ (4.19 g, 95\% over two steps) as a pale yellow semisolid. Mp $118{ }^{\circ} \mathrm{C} .{ }^{1} \mathrm{H}$ NMR (500 MHz, DMSO- $\left.d_{6}\right) \delta 8.56(\mathrm{br} \mathrm{s}, 1 \mathrm{H}, \mathrm{NH}-4), 8.03(\mathrm{~d}, J=7.4 \mathrm{~Hz}, 1 \mathrm{H}, \mathrm{H}-$ 6), 7.69-7.42 (m, 10H, Ar-H TBDPS), 7.08 (br s, 1H, NH-4), 5.59 $(\mathrm{d}, J=7.4 \mathrm{~Hz}, 1 \mathrm{H}, \mathrm{H}-5), 4.57-4.54\left(\mathrm{~m}, 1 \mathrm{H}, \mathrm{H}-2^{\prime}\right), 4.15(\mathrm{~d}, J=13.3$ $\mathrm{Hz}, 1 \mathrm{H}, \mathrm{H}-\mathrm{1}^{\prime}{ }_{\mathrm{eq}}$ ), $3.92-3.79$ (m, 4H, H-1 ${ }_{\mathrm{ax}}, \mathrm{H}-4^{\prime}, \mathrm{H}-6^{\prime}$, and $\left.\mathrm{H}-6^{\prime \prime}\right)$, 3.36-3.34 (m, 1H, H-5'), 2.43-2.37 (m, 1H, H-3 ${ }_{\text {eq }}$ ), 1.99-1.91 (m, $\left.1 \mathrm{H}, \mathrm{H}-3^{\prime}{ }^{2}\right), 1.01\left(\mathrm{~s}, 9 \mathrm{H}, 3 \times \mathrm{CH}_{3}-{ }^{t} \mathrm{Bu}\right) ;{ }^{13} \mathrm{C}$ NMR $(125 \mathrm{MHz}$, DMSO- $d_{6}$ ) $\delta 165.5$ (C-4), 155.5 (C-2), 143.3 (C-6), 135.2, 135.1 (Ar C-Ph), 132.7, 132.6 (ipso C-Ph), 130.0, 129.9, 127.9 (Ar C-Ph), 93.2 (C-5), $79.3\left(\mathrm{C}-5^{\prime}\right), 67.9\left(\mathrm{C}-1^{\prime}\right), 63.0\left(\mathrm{C}-6^{\prime}\right), 52.2\left(\mathrm{C}-4^{\prime}\right), 49.8\left(\mathrm{C}-2^{\prime}\right)$, $31.7\left(\mathrm{C}-3^{\prime}\right), 26.6\left(3 \times \mathrm{CH}_{3}-{ }^{t} \mathrm{Bu}\right), 18.9\left(1 \mathrm{C}-{ }^{t} \mathrm{Bu}\right)$; HRMS (ESITOF) $m / z:[\mathrm{M}+\mathrm{H}]^{+}$calcd for $\mathrm{C}_{26} \mathrm{H}_{32} \mathrm{~N}_{6} \mathrm{O}_{3} \mathrm{Si}, 505.2378$; found, 505.2354 .

1',5'-Anhydro-6'-O-tert-butyldiphenylsilyl-4'-azido-2', 3'-dideoxy-2'-( $N^{4}$-benzoyl-cytosine-1-yl)-D-altro-hexitol (19). To a stirred solution of compound $18(4.19 \mathrm{~g}, 8.30 \mathrm{mmol})$ in anhydrous pyridine $(70 \mathrm{~mL})$ was added benzoyl chloride $(1.63 \mathrm{~mL}, 14.11 \mathrm{mmol})$ at $0{ }^{\circ} \mathrm{C}$, and the resulting reaction mixture was slowly warmed to room temperature and stirred at the same temperature for $30 \mathrm{~h}$. The reaction mixture was then cooled to $0{ }^{\circ} \mathrm{C}$, and the $\mathrm{pH}$ was adjusted to $\sim 8$ with the addition of $5 \% \mathrm{NaHCO}_{3}$ solution. The aq layer was extracted with $\mathrm{CH}_{2} \mathrm{Cl}_{2}(3 \times 150 \mathrm{~mL}), 25 \%$ aq ammonia $(30 \mathrm{~mL})$ was added at $0{ }^{\circ} \mathrm{C}$ to the organic phase, and the mixture was stirred for 1 $h$. The reaction mixture was concentrated under reduced pressure, coevaporated with toluene $(2 \times)$, and crude residue was purified by column chromatography on silica gel $\left(R_{f}=0.51\right.$; EtOAc; gradient hexane/EtOAc, 3:2, v/v; 2:3, v/v; 0:100, v/v) to give $19(3.7 \mathrm{~g}, 75 \%$ over two steps) as a white foam. Mp $91{ }^{\circ} \mathrm{C} .{ }^{1} \mathrm{H}$ NMR $(500 \mathrm{MHz}$, $\left.\mathrm{CDCl}_{3}\right) \delta 8.61(\mathrm{~d}, J=7.5 \mathrm{~Hz}, 1 \mathrm{H}, \mathrm{H}-6), 7.91(\mathrm{~d}, J=7.8 \mathrm{~Hz}, 2 \mathrm{H}, o \mathrm{H}-$ $\mathrm{Bz}$ ), 7.74-7.68 (m, 4H, Ar-H TBDPS), $7.62(\mathrm{t}, J=7.5 \mathrm{~Hz}, 1 \mathrm{H}, p \mathrm{H}-$ $\mathrm{Bz}), 7.52(\mathrm{~d}, J=7.8 \mathrm{~Hz}, 2 \mathrm{H}, m \mathrm{H}-\mathrm{Bz}), 7.47-7.39(\mathrm{~m}, 7 \mathrm{H}, \mathrm{Ar}-\mathrm{H}$ TBDPS and H-5), 4.89-4.87 (m, 1H, H-2') $4.27(\mathrm{dd}, J=13.4,1.8$ $\mathrm{Hz}, 1 \mathrm{H}, \mathrm{H}-1^{\prime}{ }_{\mathrm{eq}}$ ), 3.96-3.86 (m, 4H, H-1 ${ }_{\mathrm{ax}}, \mathrm{H}-4^{\prime}, \mathrm{H}-6^{\prime}$, and $\left.\mathrm{H}-6^{\prime \prime}\right)$, $3.26-3.24\left(\mathrm{~m}, 1 \mathrm{H}, \mathrm{H}-5^{\prime}\right), 2.70-2.65\left(\mathrm{~m}, 1 \mathrm{H}, \mathrm{H}-3^{\prime}{ }_{\mathrm{eq}}\right), 2.03-1.97(\mathrm{~m}$, $\left.1 \mathrm{H}, \mathrm{H}-3^{\prime}{ }_{\mathrm{ax}}\right), 1.72(\mathrm{br} \mathrm{s}, 1 \mathrm{H}, \mathrm{NH}-4), 1.10\left(\mathrm{~s}, 9 \mathrm{H}, 3 \times \mathrm{CH}_{3}-{ }^{t} \mathrm{Bu}\right) ;{ }^{13} \mathrm{C}$ NMR $\left(125 \mathrm{MHz}, \mathrm{CDCl}_{3}\right) \delta 163.6$ (C-4), 161.9 (CO-Bz), 159.7 (C2), 147.6 (C-6), 135.6, 135.6, 133.2, 132.9, 132.8, 129.9, 129.0, 127.8, 127.7, 127.5 (Ar C-Bz and TBDPS), 96.9 (C-5), 80.8 (C-5'), 68.5 (C$\left.1^{\prime}\right), 62.8\left(\mathrm{C}-6^{\prime}\right), 51.6\left(\mathrm{C}-4^{\prime}\right), 51.4\left(\mathrm{C}-2^{\prime}\right), 32.4\left(\mathrm{C}-3^{\prime}\right), 26.8(3 \times$ $\mathrm{CH}_{3}-{ }^{t} \mathrm{Bu}$ ), $19.3\left(1 \mathrm{C}-{ }^{t} \mathrm{Bu}\right.$ ); HRMS (ESI-TOF) $\mathrm{m} / z:[\mathrm{M}+\mathrm{H}]^{+}$calcd for $\mathrm{C}_{33} \mathrm{H}_{36} \mathrm{~N}_{6} \mathrm{O}_{4} \mathrm{Si}, 609.2640$; found, 609.2641.

$1^{\prime}, 5^{\prime}$-Anhydro-6'-O-tert-butyldiphenylsilyl-4'-amino-2', $3^{\prime}$ dideoxy-2'-( $N^{4}$-benzoyl-cytosine-1-yl)-D-altro-hexitol (20). A synthetic protocol similar to that used for the synthesis of 16 was employed for the synthesis of 20, starting from $19(3.7 \mathrm{~g}, 6.08 \mathrm{mmol})$, $10 \% \mathrm{Pd} / \mathrm{C}(0.74 \mathrm{~g}, 0.2$ equiv w/w $)$, and $\mathrm{EtOH}(250 \mathrm{~mL})$ to obtain 20 $(2.96 \mathrm{~g}, 84 \%)$ as a white foam $\left(R_{\mathrm{f}}=0.26,10 \% \mathrm{MeOH}\right.$ in $\mathrm{CH}_{2} \mathrm{Cl}_{2}$; column chromatography gradient $\mathrm{CH}_{2} \mathrm{Cl}_{2} / \mathrm{MeOH}, 99: 1, \mathrm{v} / \mathrm{v} ; 49: 1$, v/ v; 24:1, v/v). ${ }^{1} \mathrm{H}$ NMR $\left(300 \mathrm{MHz}, \mathrm{CDCl}_{3}\right) \delta 8.66(\mathrm{~d}, J=7.4 \mathrm{~Hz}, 1 \mathrm{H}$, 
H-6), 8.63-8.60 (m, 1H, NH-4), 7.91 (d, $J=7.4 \mathrm{~Hz}, 2 \mathrm{H}, o \mathrm{H}-\mathrm{Bz})$, 7.72-7.67 (m, 4H, Ar-H TBDPS), 7.62-7.59 (m, 1H, $p \mathrm{H}-\mathrm{Bz}), 7.53$ (d, $J=7.8 \mathrm{~Hz}, 2 \mathrm{H}, m \mathrm{H}-\mathrm{Bz}), 7.47-7.37(\mathrm{~m}, 7 \mathrm{H}, \mathrm{Ar}-\mathrm{H}$ TBDPS and $\mathrm{H}-$ 5), 4.81 (br s, $\left.1 \mathrm{H}, \mathrm{H}-2^{\prime}\right), 4.25\left(\mathrm{dd}, J=13.6,1.9 \mathrm{~Hz}, 1 \mathrm{H}, \mathrm{H}^{\prime}{ }^{\prime}{ }_{\mathrm{eq}}\right)$, 3.96-3.87 (m, 3H, H-1 ${ }^{\prime}$ ax $\mathrm{H}-6^{\prime}$, and $\left.\mathrm{H}-6^{\prime \prime}\right)$, 3.21-3.09 (m, 2H, H-4 and $\left.\mathrm{H}-5^{\prime}\right), 2.43-2.35\left(\mathrm{~m}, 1 \mathrm{H}, \mathrm{H}-3^{\prime}{ }_{\mathrm{eq}}\right), 1.79-1.49\left(\mathrm{~m}, 3 \mathrm{H}, \mathrm{H}-3^{\prime}{ }_{\mathrm{ax}}\right.$ and $\left.\mathrm{NH}_{2}-4^{\prime}\right), 1.10\left(\mathrm{~s}, 9 \mathrm{H}, 3 \times \mathrm{CH}_{3}-{ }^{t} \mathrm{Bu}\right) ;{ }^{13} \mathrm{C} \mathrm{NMR}\left(75 \mathrm{MHz}, \mathrm{CDCl}_{3}\right) \delta$ 163.1 (C-4), 161.9 (CO-Bz), 159.7 (C-2), 148.3 (C-6), 135.8, 135.7, 133.3, 133.2, 130.1, 130.0, 129.2, 128.0, 127.9, 127.7, 123.8 (Ar C-Bz and TBDPS), 96.6 (C-5), $84.4\left(\mathrm{C}-5^{\prime}\right), 68.8\left(\mathrm{C}-1^{\prime}\right), 63.5\left(\mathrm{C}-6^{\prime}\right), 52.2$ $\left(\mathrm{C}-2^{\prime}\right), 42.4$ (C-4' $), 35.9\left(\mathrm{C}-3^{\prime}\right), 27.0\left(3 \times \mathrm{CH}_{3}-{ }^{t} \mathrm{Bu}\right), 19.5$ $\left(1 \mathrm{C}-{ }^{t} \mathrm{Bu}\right)$; HRMS (ESI-TOF) $\mathrm{m} / z:[\mathrm{M}+\mathrm{H}]^{+}$calcd for $\mathrm{C}_{33} \mathrm{H}_{38} \mathrm{~N}_{4} \mathrm{O}_{4} \mathrm{Si}, 583.2735$; found, 583.2747.

1',5'-Anhydro-6'-O-tert-butyldiphenylsilyl-4' -amino(trityl)$2^{\prime}, 3^{\prime}$-dideoxy-2'-( $N^{4}$-benzoyl-cytosine-1-yl)-D-altro-hexitol (21). A slightly modified synthetic protocol from that used for the synthesis of $\mathbf{1 7}$ was employed for the synthesis of $\mathbf{2 1}$, starting from $\mathbf{2 0}$ (2.5 g, $4.29 \mathrm{mmol})$, trityl chloride $(4.78 \mathrm{~g}, 17.16 \mathrm{mmol})$, and $\mathrm{N}, \mathrm{N}$ diisopropylethylamine $(8.97 \mathrm{~mL}, 51.48 \mathrm{mmol})$ in dry pyridine $(80$ $\mathrm{mL})$ at $55^{\circ} \mathrm{C}$ for $120 \mathrm{~h}$ to obtain $20(3.11 \mathrm{~g}, 88 \%)$ as a light brown semisolid $\left(R_{f}=0.65\right.$, EtOAc; column chromatography gradient hexane/EtOAc, 3:2, v/v; 2:3, v/v; 0:100, v/v). Mp $128{ }^{\circ} \mathrm{C} .{ }^{1} \mathrm{H}$ NMR $\left(300 \mathrm{MHz}, \mathrm{CDCl}_{3}\right) \delta 8.75$ (br s, $\left.1 \mathrm{H}, \mathrm{NH}-4\right), 7.97-7.91$ (m, 3H, H-6 and $o \mathrm{H}-\mathrm{Bz}), 7.63-7.07(\mathrm{~m}, 29 \mathrm{H}, \mathrm{Ar}-\mathrm{H}$ TBDPS, Trt, Bz and $\mathrm{H}-5)$, 4.59 (br s, $\left.1 \mathrm{H}, \mathrm{H}-2^{\prime}\right), 3.93-3.76\left(\mathrm{~m}, 4 \mathrm{H}, \mathrm{H}_{-}{ }^{\prime}{ }_{\mathrm{eq}}, \mathrm{H}-1^{\prime}{ }_{\mathrm{ax}}, \mathrm{H}-6^{\prime}\right.$, and $\mathrm{H}-$ $\left.6^{\prime \prime}\right), 3.44-3.39\left(\mathrm{~m}, 1 \mathrm{H}, \mathrm{H}-5^{\prime}\right), 2.63-2.54\left(\mathrm{~m}, 1 \mathrm{H}, \mathrm{H}-4^{\prime}\right), 2.33$ (br s, $\left.1 \mathrm{H}, \mathrm{NH}-4^{\prime}\right), 1.85-1.76\left(\mathrm{~m}, 1 \mathrm{H}, \mathrm{H}-3^{\prime}{ }_{\mathrm{eq}}\right), 1.70-1.60\left(\mathrm{~m}, 1 \mathrm{H}, \mathrm{H}-3^{\prime}{ }_{\mathrm{ax}}\right)$, $1.01\left(\mathrm{~s}, 9 \mathrm{H}, 3 \times \mathrm{CH}_{3}-{ }^{t} \mathrm{Bu}\right) ;{ }^{13} \mathrm{C} \mathrm{NMR}\left(75 \mathrm{MHz}, \mathrm{CDCl}_{3}\right) \delta 166.8(\mathrm{C}-$ 4), 161.5 (CO-Bz), 158.5 (C-2), 147.4 (C-6), 135.8, 135.6, 133.2, 133.2, 133.0, 129.9, 129.8, 129.2, 128.7, 128.2, 128.1, 128.0, 127.9, 127.7, 126.5 (Ar C-Bz, Trt and TBDPS), 96.4 (C-5), 82.0 (C-5'), 70.6 (1C-Trt), 68.2 (C-1'), 64.5 (C-6'), $51.3\left(\mathrm{C}-2^{\prime}\right), 48.0\left(\mathrm{C}-4^{\prime}\right)$, $33.6\left(\mathrm{C}-3^{\prime}\right), 27.0\left(3 \times \mathrm{CH}_{3}-{ }^{t} \mathrm{Bu}\right), 19.3\left(1 \mathrm{C}-{ }^{t} \mathrm{Bu}\right)$; HRMS (ESITOF) $m / z:[\mathrm{M}+\mathrm{H}]^{+}$calcd for $\mathrm{C}_{52} \mathrm{H}_{52} \mathrm{~N}_{4} \mathrm{O}_{4} \mathrm{Si}$, 825.3830; found, 825.3829 .

$1^{\prime}, 5^{\prime}$-Anhydro-4'-amino(trityl)-2', 3' -dideoxy-2' -( $N^{4}$-benzoyl-cytosine-1-yl)-D-altro-hexitol (2). To a stirred solution of 21 $(3.11 \mathrm{~g}, 3.77 \mathrm{mmol})$ in dry THF $(90 \mathrm{~mL})$ in a plastic vessel was added triethylamine trihydrofluoride $(2.46 \mathrm{~mL}, 15.08 \mathrm{mmol})$, and the resulting reaction mixture was heated at $37^{\circ} \mathrm{C}$ for $144 \mathrm{~h}$. The progress of the reaction was monitored by TLC, and after completion the reaction mixture was then cooled and volatiles were removed under reduced pressure. Crude was diluted with ethyl acetate $(200 \mathrm{~mL})$, and the remaining hydrofluoride was quenched by addition of $5 \%$ $\mathrm{NaHCO}_{3}$ solution. The aq layer was extracted with ethyl acetate (2 $\times 100 \mathrm{~mL}$ ), the combined organic layer was dried over $\mathrm{Na}_{2} \mathrm{SO}_{4}$, filtered, and concentrated under reduced pressure, and the crude residue was purified by column chromatography on silica gel $\left(R_{f}=\right.$ 0.29 , EtOAc; column chromatography gradient hexane/EtOAc, 3:2, $\mathrm{v} / \mathrm{v} ; 2: 3, \mathrm{v} / \mathrm{v} ; 0: 100, \mathrm{v} / \mathrm{v})$ to provide $2(0.4 \mathrm{~g}, 85 \%)$ as a pale yellow semisolid. Mp $214{ }^{\circ} \mathrm{C} .{ }^{1} \mathrm{H}$ NMR $\left(600 \mathrm{MHz}\right.$, DMSO- $\left.d_{6}\right) \delta 11.19$ (br s, $1 \mathrm{H}, \mathrm{NH}-4), 8.07-8.06(\mathrm{~m}, 2 \mathrm{H}, o \mathrm{H}-\mathrm{Bz}), 8.01(\mathrm{~d}, J=7.0 \mathrm{~Hz}, 1 \mathrm{H}, \mathrm{H}-$ 6), $7.66-7.63(\mathrm{~m}, 1 \mathrm{H}, p \mathrm{H}-\mathrm{Bz}), 7.54(\mathrm{t}, J=8.0 \mathrm{~Hz}, 2 \mathrm{H}, m \mathrm{H}-\mathrm{Bz})$, $7.42-7.08(\mathrm{~m}, 16 \mathrm{H}, \mathrm{Ar}-\mathrm{H}$ Trt and H-5), $4.74(\mathrm{t}, J=5.3 \mathrm{~Hz}, 1 \mathrm{H}, \mathrm{OH}-$ $\left.6^{\prime}\right), 4.40\left(\mathrm{br} \mathrm{s}, 1 \mathrm{H}, \mathrm{H}-2^{\prime}\right), 3.95\left(\mathrm{~d}, J=12.6 \mathrm{~Hz}, 1 \mathrm{H}, \mathrm{H}-1^{\prime}{ }_{\mathrm{eq}}\right), 3.77(\mathrm{dd}$, $\left.J=12.8,3.6 \mathrm{~Hz}, 1 \mathrm{H}, \mathrm{H}-1^{\prime}{ }_{\mathrm{ax}}\right), 3.57-3.54\left(\mathrm{~m}, 1 \mathrm{H}, \mathrm{H}-6^{\prime}\right), 3.42-3.39$ $\left(\mathrm{m}, 1 \mathrm{H}, \mathrm{H}-6^{\prime \prime}\right), 3.33-3.31\left(\mathrm{~m}, 1 \mathrm{H}, \mathrm{H}-5^{\prime}\right), 3.16(\mathrm{~d}, J=5.3 \mathrm{~Hz}, 1 \mathrm{H}$, $\left.\mathrm{NH}-4^{\prime}\right), 2.21-2.17\left(\mathrm{~m}, 1 \mathrm{H}, \mathrm{H}-4^{\prime}\right), 1.77-1.73\left(\mathrm{~m}, 1 \mathrm{H}, \mathrm{H}-3^{\prime}{ }_{\mathrm{eq}}\right), 1.64-$ $1.59\left(\mathrm{~m}, 1 \mathrm{H}, \mathrm{H}-3^{\prime}{ }_{\mathrm{ax}}\right), 1.01\left(\mathrm{~s}, 9 \mathrm{H}, 3 \times \mathrm{CH}_{3}-{ }^{t} \mathrm{Bu}\right) ;{ }^{13} \mathrm{C} \mathrm{NMR}(150$ MHz, DMSO- $d_{6}$ ) $\delta 167.2$ (CO-Bz), 162.4 (C-4), 154.8 (C-2), 149.7 (Ar-C), 147.6 (C-6), 146.8, 132.8, 128.6, 128.5, 128.4, 127.7, 126.2, 124.0 (Ar C-Bz and Trt), 95.7 (C-5), 80.1 (C-5'), 70.2 (1C-Trt), 66.3 (C-1'), 59.8 (C-6'), $51.1\left(\mathrm{C}-2^{\prime}\right), 48.5\left(\mathrm{C}-4^{\prime}\right), 32.6$ (C-3'); HRMS (ESI-TOF) $m / z$ : $[\mathrm{M}+\mathrm{H}]^{+}$calcd for $\mathrm{C}_{36} \mathrm{H}_{34} \mathrm{~N}_{4} \mathrm{O}_{4}, 587.2653$; found, 587.2673 .

(2R,3S)-3-(Benzyloxy)-2-((benzyloxy)methyl)-3,6-dihydro$2 H$-pyran (25). A solution of diol $22(66 \mathrm{~g}, 0.509 \mathrm{~mol})$ in dry DMF $(400 \mathrm{~mL})$ was added dropwise to a stirred suspension of $\mathrm{NaH}(55 \%$ in mineral oil, $48.8 \mathrm{~g}, 1.12 \mathrm{~mol})$ in dry DMF $(400 \mathrm{~mL})$ at $-20{ }^{\circ} \mathrm{C}$ under argon, and the resulting mixture was stirred at room temperature for $1 \mathrm{~h}$ until the $\mathrm{H}_{2}$ gas liberation was complete. The reaction mixture was again cooled to $-20{ }^{\circ} \mathrm{C}$, and benzyl bromide $(225 \mathrm{~mL}, 1.88 \mathrm{~mol})$ was added slowly to the mixture. The reaction mixture then was slowly warmed to room temperature and left stirring for $16 \mathrm{~h}$ at same temperature. Upon completion, the reaction mixture was cooled to $0{ }^{\circ} \mathrm{C}$ and quenched with saturated $\mathrm{NH}_{4} \mathrm{Cl}$ solution and diluted with water $(8 \mathrm{~L})$, and the aq layer was extracted with EtOAc $(3 \times 1 \mathrm{~L})$. The combined organic layer was dried over $\mathrm{Na}_{2} \mathrm{SO}_{4}$, filtered and concentrated in vacuo, and the resulting crude residue was purified by column chromatography on silica gel $\left(R_{f}=0.49,40 \%\right.$ EtOAc in hexane; gradient hexane/EtOAc, 19:1, v/v; 9:1, v/v; 17:3, $\mathrm{v} / \mathrm{v})$ to give $25(129 \mathrm{~g}, 90 \%)$ as a pale-yellow liquid. ${ }^{1} \mathrm{H}$ NMR (300 $\left.\mathrm{MHz}, \mathrm{CDCl}_{3}\right) \delta 7.32-7.24(\mathrm{~m}, 10 \mathrm{H}, 2 \times \mathrm{Ar}-\mathrm{H} \mathrm{Bn}), 6.05-5.95(\mathrm{~m}$, $2 \mathrm{H}, \mathrm{H}-2^{\prime}$ and $\left.\mathrm{H}-3^{\prime}\right), 4.67-4.52\left(\mathrm{~m}, 4 \mathrm{H}, 2 \times \mathrm{CH}_{2}-\mathrm{Bn}\right), 4.35-4.28(\mathrm{~m}$, $\left.1 \mathrm{H}, \mathrm{H}-1^{\prime}{ }_{\text {eq }}\right), 4.19-4.13\left(\mathrm{~m}, 1 \mathrm{H}, \mathrm{H}-\mathrm{1}^{\prime}{ }_{\mathrm{ax}}\right), 3.82-3.72\left(\mathrm{~m}, 4 \mathrm{H}, \mathrm{H}-4^{\prime}, \mathrm{H}-\right.$ $5^{\prime}, \mathrm{H}-6^{\prime}$, and $\left.\mathrm{H}-6^{\prime \prime}\right) ;{ }^{13} \mathrm{C}$ NMR (75 MHz, $\left.\mathrm{CDCl}_{3}\right) \delta 138.7,138.3(2$ $\times$ ipso C-Bn), 131.6 (C-3'), 128.5, 128.4, 128.0, 127.9, 127.9, 127.8, 127.7, 127.6 (Ar C-Bn), 123.7 (C-2'), 76.8 (C-5'), $73.7\left(\mathrm{CH}_{2}-6^{\prime} \mathrm{Bn}\right)$, $70.7\left(\mathrm{CH}_{2}-4^{\prime} \mathrm{Bn}\right), 70.0\left(\mathrm{C}-4^{\prime}\right), 68.7\left(\mathrm{C}-6^{\prime}\right), 65.9\left(\mathrm{C}-1^{\prime}\right)$; HRMS (ESITOF) $m / z:[\mathrm{M}+\mathrm{Na}]^{+}$calcd for $\mathrm{C}_{20} \mathrm{H}_{22} \mathrm{O}_{3}, 333.1461$; found, 333.1462 .

(1S,4R,5S,6S)-5-(Benzyloxy)-4-((benzyloxy)methyl)-3,7dioxabicyclo[4.1.0] heptane (26). To a stirred solution of 25 (64.4 g, $207.5 \mathrm{mmol})$ in $\mathrm{CH}_{2} \mathrm{Cl}_{2}(900 \mathrm{~mL})$ was added $\mathrm{mCPBA}(70 \%$ in water, $127.9 \mathrm{~g}, 518.7 \mathrm{mmol}$ ) at $-40{ }^{\circ} \mathrm{C}$ under argon. The reaction mixture then was slowly warmed to room temperature and left stirring for $36 \mathrm{~h}$ at same temperature. Upon completion, the reaction mixture was filtered over sodium sulfate to remove water, and white precipitate was washed with cold $\mathrm{CH}_{2} \mathrm{Cl}_{2}$. Combined filtrate was concentrated in vacuo (bath temp $15{ }^{\circ} \mathrm{C}$ ), and the resulting crude was repeatedly triturated with hexane and filtered to remove white precipitate. Combined filtrate was concentrated in vacuo, and the resulting crude residue was purified by column chromatography on silica gel $\left(R_{f}=0.42,60 \%\right.$ EtOAc in hexane; gradient hexane/EtOAc, $19: 1, \mathrm{v} / \mathrm{v} ; 9: 1, \mathrm{v} / \mathrm{v} ; 17: 3, \mathrm{v} / \mathrm{v})$ to give $26(39.9 \mathrm{~g}, 59 \%)$ as a colorless liquid. ${ }^{1} \mathrm{H}$ NMR $\left(300 \mathrm{MHz}, \mathrm{CDCl}_{3}\right) \delta 7.34-7.28(\mathrm{~m}, 10 \mathrm{H}, 2 \times \mathrm{Ar}-\mathrm{H}$ $\mathrm{Bn}$ ), 4.65 (dd, $J=12.9,11.7 \mathrm{~Hz}, 2 \mathrm{H}, \mathrm{CH}_{2}-6^{\prime} \mathrm{Bn}$ ), 4.51 (dd, $J=28.9$,

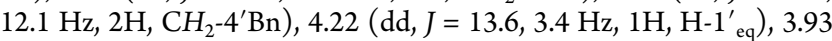
$\left(\mathrm{d}, J=13.7 \mathrm{~Hz}, 1 \mathrm{H}, \mathrm{H}-1^{\prime}{ }_{\mathrm{ax}}\right), 3.83\left(\mathrm{br} \mathrm{s}, 1 \mathrm{H}, \mathrm{H}-4^{\prime}\right), 3.68-3.64(\mathrm{~m}, 1 \mathrm{H}$, H-5 ), 3.63-3.47 (m, 2H, H-6' and H-6" ${ }^{\prime \prime}$ ), 3.32-3.28 (m, 2H, H-2' and $\left.\mathrm{H}-3^{\prime}\right) ;{ }^{13} \mathrm{C}$ NMR $\left(75 \mathrm{MHz}, \mathrm{CDCl}_{3}\right) \delta 128.6,128.5,128.4,128.2$, 127.9, 127.8 ( $\mathrm{ArC} \mathrm{C}-\mathrm{Bn}), 73.6\left(\mathrm{CH}_{2}-6^{\prime} \mathrm{Bn}\right), 73.5\left(\mathrm{CH}_{2}-4^{\prime} \mathrm{Bn}\right), 72.2$ (C$\left.5^{\prime}\right), 71.1\left(\mathrm{C}-4^{\prime}\right), 69.3$ (C-6'), $64.9\left(\mathrm{C}-1^{\prime}\right), 51.8\left(\mathrm{C}-3^{\prime}\right), 50.7\left(\mathrm{C}-2^{\prime}\right)$; HRMS (ESI-TOF) $m / z$ : $[\mathrm{M}+\mathrm{Na}]^{+}$calcd for $\mathrm{C}_{20} \mathrm{H}_{22} \mathrm{O}_{4}, 349.1410$; found, 349.1406 .

$1^{\prime}, 5^{\prime}$-Anhydro-4', 6'-di-O-benzyl-2'-deoxy-2' -(adenin-9-yl)D-allo-hexitol (27). To a stirred solution of $26(39.2 \mathrm{~g}, 120.1 \mathrm{mmol})$ and adenine $(34.1 \mathrm{~g}, 252.2 \mathrm{mmol})$ in dry DMF $(450 \mathrm{~mL})$ was added DBU $(44.9 \mathrm{~mL}, 300.3 \mathrm{mmol})$ under argon, and the reaction mixture was heated at $105{ }^{\circ} \mathrm{C}$ for $20 \mathrm{~h}$. The reaction was monitored with TLC; upon completion, the reaction mixture was cooled, and the volatiles were removed under reduced pressure. The residue was diluted with ice-water $(900 \mathrm{~mL})$ and neutralized with $1 \mathrm{~N} \mathrm{HCl}$ at 0 ${ }^{\circ} \mathrm{C}$. The aq layer was extracted with $\mathrm{CH}_{2} \mathrm{Cl}_{2}(3 \times 700 \mathrm{~mL})$. The combined organic layer was dried over $\mathrm{Na}_{2} \mathrm{SO}_{4}$, filtered, and concentrated in vacuo to provide a crude residue of an isomeric mixture of $\mathrm{N}^{7}(\mathbf{2 8})$ and $\mathrm{N}^{9}(\mathbf{2 7})$ adduct, which was used for further reaction without any purification.

The mixture was dissolved in dry pyridine $(500 \mathrm{~mL})$, and acetic anhydride $(113.6 \mathrm{~mL}, 1.20 \mathrm{~mol})$ was added at $0{ }^{\circ} \mathrm{C}$ to the reaction mixture and stirred at room temperature for $24 \mathrm{~h}$. The reaction mixture was concentrated under reduced pressure, coevaporated with toluene $(2 \times)$, and crude residue was purified by column chromatography on silica gel (column chromatography gradient $\left.\mathrm{CH}_{2} \mathrm{Cl}_{2} / \mathrm{MeOH}, 199: 1, \mathrm{v} / \mathrm{v} ; 99: 1, \mathrm{v} / \mathrm{v} ; 66: 1, \mathrm{v} / \mathrm{v}\right)$ to give di- and triacetylated adducts $\left(R_{f}=0.74\right.$ and 0.54 , respectively, $10 \% \mathrm{MeOH}$ in $\mathrm{CH}_{2} \mathrm{Cl}_{2}$ ) of 27. The di- and triacetylated adducts of 27 were combined and treated with $7 \mathrm{~N} \mathrm{NH}_{3}$ in $\mathrm{MeOH}$ for $24 \mathrm{~h}$ at room temperature. Volatiles were removed under reduced pressure, and crude residue was purified by column chromatography on silica gel $\left(R_{f}\right.$ 
$=0.35,10 \% \mathrm{MeOH}$ in $\mathrm{CH}_{2} \mathrm{Cl}_{2}$; gradient $\mathrm{CH}_{2} \mathrm{Cl}_{2} / \mathrm{MeOH}$, 99:1, v/v; $49: 1, \mathrm{v} / \mathrm{v} ; 24: 1, \mathrm{v} / \mathrm{v})$ to give $27(37.7 \mathrm{~g}, 68 \%$ over three steps $)$ as a white semisolid. ${ }^{1} \mathrm{H}$ NMR $\left(300 \mathrm{MHz}, \mathrm{CDCl}_{3}\right) \delta 8.29$ (s, $\left.1 \mathrm{H}, \mathrm{H}-8\right)$, 8.20 (s, 1H, H-2), 7.34-6.83 (m, 10H, $2 \times \mathrm{Ar}-\mathrm{H} \mathrm{Bn}$ ), 6.27 (br s, $2 \mathrm{H}$, $\left.\mathrm{NH}_{2}-6\right), 4.65-4.50\left(\mathrm{~m}, 3 \mathrm{H}, \mathrm{CH}_{2}-6^{\prime} \mathrm{Bn}\right.$ and $\left.\mathrm{H}-2^{\prime}\right), 4.37-4.12(\mathrm{~m}, 6 \mathrm{H}$, $\mathrm{H}-1^{\prime}{ }_{\text {eq }}, \mathrm{H}-1^{\prime}{ }_{\mathrm{ax}} \mathrm{H}-5^{\prime}, \mathrm{H}-3^{\prime}$, and $\left.\mathrm{CH}_{2}-4^{\prime} \mathrm{Bn}\right), 3.88(\mathrm{dd}, J=10.1,7.3 \mathrm{~Hz}$, $\left.1 \mathrm{H}, \mathrm{H}-6^{\prime}\right), 3.63\left(\mathrm{dd}, J=10.2,4.6 \mathrm{~Hz}, 1 \mathrm{H}, \mathrm{H}-6^{\prime \prime}\right), 3.53(\mathrm{t}, J=3.2 \mathrm{~Hz}$, $\left.1 \mathrm{H}, \mathrm{H}-4^{\prime}\right) ;{ }^{13} \mathrm{C}$ NMR $\left(75 \mathrm{MHz}, \mathrm{CDCl}_{3}\right) \delta 155.6(\mathrm{C}-6), 152.4(\mathrm{C}-2)$, 149.8 (C-4), 141.7 (C-8), 138.1, 137.4 (2 × ipso C-Bn), 128.6, 128.3, 128.0, 128.0, 127.9 (Ar C-Bn), 118.9 (C-5), $76.7\left(\mathrm{C}-4^{\prime}\right), 74.4\left(\mathrm{C}-5^{\prime}\right)$, $73.7\left(\mathrm{CH}_{2}-6^{\prime} \mathrm{Bn}\right), 73.1\left(\mathrm{CH}_{2}-4^{\prime} \mathrm{Bn}\right), 69.3\left(\mathrm{C}-6^{\prime}\right), 65.2\left(\mathrm{C}-3^{\prime}\right), 64.8$ $\left(\mathrm{C}-1^{\prime}\right)$, $54.2\left(\mathrm{C}-2^{\prime}\right)$; HRMS (ESI-TOF) $\mathrm{m} / z:[\mathrm{M}+\mathrm{H}]^{+}$calcd for $\mathrm{C}_{25} \mathrm{H}_{27} \mathrm{~N}_{5} \mathrm{O}_{4}$, 462.2136; found, 462.2139.

$1^{\prime}, 5^{\prime}$-Anhydro-4', 6' -di-O-benzyl-2', 3'-dideoxy-2' -(adenin-9yl)-D-allo-hexitol (30). A slightly modified synthetic protocol from that used for the synthesis of 7 was employed for the synthesis of 29, starting from 27 (37.7 g, $81.69 \mathrm{mmol})$, aq $\mathrm{NaOH}(5 \mathrm{~N} ; 89.9 \mathrm{~mL}), \mathrm{CS}_{2}$ $(89.9 \mathrm{~mL})$, and ethyl bromide $(26.1 \mathrm{~mL})$ in DMF $(800 \mathrm{~mL})$ in the first step to obtain crude xanthate 29 (46.2 g, quant), which was used for the next step without further purification. Workup was done using ice-cold water, and organic solvents were removed in vacuo keeping the bath temp below $12{ }^{\circ} \mathrm{C}$.

A Barton-McCombie condition similar to that used for the synthesis of $\mathbf{8}$ was employed for the synthesis of $\mathbf{3 0}$, starting from crude $29(46.2 \mathrm{~g}), n \mathrm{Bu}_{3} \mathrm{SnH}(48.4 \mathrm{~mL}, 179.7 \mathrm{mmol})$, and AIBN (2.01 $\mathrm{g}, 12.2 \mathrm{mmol})$ in anhydrous toluene $(800 \mathrm{~mL})$ to obtain $30(21.84 \mathrm{~g}$, $60 \%$ over two steps) as a white solid $\left(R_{f}=0.37,10 \% \mathrm{MeOH}\right.$ in $\mathrm{CH}_{2} \mathrm{Cl}_{2}$; column chromatography gradient $\mathrm{CH}_{2} \mathrm{Cl}_{2} / \mathrm{MeOH}, 99: 1, \mathrm{v} /$ v; 49:1, v/v; 97:3, v/v). Mp $148{ }^{\circ} \mathrm{C} .{ }^{1} \mathrm{H}$ NMR $\left(600 \mathrm{MHz}, \mathrm{CDCl}_{3}\right) \delta$ $8.52(\mathrm{~s}, 1 \mathrm{H}, \mathrm{H}-8), 8.34(\mathrm{~s}, 1 \mathrm{H}, \mathrm{H}-2), 7.35-6.87(\mathrm{~m}, 10 \mathrm{H}, 2 \times \mathrm{Ar}-\mathrm{H}$ $\mathrm{Bn}$ ), 6.28 (br s, $\left.2 \mathrm{H}, \mathrm{NH}_{2}-6\right), 4.70-4.69\left(\mathrm{~m}, 1 \mathrm{H}, \mathrm{H}-2^{\prime}\right), 4.56$ (dd, $J=$ 73.6, $11.9 \mathrm{~Hz}, 2 \mathrm{H}, \mathrm{CH}_{2}-6^{\prime} \mathrm{Bn}$ ), $4.43-4.40\left(\mathrm{~m}, 1 \mathrm{H}, \mathrm{H}^{\prime}{ }^{\prime}{ }_{\text {eq }}\right.$ ), 4.07 (dd, $J$ $\left.=13.0,3.0 \mathrm{~Hz}, 1 \mathrm{H}, \mathrm{H}_{-1}{ }^{\prime}{ }_{\mathrm{ax}}\right), 4.01\left(\mathrm{~s}, 2 \mathrm{H}, \mathrm{CH}_{2}-4^{\prime} \mathrm{Bn}\right), 3.83-3.79(\mathrm{~m}$, $2 \mathrm{H}, \mathrm{H}-5^{\prime}$ and $\left.\mathrm{H}-6^{\prime}\right), 3.63\left(\mathrm{dd}, J=9.0,4.1 \mathrm{~Hz}, 1 \mathrm{H}, \mathrm{H}-6^{\prime \prime}\right), 3.61-3.59$ $\left(\mathrm{m}, 1 \mathrm{H}, \mathrm{H}-4^{\prime}\right), 2.64-2.61\left(\mathrm{~m}, 1 \mathrm{H}, \mathrm{H}-3^{\prime}{ }_{\mathrm{eq}}\right), 2.00-1.96(\mathrm{~m}, 1 \mathrm{H}, \mathrm{H}-$ $\left.3^{\prime}{ }_{\mathrm{ax}}\right) ;{ }^{13} \mathrm{C} \mathrm{NMR}\left(150 \mathrm{MHz}, \mathrm{CDCl}_{3}\right) \delta 155.5(\mathrm{C}-6), 152.4(\mathrm{C}-2)$, 149.7 (C-4), 141.5 (C-8), 137.8, 137.2 ( $2 \times$ ipso C-Bn), 128.3, 128.1, 127.7, 127.7, 127.6, 127.5 (Ar C-Bn), 118.7 (C-5), 78.9 (C-5'), 73.5 $\left(\mathrm{CH}_{2}-6^{\prime} \mathrm{Bn}\right), 70.9\left(\mathrm{CH}_{2}-4^{\prime} \mathrm{Bn}\right), 70.4\left(\mathrm{C}-4^{\prime}\right), 70.0\left(\mathrm{C}-6^{\prime}\right), 69.7\left(\mathrm{C}-1^{\prime}\right)$, $46.8\left(\mathrm{C}-2^{\prime}\right), 29.4\left(\mathrm{C}-3^{\prime}\right)$; HRMS (ESI-TOF) $m / z:[\mathrm{M}+\mathrm{H}]^{+}$calcd for $\mathrm{C}_{25} \mathrm{H}_{27} \mathrm{~N}_{5} \mathrm{O}_{3}$, 446.2186; found, 446.2181.

$1^{\prime}, 5^{\prime}$-Anhydro-4', $6^{\prime}$-di-O-benzyl-2', $3^{\prime}$-dideoxy-2' - ( $N^{6}$-benzoyladenin-9-yl)-D-allo-hexitol (31). A synthetic protocol similar to that used for the synthesis of $\mathbf{1 9}$ was employed for the synthesis of 31, starting from $30(21.8 \mathrm{~g}, 48.93 \mathrm{mmol})$ and benzoyl chloride (12.5 $\mathrm{mL}, 107.64 \mathrm{mmol})$ in anhydrous pyridine $(250 \mathrm{~mL})$ to obtain 31 $(25.5 \mathrm{~g}, 95 \%)$ as a white sticky mass $\left(R_{f}=0.6,10 \% \mathrm{MeOH}\right.$ in $\mathrm{CH}_{2} \mathrm{Cl}_{2}$; column chromatography gradient $\mathrm{CH}_{2} \mathrm{Cl}_{2} / \mathrm{MeOH}, 100: 0$, v/ v; 99:1, v/v; 49:1, v/v). ${ }^{1} \mathrm{H}$ NMR $\left(600 \mathrm{MHz}, \mathrm{CDCl}_{3}\right) \delta 9.18(\mathrm{br} \mathrm{s}$, $1 \mathrm{H}, \mathrm{NH}-6), 8.81(\mathrm{~s}, 1 \mathrm{H}, \mathrm{H}-2), 8.71(\mathrm{~s}, 1 \mathrm{H}, \mathrm{H}-8), 8.05-6.82(\mathrm{~m}, 15 \mathrm{H}$, $2 \times \mathrm{Ar}-\mathrm{H} \mathrm{Bn}$ and $\mathrm{Bz}), 4.78\left(\right.$ br s, $\left.1 \mathrm{H}, \mathrm{H}-2^{\prime}\right), 4.57(\mathrm{dd}, J=72.9,11.9$ $\left.\mathrm{Hz}, 2 \mathrm{H}, \mathrm{CH}_{2}-6^{\prime} \mathrm{Bn}\right), 4.48-4.46\left(\mathrm{~m}, 1 \mathrm{H}, \mathrm{H}_{-1}{ }^{\prime}{ }_{\mathrm{eq}}\right), 4.12(\mathrm{dd}, J=13.1$, $2.9 \mathrm{~Hz}, 1 \mathrm{H}, \mathrm{H}-1^{\prime}{ }_{\mathrm{ax}}$ ), 3.99 (dd, $\left.J=43.6,11.8 \mathrm{~Hz}, 2 \mathrm{H}, \mathrm{CH}_{2}-4^{\prime} \mathrm{Bn}\right)$, $3.86-3.84\left(\mathrm{~m}, 1 \mathrm{H}, \mathrm{H}-5^{\prime}\right), 3.80$ (dd, $\left.J=9.8,6.8 \mathrm{~Hz}, 1 \mathrm{H}, \mathrm{H}-6^{\prime}\right), 3.64-$ $3.61\left(\mathrm{~m}, 2 \mathrm{H}, \mathrm{H}-6^{\prime \prime}\right.$ and $\left.\mathrm{H}-4^{\prime}\right), 2.67-2.63\left(\mathrm{~m}, 1 \mathrm{H}, \mathrm{H}-3^{\prime}{ }_{\mathrm{eq}}\right), 2.04-2.00$ $\left(\mathrm{m}, 1 \mathrm{H}, \mathrm{H}-3^{\prime}{ }_{\mathrm{ax}}\right) ;{ }^{13} \mathrm{C} \mathrm{NMR}\left(150 \mathrm{MHz}, \mathrm{CDCl}_{3}\right) \delta 164.6$ (CO-Bz), 152.2 (C-6), 151.6 (C-2), 149.7 (C-4), 144.3 (C-8), 137.8, 137.1 (2 $\times$ ipso C-Bn), 128.8, 128.6, 128.4, 128.2, 127.8, 127.6, 127.3 (Ar C$\mathrm{Bn}), 121.9$ (C-5), $79.0\left(\mathrm{C}-5^{\prime}\right), 73.6\left(\mathrm{CH}_{2}-6^{\prime} \mathrm{Bn}\right), 71.1\left(\mathrm{CH}_{2}-4^{\prime} \mathrm{Bn}\right)$, $70.3\left(\mathrm{C}-4^{\prime}\right), 70.0\left(\mathrm{C}-6^{\prime}\right), 69.6\left(\mathrm{C}-1^{\prime}\right), 47.3\left(\mathrm{C}-2^{\prime}\right), 29.4\left(\mathrm{C}-3^{\prime}\right)$; HRMS (ESI-TOF) $m / z:[\mathrm{M}+\mathrm{H}]^{+}$calcd for $\mathrm{C}_{32} \mathrm{H}_{31} \mathrm{~N}_{5} \mathrm{O}_{4}, 550.2449$; found, 550.2466 .

1',5'-Anhydro-2',3'-dideoxy-2' -(adenin-9-yl)-D-allo-hexitol (32). To a stirred solution of $31(25.5 \mathrm{~g}, 46.39 \mathrm{mmol})$ in anhydrous $\mathrm{CH}_{2} \mathrm{Cl}_{2}(300 \mathrm{~mL})$ was added $1 \mathrm{M} \mathrm{BCl}_{3}$ in $\mathrm{CH}_{2} \mathrm{Cl}_{2}(139.2 \mathrm{~mL}, 139.18$ mmol) dropwise at $-78{ }^{\circ} \mathrm{C}$ under argon. The reaction mixture then was slowly warmed to room temperature and left stirring for $3 \mathrm{~h}$ at the same temperature. Upon completion, the reaction mixture again cooled to $-40{ }^{\circ} \mathrm{C}$ and was quenched with methanol $(200 \mathrm{~mL})$. Volatiles were concentrated in vacuo to provide a crude mixture of 32 and 33. The resulting mixture of $\mathbf{3 2}$ and $\mathbf{3 3}$ was stirred with $7 \mathrm{~N} \mathrm{NH}_{3}$ in $\mathrm{MeOH}(200 \mathrm{~mL})$ at room temperature for $24 \mathrm{~h}$. The reaction mixture was concentrated under reduced pressure, and the resulting crude residue was purified by column chromatography on silica gel $\left(R_{f}\right.$ $=0.25,15 \% \mathrm{MeOH}$ in $\mathrm{CH}_{2} \mathrm{Cl}_{2}$; gradient $\mathrm{CH}_{2} \mathrm{Cl}_{2} / \mathrm{MeOH}, 24: 1$, v/v; 9:1, v/v; 6:1, v/v) to give $32(10.58 \mathrm{~g}, 86 \%)$ as a white solid. Mp 228 ${ }^{\circ} \mathrm{C} .{ }^{1} \mathrm{H}$ NMR $\left(600 \mathrm{MHz}, \mathrm{DMSO}-d_{6}\right) \delta 8.56(\mathrm{~s}, 1 \mathrm{H}, \mathrm{H}-8), 8.23(\mathrm{~s}, 1 \mathrm{H}$, $\mathrm{H}-2$ ), 7.66 (br s, $2 \mathrm{H}, \mathrm{NH}_{2}-6$ ), $4.62-4.60$ (m, $\left.1 \mathrm{H}, \mathrm{H}-2^{\prime}\right), 4.20-4.17$ (m, $1 \mathrm{H},{\mathrm{H}-1^{\prime}}_{\mathrm{eq}}$ ), 3.94 (dd, $J=12.7,3.2 \mathrm{~Hz}, 1 \mathrm{H}, \mathrm{H}-1^{\prime}{ }_{\mathrm{ax}}$ ), 3.80-3.79 $\left(\mathrm{m}, 1 \mathrm{H}, \mathrm{H}-4^{\prime}\right), 3.63\left(\mathrm{dd}, J=11.4,7.0 \mathrm{~Hz}, 1 \mathrm{H}, \mathrm{H}-6^{\prime}\right), 3.57(\mathrm{dd}, J=$ $\left.11.3,5.1 \mathrm{~Hz}, 1 \mathrm{H}, \mathrm{H}-6^{\prime \prime}\right)$, 3.54-3.51 (m, $\left.1 \mathrm{H}, \mathrm{H}-5^{\prime}\right)$, 2.24-2.20 (m, $\left.1 \mathrm{H}, \mathrm{H}-3^{\prime}{ }_{\text {eq }}\right), 2.17-2.13\left(\mathrm{~m}, 1 \mathrm{H}, \mathrm{H}-3^{\prime}{ }_{\mathrm{ax}}\right) ;{ }^{13} \mathrm{C}$ NMR $(150 \mathrm{MHz}$, DMSO- $\left.d_{6}\right) \delta 154.4$ (C-6), 150.2 (C-2), 149.2 (C-4), 141.9 (C-8), 117.8 (C-5), 80.3 (C-5'), 68.5 (C-1'), 62.5 (C-4'), 60.7 (C-6'), 47.3 (C-2'), $33.8\left(\mathrm{C}-3^{\prime}\right)$; HRMS (ESI-TOF) $m / z:[\mathrm{M}+\mathrm{H}]^{+}$calcd for $\mathrm{C}_{11} \mathrm{H}_{15} \mathrm{~N}_{5} \mathrm{O}_{3}, 266.1247$; found, 266.1260 .

$1^{\prime}, 5^{\prime}$-Anhydro-2', 3' -dideoxy-2' -( $N^{6}$-benzoyladenin-9-yl)-Dallo-hexitol (33). To a stirred solution of $32(10.58 \mathrm{~g}, 39.88 \mathrm{mmol})$ in anhydrous pyridine $(190 \mathrm{~mL})$ was added TMSCl $(30.37 \mathrm{~mL}, 239.3$ mmol) dropwise at $0{ }^{\circ} \mathrm{C}$ under argon. The reaction mixture then was slowly warmed to room temperature and left stirring for $5 \mathrm{~h}$ at the same temperature. The reaction mixture was again cooled to $0{ }^{\circ} \mathrm{C}$, and benzoyl chloride $(11.58 \mathrm{~mL}, 99.7 \mathrm{mmol})$ was added to it and stirred at room temperature for $16 \mathrm{~h}$. The reaction mixture was cooled to $0{ }^{\circ} \mathrm{C}$ and quenched with $5 \% \mathrm{NaHCO}_{3}$ solution and diluted with water $(500 \mathrm{~mL})$, and the aq layer was extracted with $\mathrm{CH}_{2} \mathrm{Cl}_{2}(3 \times 500$ $\mathrm{mL}$ ). The combined organic layer was dried over $\mathrm{Na}_{2} \mathrm{SO}_{4}$, filtered, and concentrated in vacuo. The resulting crude was dissolved in THF $(200 \mathrm{~mL})$ in a plastic vessel, and $\mathrm{Et}_{3} \mathrm{~N} \cdot 3 \mathrm{HF}(19.5 \mathrm{~mL}, 119.64 \mathrm{mmol})$ was added and stirred at room temperature for $16 \mathrm{~h}$. The reaction mixture was concentrated in reduced pressure, and crude was partitioned between $5 \% \mathrm{NaHCO}_{3}$ solution $(400 \mathrm{~mL})$ and $\mathrm{CH}_{2} \mathrm{Cl}_{2}$ $(400 \mathrm{~mL})$. The aq layer was extracted with $\mathrm{CH}_{2} \mathrm{Cl}_{2}(2 \times 400 \mathrm{~mL})$. The combined organic layer was dried over $\mathrm{Na}_{2} \mathrm{SO}_{4}$, filtered, and concentrated in vacuo. The resulting crude was stirred with $2 \mathrm{~N} \mathrm{NH}_{3}$ in $\mathrm{EtOH}(150 \mathrm{~mL})$ at $0{ }^{\circ} \mathrm{C}$ for $0.75 \mathrm{~h}$. The reaction mixture was concentrated in reduced pressure (bath temp $12{ }^{\circ} \mathrm{C}$ ), and crude residue was purified by column chromatography on silica gel $\left(R_{f}=\right.$ $0.30,10 \% \mathrm{MeOH}$ in $\mathrm{CH}_{2} \mathrm{Cl}_{2}$; gradient $\mathrm{CH}_{2} \mathrm{Cl}_{2} / \mathrm{MeOH}, 49: 1$, v/v; $24: 1, \mathrm{v} / \mathrm{v} ; 23: 2, \mathrm{v} / \mathrm{v})$ to give $33(9.87 \mathrm{~g}, 67 \%$ in four steps $)$ as a white solid. Mp $196{ }^{\circ} \mathrm{C}$. ${ }^{1} \mathrm{H}$ NMR $\left(600 \mathrm{MHz}, \mathrm{DMSO}-d_{6}\right) \delta 11.09(\mathrm{NH}-6)$, $8.76(\mathrm{~s}, 1 \mathrm{H}, \mathrm{H}-8), 8.72(\mathrm{~s}, 1 \mathrm{H}, \mathrm{H}-2), 8.05(\mathrm{~d}, J=7.8 \mathrm{~Hz}, 2 \mathrm{H}, o \mathrm{H}-\mathrm{Bz})$, $7.64(\mathrm{t}, J=7.4 \mathrm{~Hz}, 1 \mathrm{H}, p \mathrm{H}-\mathrm{Bz}), 7.55(\mathrm{t}, J=8.0 \mathrm{~Hz}, 2 \mathrm{H}, m \mathrm{H}-\mathrm{Bz})$, $4.76-4.74\left(\mathrm{~m}, 1 \mathrm{H}, \mathrm{H}-2^{\prime}\right), 4.70\left(\mathrm{~d}, J=3.5 \mathrm{~Hz}, 1 \mathrm{H}, \mathrm{OH}-4^{\prime}\right), 4.65-4.63$ (m, 1H, OH-6 $\left.6^{\prime}\right), 4.31-4.28\left(\mathrm{~m}, 1 \mathrm{H}, \mathrm{H}-1^{\prime}{ }_{\mathrm{eq}}\right), 4.00$ (dd, $J=12.8,3.1$ $\left.\mathrm{Hz}, 1 \mathrm{H}, \mathrm{H}-1^{\prime}{ }_{\mathrm{ax}}\right), 3.81-3.79\left(\mathrm{~m}, 1 \mathrm{H}, \mathrm{H}-4^{\prime}\right)$, 3.66-3.62 (m, $\left.1 \mathrm{H}, \mathrm{H}-6^{\prime}\right)$, 3.59-3.54 (m, 2H, H-6 ${ }^{\prime \prime}$ and $\left.\mathrm{H}-5^{\prime}\right), 2.27-2.24\left(\mathrm{~m}, 1 \mathrm{H}, \mathrm{H}-3^{\prime}{ }_{\mathrm{eq}}\right)$, $2.23-2.19\left(\mathrm{~m}, 1 \mathrm{H}, \mathrm{H}-3^{\prime}{ }_{\mathrm{ax}}\right) ;{ }^{13} \mathrm{C}$ NMR $\left(150 \mathrm{MHz}\right.$, DMSO- $\left.d_{6}\right) \delta 165.6$ (CO-Bz), 152.4 (C-6), 151.1 (C-2), 149.8 (C-4), 144.9 (C-8), 133.6 (ipso C-Bz), $132.4(p \mathrm{C}-\mathrm{Bz}), 128.5(\mathrm{mC}-\mathrm{Bz}), 128.5(o \mathrm{C}-\mathrm{Bz}), 125.1$ (C5), $80.4\left(\mathrm{C}-5^{\prime}\right), 68.6\left(\mathrm{C}-1^{\prime}\right), 62.6\left(\mathrm{C}-4^{\prime}\right), 61.0\left(\mathrm{C}-6^{\prime}\right), 47.4\left(\mathrm{C}-2^{\prime}\right)$, $33.7\left(\mathrm{C}-3^{\prime}\right)$; HRMS (ESI-TOF) $m / z:[\mathrm{M}+\mathrm{H}]^{+}$calcd for $\mathrm{C}_{18} \mathrm{H}_{19} \mathrm{~N}_{5} \mathrm{O}_{4}, 370.1510$; found, 370.1506 .

$1^{\prime}, 5^{\prime}$-Anhydro-6'-O-tert-butyldiphenylsilyl-2', 3' -dideoxy-2' ( $N^{6}$-benzoyladenin-9-yl)-D-allo-hexitol (34). A synthetic protocol similar to that used for the synthesis of $\mathbf{1 0}$ was employed for the synthesis of 34, starting from $33(9.87 \mathrm{~g}, 26.72 \mathrm{mmol})$ and TBDPSCl $(10.4 \mathrm{~mL}, 40.08 \mathrm{mmol})$ in anhydrous pyridine $(150 \mathrm{~mL})$ to obtain 34 $(13 \mathrm{~g}, 80 \%)$ as a white foam $\left(R_{f}=0.64,10 \% \mathrm{MeOH}\right.$ in $\mathrm{CH}_{2} \mathrm{Cl}_{2}$; column chromatography gradient $\mathrm{CH}_{2} \mathrm{Cl}_{2} / \mathrm{MeOH}, 100: 0$, v/v; 99:1, v/v; 39:1, v/v). Mp $123{ }^{\circ} \mathrm{C} .{ }^{1} \mathrm{H}$ NMR $\left(500 \mathrm{MHz}, \mathrm{CDCl}_{3}\right) \delta 9.21(\mathrm{br}$ s, $1 \mathrm{H}, \mathrm{NH}-6), 8.74(\mathrm{~s}, 1 \mathrm{H}, \mathrm{H}-8), 8.70(\mathrm{~s}, 1 \mathrm{H}, \mathrm{H}-2), 8.00-7.98(\mathrm{~m}$ $2 \mathrm{H}, o \mathrm{H}-\mathrm{Bz}), 7.71-7.66(\mathrm{~m}, 4 \mathrm{H}, \mathrm{Ar}-\mathrm{H}$ TBDPS$), 7.55-7.52(\mathrm{~m}, 1 \mathrm{H}$, $p \mathrm{H}-\mathrm{Bz}), 7.46(\mathrm{t}, J=7.7 \mathrm{~Hz}, 2 \mathrm{H}, m \mathrm{H}-\mathrm{Bz}), 7.44-7.37(\mathrm{~m}, 6 \mathrm{H}, \mathrm{Ar}-\mathrm{H}$ TBDPS), 4.77-4.75 (m, 1H, H-2'), 4.43 (dd, $J=12.9,1.9 \mathrm{~Hz}, 1 \mathrm{H}, \mathrm{H}-$ $1^{\prime}{ }_{\mathrm{eq}}$ ), $4.13\left(\mathrm{br} \mathrm{s}, 1 \mathrm{H}, \mathrm{H}-4^{\prime}\right), 4.05\left(\mathrm{dd}, J=13.0,2.9 \mathrm{~Hz}, 1 \mathrm{H}, \mathrm{H}-1^{\prime}{ }_{\mathrm{ax}}\right)$, $3.97\left(\mathrm{~d}, J=5.0 \mathrm{~Hz}, 2 \mathrm{H}, \mathrm{H}-6^{\prime}\right.$ and $\left.\mathrm{H}-6^{\prime \prime}\right), 3.62\left(\mathrm{br} \mathrm{s}, 1 \mathrm{H}, \mathrm{OH}-4^{\prime}\right)$, 3.59-3.57 (m, 1H, H-5'), 2.50-2.45 (m, 1H, H- $\left.{ }^{\prime}{ }_{\mathrm{eq}}\right), 2.21-2.16(\mathrm{~m}$, $\left.1 \mathrm{H}, \mathrm{H}-3^{\prime}{ }_{\mathrm{ax}}\right), 1.06\left(\mathrm{~s}, 9 \mathrm{H}, 3 \times \mathrm{CH}_{3}-{ }^{t} \mathrm{Bu}\right) ;{ }^{13} \mathrm{C}$ NMR $(125 \mathrm{MHz}$, $\left.\mathrm{CDCl}_{3}\right) \delta 164.9$ (CO-Bz), 152.1 (C-6), 151.8 (C-2), 149.1 (C-4), 
144.4 (C-8), 135.7, 135.6, 134.0, 132.8, 132.6, 130.1, 128.8, 128.0 (Ar C-TBDPS and Bz), 122.2 (C-5), $79.1\left(\mathrm{C}-5^{\prime}\right), 70.3\left(\mathrm{C}-1^{\prime}\right), 65.0$ (C$\left.6^{\prime}\right), 64.8\left(\mathrm{C}-4^{\prime}\right), 47.2\left(\mathrm{C}-2^{\prime}\right), 33.9\left(\mathrm{C}-3^{\prime}\right), 26.9\left(3 \times \mathrm{CH}_{3}-{ }^{t} \mathrm{Bu}\right), 19.2$ (1C ${ }^{t} \mathrm{Bu}$ ); HRMS (ESI-TOF) $m / z:[\mathrm{M}+\mathrm{H}]^{+}$calcd for $\mathrm{C}_{34} \mathrm{H}_{37} \mathrm{~N}_{5} \mathrm{O}_{4} \mathrm{Si}$, 608.2687; found, 608.2691.

$1^{\prime}, 5^{\prime}$-Anhydro-6'-O-tert-butyldiphenylsilyl-4' -O-mesyl$2^{\prime}, 3^{\prime}$-dideoxy-2'-( $N^{6}$-benzoyladenin-9-yl)-D-allo-hexitol (35). A synthetic protocol similar to that used for the synthesis of $\mathbf{1 1}$ was employed for the synthesis of 35, starting from $34(13 \mathrm{~g}, 21.39 \mathrm{mmol})$ and $\mathrm{MsCl}(4.97 \mathrm{~mL}, 64.17 \mathrm{mmol})$ in anhydrous pyridine $(230 \mathrm{~mL})$ to obtain $35(12.5 \mathrm{~g}, 85 \%)$ as a white foam $\left(R_{f}=0.45,6 \% \mathrm{MeOH}\right.$ in $\mathrm{CH}_{2} \mathrm{Cl}_{2}$; column chromatography gradient $\mathrm{CH}_{2} \mathrm{Cl}_{2} / \mathrm{MeOH}, 100: 0$, v/ v; 99:1, v/v; 66:1, v/v). Mp $148{ }^{\circ} \mathrm{C} .{ }^{1} \mathrm{H}$ NMR $\left(300 \mathrm{MHz}, \mathrm{CDCl}_{3}\right) \delta$ 9.25 (br s, 1H, NH-6), 8.74 (s, 1H, H-2), 8.50 (s, 1H, H-8), 8.02$7.37(\mathrm{~m}, 15 \mathrm{H}, \mathrm{Ar}-\mathrm{H}$ TBDPS and Bz), 5.03-5.01 (m, 1H, H-2'), 4.82 (br s, $\left.1 \mathrm{H}, \mathrm{H}-4^{\prime}\right), 4.48\left(\mathrm{~d}, J=13.0 \mathrm{~Hz}, 1 \mathrm{H}, \mathrm{H}-1^{\prime}{ }_{\mathrm{eq}}\right), 4.10-4.05(\mathrm{~m}, 1 \mathrm{H}$, $\mathrm{H}-\mathrm{1}^{\prime}{ }_{\mathrm{ax}}$ ), 3.88-3.73 (m, 3H, H-5', H-6', and H-6 $\left.{ }^{\prime \prime}\right), 2.97-2.90(\mathrm{~m}$, $1 \mathrm{H}, \mathrm{H}-3^{\prime}{ }_{\mathrm{eq}}$ ), $2.35-2.25\left(\mathrm{~m}, 1 \mathrm{H}, \mathrm{H}-3^{\prime}{ }_{\mathrm{ax}}\right), 2.50$ (s, $\left.3 \mathrm{H}, \mathrm{CH}_{3}-\mathrm{Ms}\right), 1.07$ $\left(\mathrm{s}, 9 \mathrm{H}, 3 \times \mathrm{CH}_{3}-{ }^{t} \mathrm{Bu}\right) ;{ }^{13} \mathrm{C} \mathrm{NMR}\left(75 \mathrm{MHz}, \mathrm{CDCl}_{3}\right) \delta 164.8(\mathrm{CO}-$ $\mathrm{Bz}), 152.5$ (C-6), 152.2 (C-2), 149.4 (C-4), 143.1 (C-8), 135.7, 135.7, 135.6, 132.7, 130.1, 128.9, 128.0, 127.9 (Ar C-TBDPS and Bz), 122.7 (C-5), 79.1 (C-5'), 71.3 (C-1'), 69.4 (C-6'), 62.4 (C-4'), 46.9 $\left(\mathrm{C}-2^{\prime}\right), 38.4\left(\mathrm{CH}_{3}-\mathrm{Ms}\right), 32.6\left(\mathrm{C}-3^{\prime}\right), 26.9\left(3 \times \mathrm{CH}_{3}{ }^{t} \mathrm{Bu}\right), 19.3(1 \mathrm{C}$ ${ }^{t} \mathrm{Bu}$ ); HRMS (ESI-TOF) $\mathrm{m} / z$ : $[\mathrm{M}+\mathrm{H}]^{+}$calcd for $\mathrm{C}_{35} \mathrm{H}_{39} \mathrm{~N}_{5} \mathrm{O}_{6} \mathrm{SSi}$, 686.2463; found, 686.2455 .

$1^{\prime}, 5^{\prime}$-Anhydro-6'-O-tert-butyldiphenylsilyl-4' -amino-2', 3'dideoxy-2' $-\left(N^{6}\right.$-benzoyladenin-9-yl)-D-altro-hexitol (38). To a stirred solution of compound $35(12.5 \mathrm{~g}, 18.22 \mathrm{mmol})$ in dry DMF $(200 \mathrm{~mL})$ was added sodium azide $(5.34 \mathrm{~g}, 82.01 \mathrm{mmol})$, and the resulting reaction mixture was heated at $65^{\circ} \mathrm{C}$ for $72 \mathrm{~h}$. The progress of the reaction was monitored by TLC, and, after completion, the reaction mixture was cooled and volatiles were removed under reduced pressure. The crude residue was suspended in $10 \% \mathrm{MeOH}$ in $\mathrm{CH}_{2} \mathrm{Cl}_{2}$, solid residue was filtered off, washed, and filtrate was concentrated in vacuo to give a mixture of compounds $(36,37$, and desilylated analogues of 36 and 37). Without purification, the resulting crude was treated with TBDPSCl $(4.74 \mathrm{~mL}, 18.22 \mathrm{mmol})$ in anhydrous pyridine $(200 \mathrm{~mL})$ at $45^{\circ} \mathrm{C}$ for $16 \mathrm{~h}$. The reaction mixture was then cooled to $0{ }^{\circ} \mathrm{C}$ and neutralized with $5 \% \mathrm{NaHCO}_{3}$ solution. The aq layer was extracted with $\mathrm{CH}_{2} \mathrm{Cl}_{2}(3 \times 500 \mathrm{~mL})$. The combined organic layer was dried over $\mathrm{Na}_{2} \mathrm{SO}_{4}$, filtered, and concentrated under reduced pressure, and the resulting crude residue was purified by column chromatography on silica gel $\left(R_{f}=0.56,6 \%\right.$ $\mathrm{MeOH}$ in $\mathrm{CH}_{2} \mathrm{Cl}_{2}$; gradient $\mathrm{CH}_{2} \mathrm{Cl}_{2} / \mathrm{MeOH}, 100: 0$, v/v; 99:1, v/v; $66: 1, \mathrm{v} / \mathrm{v})$ to give a nonseparable mixture of 36 and $37(10.12 \mathrm{~g})$ as a white foam. HRMS (ESI-TOF) $m / z:[\mathrm{M}+\mathrm{H}]^{+}$calcd for $\mathrm{C}_{34} \mathrm{H}_{36} \mathrm{~N}_{8} \mathrm{O}_{3} \mathrm{Si}, 633.2752$; found, 633.2756.

To a stirred solution of a 36 and 37 mixture ( $10.12 \mathrm{~g}, 1$ equiv) in $\mathrm{MeOH}(350 \mathrm{~mL}$, degaussed with argon) were added three drops of glacial $\mathrm{AcOH}$ followed by $10 \% \mathrm{Pd} / \mathrm{C}$ (Degussa type, $1.52 \mathrm{~g}, 0.15$ equiv $\mathrm{w} / \mathrm{w}$ ), and evacuation was then carried out with hydrogen atmosphere replacements $(3 \times)$. The reaction mixture was stirred at room temperature for $16 \mathrm{~h}$ under an atmospheric pressure of hydrogen. After completion of the reaction, the catalyst was removed by filtration through a Celite pad, and the pad was thoroughly washed with $\mathrm{MeOH}$. The combined filtrate was concentrated under reduced pressure, and the crude residue was purified by column chromatography on silica gel $\left(R_{f}=0.27,10 \% \mathrm{MeOH}\right.$ in $\mathrm{CH}_{2} \mathrm{Cl}_{2}$; gradient $\left.\mathrm{CH}_{2} \mathrm{Cl}_{2} / \mathrm{MeOH}, 49: 1, \mathrm{v} / \mathrm{v} ; 24: 1, \mathrm{v} / \mathrm{v} ; 19: 1, \mathrm{v} / \mathrm{v}\right)$ to afford $38(2.21 \mathrm{~g}$, $20 \%$ over two steps) as a white foam. Mp $144{ }^{\circ} \mathrm{C} .{ }^{1} \mathrm{H}$ NMR (500 $\mathrm{MHz}, \mathrm{CDCl}_{3}$ ) $\delta 9.36$ (br s, $\left.1 \mathrm{H}, \mathrm{NH}-6\right), 8.81(\mathrm{~s}, 1 \mathrm{H}, \mathrm{H}-2), 8.65$ (s, $1 \mathrm{H}, \mathrm{H}-8), 8.03$ (d, J = 7.6 Hz, 2H,oH-Bz), 7.73-7.69 (m, 4H, Ar HTBDPS), $7.59(\mathrm{t}, J=7.4 \mathrm{~Hz}, 1 \mathrm{H}, p \mathrm{H}-\mathrm{Bz}), 7.51(\mathrm{t}, J=7.5 \mathrm{~Hz}, 2 \mathrm{H}$, $m \mathrm{H}-\mathrm{Bz}$ ), 7.45-7.38 (m, 6H, Ar-H TBDPS), 4.96 (br s, $\left.1 \mathrm{H}, \mathrm{H}-2^{\prime}\right)$, $4.36\left(\mathrm{~d}, J=12.8 \mathrm{~Hz}, 1 \mathrm{H}, \mathrm{H}-1^{\prime}{ }_{\mathrm{eq}}\right), 3.99-3.91\left(\mathrm{~m}, 3 \mathrm{H}, \mathrm{H}-1^{\prime}{ }_{\mathrm{ax}}, \mathrm{H}-6^{\prime}\right.$, and $\left.\mathrm{H}-6^{\prime \prime}\right), 3.25-3.22\left(\mathrm{~m}, 1 \mathrm{H}, \mathrm{H}-5^{\prime}\right), 3.13-3.08\left(\mathrm{~m}, 1 \mathrm{H}, \mathrm{H}-4^{\prime}\right)$, $2.43-2.38\left(\mathrm{~m}, 1 \mathrm{H}, \mathrm{H}-3^{\prime}{ }_{\mathrm{eq}}\right), 1.89-1.83\left(\mathrm{~m}, 1 \mathrm{H}, \mathrm{H}-3^{\prime}{ }_{\mathrm{ax}}\right), 1.77$ (br s, $\left.2 \mathrm{H}, \mathrm{NH}_{2}-4^{\prime}\right), 1.10\left(\mathrm{~s}, 9 \mathrm{H}, 3 \times \mathrm{CH}_{3}-{ }^{t} \mathrm{Bu}\right) ;{ }^{13} \mathrm{C}$ NMR $(125 \mathrm{MHz}$, $\left.\mathrm{CDCl}_{3}\right) \delta 164.7$ (CO-Bz), 152.4 (C-6), 151.7 (C-2), 149.5 (C-4), 142.8 (C-8), 135.6, 135.5, 133.8, 133.0, 132.9, 132.6, 129.9, 129.8,
128.7, 128.7, 127.9, 127.8, 127.7 (Ar C-TBDPS and Bz), 122.3 (C-5), $84.5\left(\mathrm{C}-5^{\prime}\right), 69.2\left(\mathrm{C}-1^{\prime}\right), 63.9\left(\mathrm{C}-6^{\prime}\right), 50.4\left(\mathrm{C}-2^{\prime}\right), 43.4\left(\mathrm{C}-4^{\prime}\right), 37.0$ (C-3'), $26.9\left(3 \times \mathrm{CH}_{3}-{ }^{t} \mathrm{Bu}\right), 19.2\left(1 \mathrm{C}{ }^{t} \mathrm{Bu}\right)$; HRMS (ESI-TOF) $\mathrm{m} / z$ : $[\mathrm{M}+\mathrm{H}]^{+}$calcd for $\mathrm{C}_{34} \mathrm{H}_{38} \mathrm{~N}_{6} \mathrm{O}_{3} \mathrm{Si}$, 607.2847; found, 607.2874.

$1^{\prime}, 5^{\prime}$-Anhydro-6'-O-tert-butyldiphenylsilyl-4'-amino(trityl)$2^{\prime}, 3^{\prime}$-dideoxy-2' -( $N^{6}$-benzoyladenin-9-yl)-D-altro-hexitol (39). To a stirred solution of compound $38(2.21 \mathrm{~g}, 3.64 \mathrm{mmol})$ in dry $\mathrm{CH}_{2} \mathrm{Cl}_{2}(60 \mathrm{~mL})$ were added triethylamine $(5.06 \mathrm{~mL}, 36.4 \mathrm{mmol})$ followed by trityl chloride $(3.05 \mathrm{~g}, 10.94 \mathrm{mmol})$, and the resulting reaction mixture was stirred at $40{ }^{\circ} \mathrm{C}$ for $16 \mathrm{~h}$. The progress of the reaction was monitored by TLC, and, after completion, the reaction mixture was cooled and quenched with $5 \% \mathrm{NaHCO}_{3}$ solution. The aq layer was extracted with $\mathrm{CH}_{2} \mathrm{Cl}_{2}(3 \times 100 \mathrm{~mL})$. The combined organic layer was dried over $\mathrm{Na}_{2} \mathrm{SO}_{4}$, filtered and concentrated under reduced pressure, and the resulting crude residue was purified by column chromatography on silica gel $\left(R_{f}=0.72\right.$, EtOAc; gradient hexane/EtOAc, 4:1, v/v; 3:2, v/v; 2:3, v/v) to give $39(2.48 \mathrm{~g}, 80 \%)$ as a white foam. $\mathrm{Mp} 152{ }^{\circ} \mathrm{C} .{ }^{1} \mathrm{H}$ NMR $\left(500 \mathrm{MHz}, \mathrm{CDCl}_{3}\right) \delta 9.24(\mathrm{br}$ s, $1 \mathrm{H}, \mathrm{NH}-6), 8.74(\mathrm{~s}, 1 \mathrm{H}, \mathrm{H}-2), 8.08-8.06(\mathrm{~m}, 3 \mathrm{H}, \mathrm{H}-8$ and $\mathrm{Ar} \mathrm{H}-$ anisyl), 7.67-7.03 (m, 28H, Ar H-TBDPS, Bz and Trt), 4.67-4.65 (m, $\left.1 \mathrm{H}, \mathrm{H}-2^{\prime}\right), 4.12\left(\mathrm{dd}, J=14.3,7.2 \mathrm{~Hz}, 1 \mathrm{H}, \mathrm{H}-1^{\prime}{ }_{\mathrm{eq}}\right.$ ), 3.91 (dd, $J=$ 12.5, 3.2 Hz, $\left.1 \mathrm{H}, \mathrm{H}-1^{\prime}{ }_{\mathrm{ax}}\right), 3.88-3.83\left(\mathrm{~m}, 2 \mathrm{H}, \mathrm{H}-6^{\prime}\right.$ and $\left.\mathrm{H}-6^{\prime \prime}\right)$, 3.44$3.41\left(\mathrm{~m}, 1 \mathrm{H}, \mathrm{H}-5^{\prime}\right), 2.61-2.58\left(\mathrm{~m}, 1 \mathrm{H}, \mathrm{H}-4^{\prime}\right), 2.29$ (br s, $1 \mathrm{H}, \mathrm{NH}-$ $\left.4^{\prime}\right), 1.80-1.70\left(\mathrm{~m}, 2 \mathrm{H}, \mathrm{H}-3^{\prime}{ }_{\mathrm{eq}}\right.$ and $\left.\mathrm{H}-3^{\prime}{ }_{\mathrm{ax}}\right), 1.02(\mathrm{~s}, 9 \mathrm{H}, 3 \times$ $\left.\mathrm{CH}_{3}-{ }^{t} \mathrm{Bu}\right) ;{ }^{13} \mathrm{C}$ NMR $\left(125 \mathrm{MHz}, \mathrm{CDCl}_{3}\right) \delta 164.6$ (CO-Bz), 152.2 (C-6), 151.3 (C-2), 149.2 (C-4), 145.9 (ipso C-Trt), 142.2 (C-8), 135.6, 135.5, 133.8, 133.0, 132.9, 132.7, 129.8, 129.7, 128.8, 128.5, 127.8, 127.7, 127.6, 126.3 (Ar C-TBDPS, Trt and Bz), 122.3 (C-5), $81.8\left(\mathrm{C}-5^{\prime}\right), 70.4$ (1C-Trt), $67.9\left(\mathrm{C}-1^{\prime}\right), 64.4\left(\mathrm{C}-6^{\prime}\right), 49.8\left(\mathrm{C}-2^{\prime}\right)$, $48.5\left(\mathrm{C}-4^{\prime}\right), 34.6\left(\mathrm{C}-3^{\prime}\right), 26.8\left(3 \times \mathrm{CH}_{3}-{ }^{t} \mathrm{Bu}\right), 19.1\left(1 \mathrm{C}{ }^{t} \mathrm{Bu}\right)$; HRMS (ESI-TOF) $m / z:[\mathrm{M}+\mathrm{H}]^{+}$calcd for $\mathrm{C}_{53} \mathrm{H}_{52} \mathrm{~N}_{6} \mathrm{O}_{3} \mathrm{Si}, 849.3943$; found, 849.3931 .

$1^{\prime}, 5^{\prime}$-Anhydro-4' -amino(trityl)-2',3'-dideoxy-2'-( $N^{6}$-benzoyladenin-9-yl)-D-altro-hexitol (3). A synthetic protocol similar to that used for the synthesis of 2 was employed for the synthesis of $\mathbf{3}$, starting from $39(2.48 \mathrm{~g}, 2.92 \mathrm{mmol})$ and triethylamine trihydrofluoride $(1.90 \mathrm{~mL}, 11.68 \mathrm{mmol})$ in anhydrous THF $(60 \mathrm{~mL})$ at $46{ }^{\circ} \mathrm{C}$ for $72 \mathrm{~h}$ to obtain $3(1.55 \mathrm{~g}, 87 \%)$ as a white semisolid $\left(R_{f}=0.34,5 \%\right.$ $\mathrm{MeOH}$ in EtOAc; column chromatography gradient EtOAc/MeOH, 100:0, v/v; 99:1, v/v; 49:1, v/v). Mp $192{ }^{\circ} \mathrm{C} .{ }^{1} \mathrm{H}$ NMR $(600 \mathrm{MHz}$, DMSO- $\left.d_{6}\right) \delta 11.16(\mathrm{br} \mathrm{s}, 1 \mathrm{H}, \mathrm{NH}-6), 8.68(\mathrm{~s}, 1 \mathrm{H}, \mathrm{H}-2), 8.22(\mathrm{~m}, 1 \mathrm{H}$, $\mathrm{H}-8), 8.09$ (d, $J=7.7 \mathrm{~Hz}, 2 \mathrm{H}, o \mathrm{H}-\mathrm{Bz}), 7.65(\mathrm{t}, J=7.5 \mathrm{~Hz}, 1 \mathrm{H}, p \mathrm{H}-$ $\mathrm{Bz}), 7.57(\mathrm{t}, J=7.8 \mathrm{~Hz}, 2 \mathrm{H}, m \mathrm{H}-\mathrm{Bz}), 7.32-7.05$ (m, 15H, Ar H-Trt), 4.77 (br s, $\left.1 \mathrm{H}, \mathrm{OH}-6^{\prime}\right), 4.67-4.65\left(\mathrm{~m}, 1 \mathrm{H}, \mathrm{H}-2^{\prime}\right), 4.17$ (d, $J=12.3$ $\mathrm{Hz}, 1 \mathrm{H}, \mathrm{H}-1^{\prime}{ }_{\mathrm{eq}}$ ), 3.88 (dd, $J=12.5,3.1 \mathrm{~Hz}, 1 \mathrm{H}, \mathrm{H}-1^{\prime}{ }_{\text {ax }}$ ), $3.68-3.64$ $\left(\mathrm{m}, 1 \mathrm{H}, \mathrm{H}-6^{\prime}\right), 3.58-3.55\left(\mathrm{~m}, 1 \mathrm{H}, \mathrm{H}-6^{\prime \prime}\right), 3.45-3.42\left(\mathrm{~m}, 1 \mathrm{H}, \mathrm{H}-5^{\prime}\right)$, $3.10\left(\mathrm{~d}, J=5.2 \mathrm{~Hz}, 1 \mathrm{H}, \mathrm{NH}-4^{\prime}\right), 2.31-2.27\left(\mathrm{~m}, 1 \mathrm{H}, \mathrm{H}-4^{\prime}\right), 1.71-1.63$ $\left(\mathrm{m}, 2 \mathrm{H}, \mathrm{H}-3^{\prime}{ }_{\mathrm{eq}}\right.$ and $\left.\mathrm{H}-3^{\prime}{ }_{\mathrm{ax}}\right) ;{ }^{13} \mathrm{C}$ NMR (150 MHz, DMSO- $\left.d_{6}\right) \delta 165.7$ (CO-Bz), 152.1 (C-6), 151.1 (C-2), 150.1 (C-4), 146.7 (ipso C-Trt), 143.1 (C-8), 133.6, 132.4, 128.5, 128.4, 127.5, 126.2 (Ar C-Trt and Bz), 125.4 (C-5), 80.9 (C-5'), 70.1 (1C-Trt), 67.0 (C-1'), 61.9 (C$\left.6^{\prime}\right), 49.7$ (C-2'), 48.2 (C-4'), 33.9 (C-3'); HRMS (ESI-TOF) $\mathrm{m} / z$ : $[\mathrm{M}+\mathrm{H}]^{+}$calcd for $\mathrm{C}_{37} \mathrm{H}_{34} \mathrm{~N}_{6} \mathrm{O}_{3}, 611.2765$; found, 611.2761.

$1^{\prime}, 5^{\prime}$-Anhydro-4', 6' -di-O-benzyl-2' -deoxy-2' -(2-amino-6chloropurin-9-yl)-D-allo-hexitol (40). To a stirred solution of 26 $(45 \mathrm{~g}, 137.9 \mathrm{mmol})$ and adenine $(28.1 \mathrm{~g}, 165.5 \mathrm{mmol})$ in dry DMSO $(450 \mathrm{~mL})$ was added DBU $(26.8 \mathrm{~mL}, 179.3 \mathrm{mmol})$ under argon, and the reaction mixture was heated at $88{ }^{\circ} \mathrm{C}$ for $36 \mathrm{~h}$. The reaction was monitored with TLC; upon completion, the reaction mixture was cooled and the residue was diluted with ice-water $(4 \mathrm{~L})$ and neutralized with $0.5 \mathrm{~N} \mathrm{HCl}$ at $0{ }^{\circ} \mathrm{C}$. The aqueous layer was extracted with EtOAc $(3 \times 800 \mathrm{~mL})$. The combined organic layer was dried over $\mathrm{Na}_{2} \mathrm{SO}_{4}$, filtered and concentrated in vacuo, and the crude residue was purified by column chromatography on silica gel $\left(R_{f}=\right.$ $0.42,8 \% \mathrm{MeOH}$ in $\mathrm{CH}_{2} \mathrm{Cl}_{2}$; gradient $\mathrm{CH}_{2} \mathrm{Cl}_{2} / \mathrm{MeOH}$, 99:1, v/v; $49: 1, \mathrm{v} / \mathrm{v} ; 39: 1, \mathrm{v} / \mathrm{v})$ to give $\mathbf{4 0}(41.03 \mathrm{~g}, 60 \%)$ as a white solid. $\mathrm{Mp}$ $153{ }^{\circ} \mathrm{C} .{ }^{1} \mathrm{H}$ NMR $\left(500 \mathrm{MHz}, \mathrm{CDCl}_{3}\right) \delta 8.20(\mathrm{~s}, 1 \mathrm{H}, \mathrm{H}-8), 7.36-6.91$ $\left(\mathrm{m}, 10 \mathrm{H}, 2 \times \mathrm{Ar} \mathrm{H}-\mathrm{Bn}\right.$ ), 5.15 (br s, $\left.2 \mathrm{H}, \mathrm{NH}_{2}-2\right), 4.58$ (dd, $J=36.9$, $\left.11.9 \mathrm{~Hz}, 2 \mathrm{H}, \mathrm{CH}_{2}-6^{\prime} \mathrm{Bn}\right), 4.35-4.19$ (m, $7 \mathrm{H}, \mathrm{CH}_{2}-4^{\prime} \mathrm{Bn}, \mathrm{H}^{\prime} 2^{\prime}, \mathrm{H}^{\prime} 1^{\prime}{ }_{\text {eq }}$, $\mathrm{H}-1^{\prime}{ }_{\mathrm{ax}}, \mathrm{H}-5^{\prime}$, and $\left.\mathrm{H}-3^{\prime}\right), 3.85$ (dd, $\left.J=10.2,7.1 \mathrm{~Hz}, 1 \mathrm{H}, \mathrm{H}-6^{\prime}\right), 3.63$ 
$\left(\mathrm{dd}, J=10.2,4.6 \mathrm{~Hz}, 1 \mathrm{H}, \mathrm{H}-6^{\prime \prime}\right), 3.51\left(\mathrm{t}, J=3.5 \mathrm{~Hz}, 1 \mathrm{H}, \mathrm{H}-4^{\prime}{ }^{13} \mathrm{C}\right.$ NMR (125 MHz, CDCl ${ }_{3}$ ) $\delta 158.7$ (C-2), 153.7 (C-4), 151.0 (C-6), 143.2 (C-8), 137.8, 137.0 ( $2 \times$ ipso C-Bn), 128.5, 128.3, 128.0, 127.9 ( $\mathrm{Ar} C-\mathrm{Bn}), 124.7$ (C-5), $76.5\left(\mathrm{C}-4^{\prime}\right), 74.1\left(\mathrm{CH}_{2}-6^{\prime} \mathrm{Bn}\right), 73.6\left(\mathrm{CH}_{2}-\right.$ 4'Bn), 73.3 (C-5'), 68.8 (C-6'), 65.7 (C-3'), 64.1 (C-1'), 53.9 (C$2^{\prime}$ ); HRMS (ESI-TOF) $m / z$ : $[\mathrm{M}+\mathrm{H}]^{+}$calcd for $\mathrm{C}_{25} \mathrm{H}_{26} \mathrm{ClN}_{5} \mathrm{O}_{4}$, 496.1746; found, 496.1747.

$1^{\prime}, 5^{\prime}$-Anhydro-4', 6' -di-O-benzyl-2' -deoxy-2' -(guanin-9-yl)D-allo-hexitol (41). To a stirred solution of $40(41 \mathrm{~g}, 82.66 \mathrm{mmol})$ in $2 \mathrm{~N} \mathrm{NaOH}$ and 1,4-dioxane $(1: 1,450 \mathrm{~mL})$ was added DABCO $(2.72 \mathrm{~g}, 24.25 \mathrm{mmol})$, and the reaction mixture was heated at $90{ }^{\circ} \mathrm{C}$ for $16 \mathrm{~h}$. The reaction was monitored with TLC; upon completion, the reaction mixture was cooled and volatiles were removed under reduced pressure. The resulting crude was diluted with ice-cold water, and the $\mathrm{pH}$ was adjusted to neutral with $1 \mathrm{~N} \mathrm{HCl}$ at $0{ }^{\circ} \mathrm{C}$. The solid formed was filtered off, washed with water, $3 \% \mathrm{MeOH}$ in $\mathrm{CH}_{2} \mathrm{Cl}_{2}$, and dried in vacuo $\left(R_{f}=0.13,15 \% \mathrm{MeOH}\right.$ in $\left.\mathrm{CH}_{2} \mathrm{Cl}_{2}\right)$ to give $41(32.8 \mathrm{~g}$, $83 \%)$ as a white solid. ${ }^{1} \mathrm{H}$ NMR $\left(600 \mathrm{MHz}, \mathrm{DMSO}-d_{6}\right) \delta 10.89$ (br s, $1 \mathrm{H}, \mathrm{NH}-1), 8.10$ (s, 1H, H-8), 7.36-7.01 (m, 10H, $2 \times \mathrm{Ar} \mathrm{H}-\mathrm{Bn})$, 6.67 (br s, $2 \mathrm{H}, \mathrm{NH}_{2}-2$ ), 4.51 (dd, $J=37.1,12.0 \mathrm{~Hz}, 2 \mathrm{H}, \mathrm{CH}_{2}-6^{\prime} \mathrm{Bn}$ ), 4.32 (dd, $J=31.5,11.8 \mathrm{~Hz}, 2 \mathrm{H}, \mathrm{CH}_{2}-4^{\prime} \mathrm{Bn}$ ), 4.19-4.15 (m, $2 \mathrm{H}, \mathrm{H}-2^{\prime}$ and $\left.\mathrm{H}-3^{\prime}\right), 4.12-4.08\left(\mathrm{~m}, 2 \mathrm{H}, \mathrm{H}-1^{\prime}{ }_{\mathrm{eq}}\right.$ and $\left.\mathrm{H}-5^{\prime}\right), 4.01$ (dd, $J=12.4$, $\left.3.2 \mathrm{~Hz}, 1 \mathrm{H}, \mathrm{H}-1^{\prime}{ }_{\mathrm{ax}}\right), 3.77\left(\mathrm{dd}, J=10.2,7.4 \mathrm{~Hz}, 1 \mathrm{H}, \mathrm{H}-6^{\prime}\right), 3.61(\mathrm{dd}, J$ $\left.=10.5,4.8 \mathrm{~Hz}, 1 \mathrm{H}, \mathrm{H}-6^{\prime \prime}\right), 3.45\left(\mathrm{t}, J=3.6 \mathrm{~Hz}, 1 \mathrm{H}, \mathrm{H}-4^{\prime}\right) ;{ }^{13} \mathrm{C}$ NMR $\left(150 \mathrm{MHz}, \mathrm{DMSO}-d_{6}\right) \delta 156.0$ (C-6), 154.0 (C-2), 150.9 (C-4), 138.4, 138.1 ( $2 \times$ ipso C-Bn), 137.1 (C-8), 128.3, 128.3, 128.1, 128.0, 127.7, 127.6, 127.5, 127.4 (Ar C-Bn), 113.7 (C-5), 77.0 (C-4'), 73.7 (C-5'), $72.4\left(\mathrm{CH}_{2}-6^{\prime} \mathrm{Bn}\right), 72.2\left(\mathrm{CH}_{2}-4^{\prime} \mathrm{Bn}\right), 68.1\left(\mathrm{C}-6^{\prime}\right), 64.8\left(\mathrm{C}-3^{\prime}\right)$, $63.8\left(\mathrm{C}-1^{\prime}\right), 53.3\left(\mathrm{C}-2^{\prime}\right)$; HRMS (ESI-TOF) $m / z:[\mathrm{M}+\mathrm{H}]^{+}$calcd for $\mathrm{C}_{25} \mathrm{H}_{27} \mathrm{~N}_{5} \mathrm{O}_{5}$, 478.2085; found, 478.2077.

$1^{\prime}, 5^{\prime}$-Anhydro-4', 6' -di-O-benzyl-2' -deoxy-2' -( $N^{2}$-iso-butyrylguanin-9-yl)-D-allo-hexitol (42). A synthetic protocol similar to that used for the synthesis of $\mathbf{3 3}$ was employed for the synthesis of $\mathbf{4 2}$, starting from 41 (32.8 g, $68.69 \mathrm{mmol})$, TMSCl $(34.9 \mathrm{~mL}, 274.76$ $\mathrm{mmol})$ in anhydrous pyridine $(500 \mathrm{~mL})$; isobutyric anhydride $(47.8$ $\mathrm{mL}, 288.5 \mathrm{mmol}$ ) in a second step; triethylamine trihydrofluoride $(16.8 \mathrm{~mL}, 103.03 \mathrm{mmol})$ in anhydrous THF $(400 \mathrm{~mL})$ in a third step; and $\mathrm{N} \mathrm{NH}_{3}$ in EtOH $(300 \mathrm{~mL})$ in a fourth step to obtain $42(31.6 \mathrm{~g}$, $84 \%$ over four steps $)$ as a white semisolid $\left(R_{f}=0.30,10 \% \mathrm{MeOH}\right.$ in $\mathrm{CH}_{2} \mathrm{Cl}_{2}$; column chromatography gradient $\mathrm{CH}_{2} \mathrm{Cl}_{2} / \mathrm{MeOH}, 100: 0$, v/ v; 99:1, v/v; 39:1, v/v). Mp $201{ }^{\circ} \mathrm{C} .{ }^{1} \mathrm{H} \operatorname{NMR}\left(500 \mathrm{MHz}, \mathrm{CDCl}_{3}\right) \delta$ 12.48 (br s, $1 \mathrm{H}, \mathrm{NH}-1$ ), 11.00 (br s, $1 \mathrm{H}, \mathrm{NH}-2$ ), 8.35 (s, $1 \mathrm{H}, \mathrm{H}-8$ ), 7.31-6.86 (m, 10H, $2 \times \mathrm{Ar} H-\mathrm{Bn}), 6.07$ (br s, $\left.1 \mathrm{H}, \mathrm{OH}-3^{\prime}\right), 4.52$ (dd, $\left.J=53.6,12.0 \mathrm{~Hz}, 2 \mathrm{H}, \mathrm{CH}_{2}-6^{\prime} \mathrm{Bn}\right), 4.44-4.40\left(\mathrm{~m}, 3 \mathrm{H},{\mathrm{H}-1^{\prime}}_{\text {eq }}, \mathrm{H}-2^{\prime}\right.$, and $\left.\mathrm{H}-3^{\prime}\right), 4.26-4.23\left(\mathrm{~m}, 2 \mathrm{H}\right.$, and $\left.\mathrm{H}-5^{\prime}\right), 4.18(\mathrm{~d}, J=11.8 \mathrm{~Hz}, 1 \mathrm{H}, \mathrm{H}-$ $\left.1^{\prime}{ }_{\mathrm{ax}}\right), 4.14\left(\mathrm{~s}, 2 \mathrm{H}, \mathrm{CH}_{2}-4^{\prime} \mathrm{Bn}\right), 3.78\left(\mathrm{dd}, J=10.0,7.7 \mathrm{~Hz}, 1 \mathrm{H}, \mathrm{H}-6^{\prime}\right)$, $3.51-3.48\left(\mathrm{~m}, 2 \mathrm{H}, \mathrm{H}-6^{\prime \prime}\right.$ and $\left.\mathrm{H}-4^{\prime}\right), 2.92(\mathrm{p}, J=6.8 \mathrm{~Hz}, 1 \mathrm{H}$, $\left.\mathrm{CH}-{ }^{i} \mathrm{Pr}\right), 1.27\left(\mathrm{t}, J=6.7 \mathrm{~Hz}, 6 \mathrm{H}, 2 \times \mathrm{CH}_{3}-{ }^{i} \mathrm{Pr}\right) ;{ }^{13} \mathrm{C}$ NMR $(125$ $\left.\mathrm{MHz}, \mathrm{CDCl}_{3}\right) \delta 180.4\left(\mathrm{CO}-{ }^{i} \mathrm{Bu}\right), 156.1$ (C-6), 149.5 (C-2), 148.0 (C-4), 140.7 (C-8), 137.9, 137.5 ( $2 \times$ ipso C-Bn), 128.4, 128.1, 127.7, 127.6, 127.5, 127.4 (Ar C-Bn), 118.9 (C-5), $76.0\left(\mathrm{C}-4^{\prime}\right), 74.4\left(\mathrm{C}-5^{\prime}\right)$, $73.3\left(\mathrm{CH}_{2}-6^{\prime} \mathrm{Bn}\right), 72.4\left(\mathrm{CH}_{2}-4^{\prime} \mathrm{Bn}\right), 70.0\left(\mathrm{C}-6^{\prime}\right), 64.9\left(\mathrm{C}-3^{\prime}\right), 64.2$ $\left(\mathrm{C}-1^{\prime}\right), 53.5\left(\mathrm{C}-2^{\prime}\right), 36.1\left(\mathrm{CH}-{ }^{i} \mathrm{Pr}\right), 19.1,19.0\left(2 \times \mathrm{CH}_{3}-{ }^{i} \mathrm{Pr}\right)$; HRMS (ESI-TOF) $m / z:[\mathrm{M}+\mathrm{H}]^{+}$calcd for $\mathrm{C}_{29} \mathrm{H}_{33} \mathrm{~N}_{5} \mathrm{O}_{6}, 548.2503$; found, 548.2513 .

$1^{\prime}, 5^{\prime}$-Anhydro-4', 6' -di-O-benzyl-3', 2' -dideoxy-2'-( $N^{2}$-isobutyrylguanin-9-yl)-D-allo-hexitol (44). A slightly modified synthetic protocol from that used for the synthesis of 7 was employed for the synthesis of 43 , starting from $42(31.6 \mathrm{~g}, 57.7 \mathrm{mmol})$, aq $\mathrm{NaOH}(50 \%$ w/v; $22.6 \mathrm{~mL}), \mathrm{CS}_{2}(33.9 \mathrm{~mL})$, and 3-bromo propionitrile $(33.9 \mathrm{~mL})$ in DMSO $(700 \mathrm{~mL})$ in a first step to obtain $1^{\prime}, 5^{\prime}$-anhydro-4', $6^{\prime}$-di-O-benzyl-3' -(2-cyanoethyl)carbonodithioate$2^{\prime}$-deoxy-2'-( $N^{2}$-iso-butyrylguanin-9-yl)-D-allo-hexitol xanthate 43 $(31.22 \mathrm{~g}, 80 \%)$ as an off-white semisolid $\left(R_{f}=0.51,10 \% \mathrm{MeOH}\right.$ in $\mathrm{CH}_{2} \mathrm{Cl}_{2}$; column chromatography gradient $\mathrm{CH}_{2} \mathrm{Cl}_{2} / \mathrm{MeOH}, 100: 0$, v/ v; 99:1, v/v; 49:1, v/v). ${ }^{1} \mathrm{H}$ NMR $\left(600 \mathrm{MHz}, \mathrm{CDCl}_{3}\right) \delta 11.97(\mathrm{br} \mathrm{s}$, $1 \mathrm{H}, \mathrm{NH}-1), 8.72$ (br s, $1 \mathrm{H}, \mathrm{NH}-2), 8.10$ (s, $1 \mathrm{H}, \mathrm{H}-8), 7.37-7.00$ (m, $10 \mathrm{H}, 2 \times \mathrm{Ar} H-\mathrm{Bn}$ ), 6.17 (br s, $\left.1 \mathrm{H}, \mathrm{H}-3^{\prime}\right), 4.57-4.45\left(\mathrm{~m}, 3 \mathrm{H}, \mathrm{CH}_{2^{-}}\right.$ $6^{\prime} \mathrm{Bn}$ and $\left.\mathrm{H}-2^{\prime}\right), 4.43-4.40\left(\mathrm{~m}, 1 \mathrm{H}, \mathrm{H}-1^{\prime}{ }_{\mathrm{eq}}\right), 4.34(\mathrm{dd}, J=17.2,12.0$ $\mathrm{Hz}, 2 \mathrm{H}, \mathrm{CH}_{2}-4^{\prime} \mathrm{Bn}$, and $\left.\mathrm{H}-3^{\prime}\right), 4.21\left(\mathrm{dd}, J=13.0,3.6 \mathrm{~Hz}, 1 \mathrm{H}, \mathrm{H}-1^{\prime}{ }_{\mathrm{ax}}\right)$,
3.97-3.95 (m, 1H, H-5'), $3.78\left(\mathrm{dd}, J=10.1,6.4 \mathrm{~Hz}, 1 \mathrm{H}, \mathrm{H}-6^{\prime} 3.67\right.$ (t, $\left.J=2.8 \mathrm{~Hz}, 1 \mathrm{H}, \mathrm{H}-4^{\prime}\right), 3.60-3.33\left(\mathrm{~m}, 3 \mathrm{H}, \mathrm{SCH}_{2} \mathrm{CH}_{2} \mathrm{CN}\right.$ and $\left.\mathrm{H}-6^{\prime \prime}\right)$, 2.91-2.77 (m, $\left.2 \mathrm{H}, \mathrm{SCH}_{2} \mathrm{CH}_{2} \mathrm{CN}\right), 2.63\left(\mathrm{p}, J=6.8 \mathrm{~Hz}, 1 \mathrm{H}, \mathrm{CH}-{ }^{i} \mathrm{Pr}\right)$, 1.27-1.24 (m, 6H, $\left.2 \times \mathrm{CH}_{3}-{ }^{i} \mathrm{Pr}\right) ;{ }^{13} \mathrm{C}$ NMR $\left(150 \mathrm{MHz}, \mathrm{CDCl}_{3}\right) \delta$ $211.7\left(\mathrm{OCS}_{2}\right), 178.5\left(\mathrm{CO}-{ }^{i} \mathrm{Bu}\right), 155.5$ (C-6), 148.1 (C-2), 147.4 (C4), 139.1 (C-8), 137.5, 136.7 ( $2 \times$ ipso C-Bn), 128.5, 128.3, 128.1, 128.0, 128.0, 127.9 (Ar C-Bn), $120.2(\mathrm{CN}), 117.3$ (C-5), 75.7 (C-3'), $75.3\left(\mathrm{C}-5^{\prime}\right), 73.8\left(\mathrm{CH}_{2}-6^{\prime} \mathrm{Bn}\right), 72.7\left(\mathrm{CH}_{2}-4^{\prime} \mathrm{Bn}\right), 71.7\left(\mathrm{C}-4^{\prime}\right), 69.6$ $\left(\mathrm{C}-6^{\prime}\right), 65.9\left(\mathrm{C}-1^{\prime}\right), \quad 50.1 \quad\left(\mathrm{C}-2^{\prime}\right), 40.9\left(\mathrm{CH}-{ }^{i} \mathrm{Pr}\right), 31.4$ $\left(\mathrm{SCH}_{2} \mathrm{CH}_{2} \mathrm{CN}\right), 19.0,18.9\left(2 \times \mathrm{CH}_{3}-{ }^{i} \mathrm{Pr}\right), 17.8\left(\mathrm{SCH}_{2} \mathrm{CH}_{2} \mathrm{CN}\right)$; HRMS (ESI-TOF) $m / z:[\mathrm{M}+\mathrm{H}]^{+}$calcd for $\mathrm{C}_{33} \mathrm{H}_{36} \mathrm{~N}_{6} \mathrm{O}_{6} \mathrm{~S}_{2}$, 677.2210; found, 677.2217.

A Barton-McCombie condition similar to that used for the synthesis of 8 was employed for the synthesis of 44, starting from 43 $(31.22 \mathrm{~g}, 46.17 \mathrm{mmol}), n \mathrm{Bu}_{3} \mathrm{SnH}(33.1 \mathrm{~mL}, 122.8 \mathrm{mmol})$, and AIBN $(1.52 \mathrm{~g}, 9.23 \mathrm{mmol})$ in anhydrous toluene $(620 \mathrm{~mL})$ to obtain 44 $(20.13 \mathrm{~g}, 82 \%)$ as a white solid $\left(R_{f}=0.39,10 \% \mathrm{MeOH}\right.$ in $\mathrm{CH}_{2} \mathrm{Cl}_{2}$; column chromatography gradient $\mathrm{CH}_{2} \mathrm{Cl}_{2} / \mathrm{MeOH}, 99: 1$, v/v; 49:1, v/ v; 39:1, v/v). $\mathrm{Mp} 78^{\circ} \mathrm{C} .{ }^{1} \mathrm{H}$ NMR $\left(600 \mathrm{MHz}, \mathrm{CDCl}_{3}\right) \delta 12.14$ (br s, $1 \mathrm{H}, \mathrm{NH}-1$ ), 9.87 (br s, $1 \mathrm{H}, \mathrm{NH}-2), 8.35$ (s, $1 \mathrm{H}, \mathrm{H}-8), 7.32-6.94(\mathrm{~m}$, $10 \mathrm{H}, 2 \times \mathrm{Ar} H-\mathrm{Bn}), 4.50$ (dd, $J=61.8,11.9 \mathrm{~Hz}, 2 \mathrm{H}, \mathrm{CH}_{2}-6^{\prime} \mathrm{Bn}$ ), $4.42-4.40\left(\mathrm{~m}, 1 \mathrm{H}, \mathrm{H}-2^{\prime}\right), 4.25\left(\mathrm{~d}, J=12.9 \mathrm{~Hz}, 1 \mathrm{H}, \mathrm{H}-1^{\prime}{ }_{\mathrm{eq}}\right), 4.06(\mathrm{dd}$, $\left.J=39.8,11.9 \mathrm{~Hz}, 2 \mathrm{H}, \mathrm{CH}_{2}-4^{\prime} \mathrm{Bn}\right), 3.94(\mathrm{dd}, J=39.8,11.9 \mathrm{~Hz}, 1 \mathrm{H}, \mathrm{H}-$ $\left.1^{\prime}{ }_{\mathrm{ax}}\right), 3.76-3.71\left(\mathrm{~m}, 2 \mathrm{H}, \mathrm{H}-6^{\prime}\right.$ and $\left.\mathrm{H}-5^{\prime}\right), 3.57-3.54\left(\mathrm{~m}, 2 \mathrm{H}, \mathrm{H}-6^{\prime \prime}\right.$ and $\left.\mathrm{H}-4^{\prime}\right), 2.89-2.83\left(\mathrm{~m}, 1 \mathrm{H}, \mathrm{CH}-{ }^{i} \mathrm{Pr}\right), 2.44-2.40\left(\mathrm{~m}, 1 \mathrm{H}, \mathrm{H}-3^{\prime}{ }_{\mathrm{eq}}\right)$, $1.90-1.87\left(\mathrm{~m}, 1 \mathrm{H}, \mathrm{H}-3^{\prime}{ }_{\mathrm{ax}}\right), 1.11,1.10(2 \mathrm{~d}, J=6.8 \mathrm{~Hz}, 6 \mathrm{H}, 2 \times$ $\left.\mathrm{CH}_{3}-{ }^{i} \mathrm{Pr}\right) ;{ }^{13} \mathrm{C}$ NMR $\left(150 \mathrm{MHz}, \mathrm{CDCl}_{3}\right) \delta 179.3\left(\mathrm{CO}-{ }^{i} \mathrm{Bu}\right), 155.9$ (C-6), 148.4 (C-2), 147.4 (C-4), 140.1 (C-8), 137.8, 137.3 (2 $\times$ ipso C-Bn), 128.4, 128.2, 127.7, 127.7, 127.6 (Ar C-Bn), 119.9 (C-5), 78.7 $\left(\mathrm{C}-5^{\prime}\right), 73.5\left(\mathrm{CH}_{2}-6^{\prime} \mathrm{Bn}\right), 71.1\left(\mathrm{CH}_{2}-4^{\prime} \mathrm{Bn}\right), 70.4\left(\mathrm{C}-4^{\prime}\right), 69.9\left(\mathrm{C}-6^{\prime}\right)$, $69.5\left(\mathrm{C}-1^{\prime}\right), 47.0\left(\mathrm{C}-2^{\prime}\right), 36.1\left(\mathrm{CH}-{ }^{i} \mathrm{Pr}\right), 29.5\left(\mathrm{C}-3^{\prime}\right), 19.1,19.0(2 \times$ $\mathrm{CH}_{3}-{ }^{i} \mathrm{Pr}$ ); HRMS (ESI-TOF) $\mathrm{m} / z$ : $[\mathrm{M}+\mathrm{H}]^{+}$calcd for $\mathrm{C}_{29} \mathrm{H}_{33} \mathrm{~N}_{5} \mathrm{O}_{5}$, 532.2554; found, 532.2559.

$1^{\prime}, 5^{\prime}$-Anhydro-3',2'-dideoxy-2' -( $N^{2}$-iso-butyrylguanin-9-yl)D-allo-hexitol (45). To a stirred solution of $44(20.13 \mathrm{~g}, 37.87$ mmol) in anhydrous $\mathrm{CH}_{2} \mathrm{Cl}_{2}(400 \mathrm{~mL})$ was added $1 \mathrm{M} \mathrm{BCl}_{3}$ in $\mathrm{CH}_{2} \mathrm{Cl}_{2}(151.5 \mathrm{~mL}, 151.5 \mathrm{mmol})$ dropwise at $-78{ }^{\circ} \mathrm{C}$ under argon. The reaction mixture then was slowly warmed to room temperature and left stirring for $3 \mathrm{~h}$ at same temperature. Upon completion, the reaction mixture was again cooled to $-40{ }^{\circ} \mathrm{C}$ and quenched with methanol $(300 \mathrm{~mL})$. Volatiles were concentrated in reduced pressure, and the resulting crude residue was purified by column chromatography on silica gel $\left(R_{f}=0.17,15 \% \mathrm{MeOH}\right.$ in $\mathrm{CH}_{2} \mathrm{Cl}_{2}$; gradient $\left.\mathrm{CH}_{2} \mathrm{Cl}_{2} / \mathrm{MeOH}, 24: 1, \mathrm{v} / \mathrm{v} ; 9: 1, \mathrm{v} / \mathrm{v} ; 6: 1, \mathrm{v} / \mathrm{v}\right)$ to give $45(11.84 \mathrm{~g}$, $89 \%)$ as a white solid. Mp $215^{\circ} \mathrm{C} .{ }^{1} \mathrm{H}$ NMR (600 MHz, DMSO- $\left.d_{6}\right) \delta$ 12.01 (br s, $1 \mathrm{H}, \mathrm{NH}-1$ ), 11.70 (br s, $1 \mathrm{H}, \mathrm{NH}-2$ ), 8.31 (s, $1 \mathrm{H}, \mathrm{H}-8)$, $4.83\left(\mathrm{~d}, J=3.4 \mathrm{~Hz}, 1 \mathrm{H}, \mathrm{OH}-4^{\prime}\right), 4.72\left(\mathrm{t}, J=5.9 \mathrm{~Hz}, 1 \mathrm{H}, \mathrm{OH}-6^{\prime}\right)$, $4.43-4.41\left(\mathrm{~m}, 1 \mathrm{H}, \mathrm{H}-2^{\prime}\right), 4.13\left(\mathrm{~d}, J=12.5 \mathrm{~Hz}, 1 \mathrm{H}, \mathrm{H}-1^{\prime}{ }_{\mathrm{eq}}\right), 3.91$ (dd, $\left.J=12.6,3.0 \mathrm{~Hz}, 1 \mathrm{H}, \mathrm{H}-1^{\prime}{ }_{\mathrm{ax}}\right), 3.79-3.77\left(\mathrm{~m}, 1 \mathrm{H}, \mathrm{H}-4^{\prime}\right), 3.63-3.51$ (m, $2 \mathrm{H}, \mathrm{H}-6^{\prime}$ and $\left.\mathrm{H}-6^{\prime \prime}\right), 3.50-3.48\left(\mathrm{~m}, 1 \mathrm{H}, \mathrm{H}-5^{\prime}\right), 2.79(\mathrm{p}, J=6.8$ $\left.\mathrm{Hz}, 1 \mathrm{H}, \mathrm{CH}-{ }^{i} \mathrm{Pr}\right), 2.20-2.17\left(\mathrm{~m}, 1 \mathrm{H}, \mathrm{H}-3^{\prime}{ }_{\mathrm{eq}}\right), 2.14-2.10(\mathrm{~m}, 1 \mathrm{H}, \mathrm{H}-$ $\left.3^{\prime}{ }_{\mathrm{ax}}\right), 1.25\left(\mathrm{~d}, J=6.9 \mathrm{~Hz}, 6 \mathrm{H}, 2 \times \mathrm{CH}_{3}-{ }^{i} \mathrm{Pr}\right) ;{ }^{13} \mathrm{C} \mathrm{NMR}(150 \mathrm{MHz}$, DMSO- $\left.d_{6}\right) \delta 180.1\left(\mathrm{CO}-{ }^{i} \mathrm{Bu}\right), 155.1(\mathrm{C}-6), 148.5(\mathrm{C}-2), 147.6(\mathrm{C}-$ 4), 140.1 (C-8), 119.3 (C-5), $80.2\left(\mathrm{C}-5^{\prime}\right), 68.6\left(\mathrm{C}-1^{\prime}\right), 62.3$ (C-4'), $60.5\left(\mathrm{C}-6^{\prime}\right), 47.4\left(\mathrm{C}-2^{\prime}\right), 34.8\left(\mathrm{CH}-{ }^{i} \mathrm{Pr}\right), 33.9\left(\mathrm{C}-3^{\prime}\right), 19.0(2 \times$ $\mathrm{CH}_{3}-{ }^{i} \mathrm{Pr}$ ); HRMS (ESI-TOF) $\mathrm{m} / z$ : $[\mathrm{M}+\mathrm{H}]^{+}$calcd for $\mathrm{C}_{15} \mathrm{H}_{21} \mathrm{~N}_{5} \mathrm{O}_{5}$, 352.1615; found, 352.1612 .

$1^{\prime}, 5^{\prime}$-Anhydro-6'-O-tert-butyldiphenylsilyl-3',2' -dideoxy-2' $\left(N^{2}\right.$-iso-butyrylguanin-9-yl)-D-allo-hexitol (46). A synthetic protocol similar to that used for the synthesis of $\mathbf{1 0}$ was employed for the synthesis of 46, starting from $45(11.84 \mathrm{~g}, 33.70 \mathrm{mmol})$ and TBDPSCl $(17.5 \mathrm{~mL}, 67.39 \mathrm{mmol})$ in anhydrous pyridine $(230 \mathrm{~mL})$ to obtain $46(14.91 \mathrm{~g}, 75 \%)$ as a white foam $\left(R_{f}=0.46,10 \% \mathrm{MeOH}\right.$ in $\mathrm{CH}_{2} \mathrm{Cl}_{2}$; column chromatography gradient $\mathrm{CH}_{2} \mathrm{Cl}_{2} / \mathrm{MeOH}$, 99:1, v/ v; 49:1, v/v; 97:3, v/v). $\mathrm{Mp} 166^{\circ} \mathrm{C} .{ }^{1} \mathrm{H} \operatorname{NMR}\left(500 \mathrm{MHz}, \mathrm{CD}_{3} \mathrm{OD}\right) \delta$ 8.40 (s, 1H, H-8), 7.73-7.38 (m, 10H, Ar H-TBDPS), 4.54-4.52 (m, $\left.1 \mathrm{H}, \mathrm{H}-2^{\prime}\right), 4.29$ (d, $J=13.0 \mathrm{~Hz}, 1 \mathrm{H}, \mathrm{H}-1^{\prime}{ }_{\mathrm{eq}}$ ), 4.00 (dd, $J=13.0,3.0$ $\mathrm{Hz}, 1 \mathrm{H}, \mathrm{H}-\mathrm{1}^{\prime}{ }_{\mathrm{ax}}$ ), 3.91-3.90 (m, 3H, H-4', H-6 ${ }^{\prime}$, and $\left.\mathrm{H}-6^{\prime \prime}\right)$, 3.71$3.68\left(\mathrm{~m}, 1 \mathrm{H}, \mathrm{H}-5^{\prime}\right), 2.69\left(\mathrm{~h}, J=6.9 \mathrm{~Hz}, 1 \mathrm{H}, \mathrm{CH}-{ }^{i} \mathrm{Pr}\right), 2.31-2.27(\mathrm{~m}$, $1 \mathrm{H}, \mathrm{H}-3^{\prime}{ }_{\text {eq }}$ ), $2.22-2.18\left(\mathrm{~m}, 1 \mathrm{H}, \mathrm{H}-3^{\prime}{ }_{\mathrm{ax}}\right), 1.21$ (d, $J=6.9 \mathrm{~Hz}, 6 \mathrm{H}, 2 \times$ 
$\left.\mathrm{CH}_{3}{ }^{i} \mathrm{Pr}\right), 1.04\left(\mathrm{~s}, 9 \mathrm{H}, 3 \times \mathrm{CH}_{3}-{ }^{t} \mathrm{Bu}\right) ;{ }^{13} \mathrm{C}$ NMR $(125 \mathrm{MHz}$, $\left.\mathrm{CD}_{3} \mathrm{OD}\right) \delta 181.6\left(\mathrm{CO}-{ }^{i} \mathrm{Bu}\right), 157.5$ (C-6), 150.5 (C-2), $149.2(\mathrm{C}-4)$, 142.2 (C-8), 136.8, 136.7 (Ar C-TBDPS), 134.7, 134.6 ( $2 \times$ ipso CBn), 130.9, 128.8, 128.7 (Ar C-TBDPS), 119.9 (C-5), 81.7 (C-5'), $70.6\left(\mathrm{C}-1^{\prime}\right), 65.6\left(\mathrm{C}-6^{\prime}\right), 64.6\left(\mathrm{C}-4^{\prime}\right), 49.1\left(\mathrm{C}-2^{\prime}\right), 36.9\left(\mathrm{CH}-{ }^{i} \mathrm{Pr}\right)$, $35.2\left(\mathrm{C}-3^{\prime}\right), 27.3\left(3 \times \mathrm{CH}_{3}-{ }^{t} \mathrm{Bu}\right), 20.0\left(1 \mathrm{C}-{ }^{t} \mathrm{Bu}\right), 19.4,19.3(2 \times$ $\mathrm{CH}_{3}-{ }^{i} \mathrm{Pr}$ ); HRMS (ESI-TOF) $\mathrm{m} / z:[\mathrm{M}+\mathrm{H}]^{+}$calcd for $\mathrm{C}_{31} \mathrm{H}_{39} \mathrm{~N}_{5} \mathrm{O}_{5} \mathrm{Si}$, 590.2793; found, 590.2802.

1 ',5'-Anhydro-6'-O-tert-butyldiphenylsilyl-4'-O-mesyl$3^{\prime}, 2^{\prime}$-dideoxy-2' - $\left(N^{2}\right.$-iso-butyrylguanin-9-yl)-D-allo-hexitol (47). A synthetic protocol similar to that used for the synthesis of 11 was employed for the synthesis of 47 , starting from 46 (14.91 g, 25.28 $\mathrm{mmol})$ and $\mathrm{MsCl}(5.87 \mathrm{~mL}, 75.84 \mathrm{mmol})$ in anhydrous pyridine $(250$ $\mathrm{mL})$ to obtain $35(14.01 \mathrm{~g}, 83 \%)$ as a white foam $\left(R_{f}=0.60,10 \%\right.$ $\mathrm{MeOH}$ in $\mathrm{CH}_{2} \mathrm{Cl}_{2}$; column chromatography gradient $\mathrm{CH}_{2} \mathrm{Cl}_{2} /$ $\mathrm{MeOH}, 100: 0$, v/v; 99:1, v/v; 97:3, v/v). Mp $194{ }^{\circ} \mathrm{C} .{ }^{1} \mathrm{H}$ NMR $\left(500 \mathrm{MHz}, \mathrm{CDCl}_{3}\right) \delta 12.02($ br s, $1 \mathrm{H}, \mathrm{NH}-1), 8.78$ (br s, $\left.1 \mathrm{H}, \mathrm{NH}-2\right)$, 8.07 (s, 1H, H-8), 7.68-7.38 (m, 10H, Ar H-TBDPS), 4.98 (t, $J=3.0$ $\left.\mathrm{Hz}, 1 \mathrm{H}, \mathrm{H}-4^{\prime}\right), 4.45-4.40\left(\mathrm{~m}, 1 \mathrm{H}, \mathrm{H}-2^{\prime}\right.$ and $\left.\mathrm{H}^{-1^{\prime}}{ }_{\mathrm{eq}}\right), 3.99(\mathrm{dd}, J=$ 13.1, $\left.2.9 \mathrm{~Hz}, 1 \mathrm{H}, \mathrm{H}-\mathrm{1}_{\mathrm{ax}}{ }^{\prime}\right), 3.81-3.75\left(\mathrm{~m}, 2 \mathrm{H}, \mathrm{H}-6^{\prime}\right.$ and $\left.\mathrm{H}-6^{\prime \prime}\right)$, 3.74$3.70\left(\mathrm{~m}, 1 \mathrm{H}, \mathrm{H}-5^{\prime}\right), 2.78-2.73\left(\mathrm{~m}, 1 \mathrm{H}, \mathrm{H}-3^{\prime}{ }_{\mathrm{eq}}\right), 2.69(\mathrm{~h}, J=6.9 \mathrm{~Hz}$, $1 \mathrm{H}, \mathrm{CH}-{ }^{\mathrm{i}} \mathrm{Pr}$ ), 2.53 (s, $\left.3 \mathrm{H}, \mathrm{CH}_{3}-\mathrm{Ms}\right), 2.16-2.11\left(\mathrm{~m}, 1 \mathrm{H}, \mathrm{H}-3^{\prime}{ }_{\mathrm{ax}}\right)$, $1.27,1.26\left(2 \mathrm{~d}, J=6.9 \mathrm{~Hz}, 6 \mathrm{H}, 2 \times \mathrm{CH}_{3}-{ }^{i} \mathrm{Pr}\right), 1.06(\mathrm{~s}, 9 \mathrm{H}, 3 \times$ $\left.\mathrm{CH}_{3}-{ }^{t} \mathrm{Bu}\right) ;{ }^{13} \mathrm{C}$ NMR $\left(150 \mathrm{MHz}, \mathrm{CDCl}_{3}\right) \delta 178.4\left(\mathrm{CO}-{ }^{i} \mathrm{Bu}\right), 155.7$ (C-6), 148.3 (C-2), 147.2 (C-4), 138.8 (C-8), 135.6, 135.5 (Ar CTBDPS), 133.0, 132.8 ( $2 \times$ ipso C-Bn $), 130.0,129.9,127.8,127.7(\mathrm{Ar}$ C-TBDPS), 120.3 (C-5), 78.8 (C-5'), 70.6 (C-4'), 69.1 (C-1'), 62.1

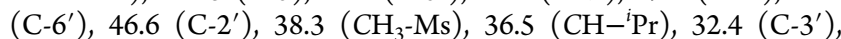
$26.8\left(3 \times \mathrm{CH}_{3}-{ }^{t} \mathrm{Bu}\right), 19.1\left(1 \mathrm{C}-{ }^{t} \mathrm{Bu}\right), 19.0,18.9\left(2 \times \mathrm{CH}_{3}-{ }^{i} \mathrm{Pr}\right)$; HRMS (ESI-TOF) $m / z:[\mathrm{M}+\mathrm{H}]^{+}$calcd for $\mathrm{C}_{32} \mathrm{H}_{41} \mathrm{~N}_{5} \mathrm{O}_{7} \mathrm{SSi}$, 668.2568; found, 668.2569.

$1^{\prime}, 5^{\prime}$-Anhydro-6'-O-tert-butyldiphenylsilyl-4'-amino-3', 2'dideoxy-2'-( $N^{2}$-iso-butyrylguanin-9-yl)-D-altro-hexitol (50). A synthetic protocol similar to that used for the synthesis of $\mathbf{3 6}$ and 37 was employed for the synthesis of $\mathbf{4 8}$ and 49 , starting from 47 (14.01 g, $20.98 \mathrm{mmol})$ and sodium azide $(6.82 \mathrm{~g}, 104.89 \mathrm{mmol})$ in anhydrous DMF $(220 \mathrm{~mL})$ in a first step; and TBDPSCl $(5.45 \mathrm{~mL}$, $20.98 \mathrm{mmol})$ in anhydrous pyridine $(220 \mathrm{~mL})$ in a second step to obtain a nonseparable mixture of $\mathbf{3 6}$ and $\mathbf{3 7}(10.9 \mathrm{~g})$ as a white foam $\left(R_{f}=0.65,10 \% \mathrm{MeOH}\right.$ in $\mathrm{CH}_{2} \mathrm{Cl}_{2}$; column chromatography gradient $\mathrm{CH}_{2} \mathrm{Cl}_{2} / \mathrm{MeOH}, 100: 0, \mathrm{v} / \mathrm{v} ; 99: 1, \mathrm{v} / \mathrm{v} ; 39: 1, \mathrm{v} / \mathrm{v}$ ). HRMS (ESI-TOF) $m / z:[\mathrm{M}+\mathrm{H}]^{+}$calcd for $\mathrm{C}_{31} \mathrm{H}_{38} \mathrm{~N}_{8} \mathrm{O}_{4} \mathrm{Si}, 615.2858$; found, 615.2833.

A synthetic protocol similar to that used for the synthesis of $\mathbf{3 8}$ was employed for the synthesis of 50, starting from a mixture of $\mathbf{3 6}$ and $\mathbf{3 7}$ $(10.9 \mathrm{~g}), 5$ drops of $\mathrm{AcOH}$, and $10 \% \mathrm{Pd} / \mathrm{C}$ Degussa type (2.18 g, 0.2 equiv w/w) in $\mathrm{MeOH}(980 \mathrm{~mL})$ to obtain $\mathbf{5 0}(3.70 \mathrm{~g}, 30 \%$ over two steps $)$ as a white semisolid $\left(R_{f}=0.42,10 \% \mathrm{MeOH}\right.$ in $\mathrm{CH}_{2} \mathrm{Cl}_{2}$; column chromatography gradient $\mathrm{CH}_{2} \mathrm{Cl}_{2} / \mathrm{MeOH}, 99: 1, \mathrm{v} / \mathrm{v} ; 49: 1$, v/ v; 24:1, v/v). ${ }^{1} \mathrm{H}$ NMR (500 MHz, $\left.\mathrm{CDCl}_{3}\right) \delta 8.20(\mathrm{~s}, 1 \mathrm{H}, \mathrm{H}-8)$, 7.70-7.37 (m, 10H, Ar H-TBDPS), 4.56 (br s, $\left.1 \mathrm{H}, \mathrm{H}-2^{\prime}\right), 4.28$ (d, $J=$ $\left.12.9 \mathrm{~Hz}, 1 \mathrm{H}, \mathrm{H}-1^{\prime}{ }_{\mathrm{eq}}\right), 3.95-3.85$ (m, 3H, H-1 ${ }^{\prime}{ }_{\mathrm{ax}}, \mathrm{H}-6^{\prime}$, and $\left.\mathrm{H}-6^{\prime \prime}\right)$, 3.19-3.16 (m, 1H, H-5'), 3.10-3.05 (m, 1H, H-4'), 2.66 (h, $J=6.9$ $\left.\mathrm{Hz}, 1 \mathrm{H}, \mathrm{CH}-{ }^{i} \mathrm{Pr}\right), 2.30-2.26\left(\mathrm{~m}, 1 \mathrm{H}, \mathrm{H}-3^{\prime}{ }_{\mathrm{eq}}\right), 1.75-1.69(\mathrm{~m}, 1 \mathrm{H}, \mathrm{H}-$ $\left.3^{\prime}{ }_{\mathrm{ax}}\right), 1.26,1.25\left(2 \mathrm{~d}, J=6.9 \mathrm{~Hz}, 6 \mathrm{H}, 2 \times \mathrm{CH}_{3}-\mathrm{Pr}\right), 1.07$ (s, 9H, $3 \times$ $\left.\mathrm{CH}_{3}-{ }^{t} \mathrm{Bu}\right) ;{ }^{13} \mathrm{C}$ NMR $\left(125 \mathrm{MHz}, \mathrm{CDCl}_{3}\right) \delta 178.4\left(\mathrm{CO}-{ }^{i} \mathrm{Bu}\right), 155.7$ (C-6), 148.1 (C-2), 147.2 (C-4), 138.7 (C-8), 135.6, 135.6 (Ar CTBDPS), 133.1, 132.9 ( $2 \times$ ipso C-Bn $), 129.9,129.9,127.8,127.8(\mathrm{Ar}$ C-TBDPS), 120.7 (C-5), 84.4 (C-5'), 69.1 (C-1'), 64.1 (C-6'), 50.2 $\left(\mathrm{C}-2^{\prime}\right), 43.7$ (C-4'), 37.1 (C-3'), $36.5\left(\mathrm{CH}-{ }^{i} \mathrm{Pr}\right), 26.9(3 \times$ $\left.\mathrm{CH}_{3}-{ }^{t} \mathrm{Bu}\right), 19.2\left(1 \mathrm{C}-{ }^{t} \mathrm{Bu}\right), 19.0,18.9\left(2 \times \mathrm{CH}_{3}-{ }^{i} \mathrm{Pr}\right)$; HRMS (ESI-TOF) $m / z:[\mathrm{M}+\mathrm{H}]^{+}$calcd for $\mathrm{C}_{31} \mathrm{H}_{40} \mathrm{~N}_{6} \mathrm{O}_{4} \mathrm{Si}$, 589.2953; found, 589.2962.

$1^{\prime}, 5^{\prime}$-Anhydro-6'-O-tert-butyldiphenylsilyl-4' -amino(trityl)$3^{\prime}, 2^{\prime}$-dideoxy-2' - $\left(N^{2}\right.$-iso-butyrylguanin-9-yl)-D-altro-hexitol (51). A synthetic protocol similar to that used for the synthesis of 39 was employed for the synthesis of 51, starting from $\mathbf{5 0}$ (3.70 g, 6.28 $\mathrm{mmol})$, trityl chloride $(5.25 \mathrm{~g}, 18.85 \mathrm{mmol})$, and anhydrous triethylamine $(8.73 \mathrm{~mL}, 62.8 \mathrm{mmol})$ in anhydrous $\mathrm{CH}_{2} \mathrm{Cl}_{2}(100$ $\mathrm{mL})$ to give $51(5.11 \mathrm{~g}, 98 \%)$ as a white semisolid $\left(R_{f}=0.47\right.$, EtOAc; column chromatography gradient hexane/EtOAc, 4:1, v/v; 3:2, v/v;
$1: 4, \mathrm{v} / \mathrm{v}) .{ }^{1} \mathrm{H}$ NMR $\left(500 \mathrm{MHz}, \mathrm{CDCl}_{3}\right) \delta 11.83$ (br s, $1 \mathrm{H}, \mathrm{NH}-1$ ), 7.99 (br s, 1H, NH-2), 7.61-7.57 (m, 4H, Ar H-Trt), 7.55 (s, 1H, H8), 7.45-7.10 (m, 21H, Ar H-TBDPS and Trt), 4.37-4.33 (m, $1 \mathrm{H}$, $\mathrm{H}-2^{\prime}$ ), 3.89 (dd, $J=12.3,4.2 \mathrm{~Hz}, 1 \mathrm{H}, \mathrm{H}_{-1}{ }^{\prime}{ }_{\mathrm{eq}}$ ), 3.80 (dd, $J=12.3,3.5$ $\left.\mathrm{Hz}, 1 \mathrm{H} \mathrm{H}-1^{\prime}{ }_{\mathrm{ax}}\right), 3.72\left(\mathrm{dd}, J=11.3,5.2 \mathrm{~Hz}, 1 \mathrm{H}, \mathrm{H}-6^{\prime}\right), 3.66(\mathrm{dd}, J=$ $\left.12.3,4.6 \mathrm{~Hz}, 1 \mathrm{H}, \mathrm{H}-6^{\prime \prime}\right), 3.31-3.28\left(\mathrm{~m}, 1 \mathrm{H}, \mathrm{H}-5^{\prime}\right), 2.66-2.62(\mathrm{~m}$, $\left.1 \mathrm{H}, \mathrm{H}-4^{\prime}\right), 2.58\left(\mathrm{~h}, J=6.8 \mathrm{~Hz}, 1 \mathrm{H}, \mathrm{CH}-{ }^{i} \mathrm{Pr}\right), 1.80-1.67(\mathrm{~m}, 3 \mathrm{H}, \mathrm{H}-$ $3^{\prime}{ }_{\text {eq }}, \mathrm{H}-3^{\prime}{ }_{\text {ax }}$, and $\left.\mathrm{NH}-4^{\prime}\right), 1.29,1.28(2 \mathrm{~d}, J=6.9 \mathrm{~Hz}, 6 \mathrm{H}, 2 \times$ $\left.\mathrm{CH}_{3}-{ }^{i} \mathrm{Pr}\right), 0.99\left(\mathrm{~s}, 9 \mathrm{H}, 3 \times \mathrm{CH}_{3}-{ }^{t} \mathrm{Bu}\right) ;{ }^{13} \mathrm{C} \mathrm{NMR}\left(150 \mathrm{MHz}, \mathrm{CDCl}_{3}\right)$ $\delta 177.9\left(\mathrm{CO}-{ }^{i} \mathrm{Bu}\right), 155.5(\mathrm{C}-6), 147.6(\mathrm{C}-2), 146.6(\mathrm{C}-4), 137.8(\mathrm{C}-$ 8), 135.6, 135.5, 133.0, 132.9, 129.8, 129.7, 128.6, 127.7, 126.4 ( $\mathrm{Ar} C$ TBDPS and Trt), 121.0 (C-5), 81.0 (C-5'), 70.7 (1C-Trt), 67.4 (C$\left.1^{\prime}\right), 64.3\left(\mathrm{C}-6^{\prime}\right), 49.2\left(\mathrm{C}-2^{\prime}\right), 48.6\left(\mathrm{C}-4^{\prime}\right), 36.6\left(\mathrm{CH}-{ }^{i} \mathrm{Pr}\right), 34.5(\mathrm{C}-$ $\left.3^{\prime}\right), 26.8\left(3 \times \mathrm{CH}_{3}-{ }^{t} \mathrm{Bu}\right), 19.1\left(1 \mathrm{C}-{ }^{t} \mathrm{Bu}\right), 19.0,18.9\left(2 \times \mathrm{CH}_{3}-{ }^{i} \mathrm{Pr}\right)$; HRMS (ESI-TOF) $m / z:[\mathrm{M}+\mathrm{H}]^{+}$calcd for $\mathrm{C}_{50} \mathrm{H}_{54} \mathrm{~N}_{6} \mathrm{O}_{4} \mathrm{Si}$, 831.4048; found, 831.4048.

$1^{\prime}, 5^{\prime}$-Anhydro-4'-amino(trityl)-3', 2' -dideoxy-2' -( $N^{2}$-iso-butyrylguanin-9-yl)-D-altro-hexitol (4). A synthetic protocol similar to that used for the synthesis of $\mathbf{3}$ was employed for the synthesis of $\mathbf{4}$, starting from $51(5.1 \mathrm{~g}, 6.14 \mathrm{mmol})$ and triethylamine trihydrofluoride $(4.5 \mathrm{~mL}, 27.61 \mathrm{mmol})$ in anhydrous THF $(120 \mathrm{~mL})$ at $46{ }^{\circ} \mathrm{C}$ for $60 \mathrm{~h}$ to obtain $\left(R_{f}=0.19,10 \% \mathrm{MeOH}\right.$ in EtOAc; column chromatography gradient $\mathrm{MeOH} / \mathrm{EtOAc}, 1: 99, \mathrm{v} / \mathrm{v} ; 1: 49, \mathrm{v} / \mathrm{v} ; 1: 19$, $\mathrm{v} / \mathrm{v})$ to give $\mathbf{5 0}(3.09 \mathrm{~g}, 85 \%)$ as a white semisolid. Mp $241{ }^{\circ} \mathrm{C} .{ }^{1} \mathrm{H}$ NMR (500 MHz, DMSO- $d_{6}$ ) $\delta 12.08$ (br s, $\left.1 \mathrm{H}, \mathrm{NH}-1\right), 11.59$ (br s, $1 \mathrm{H}, \mathrm{NH}-2), 7.77$ (s, 1H, H-8), 7.33-7.07 (m, 15H, Ar H-Trt), 4.74 $\left(\mathrm{t}, J=5.6 \mathrm{~Hz}, 1 \mathrm{H}, \mathrm{OH}-6^{\prime}\right), 4.36-4.33\left(\mathrm{~m}, 1 \mathrm{H}, \mathrm{H}-2^{\prime}\right), 3.99(\mathrm{~d}, J=$ $12.1 \mathrm{~Hz}, 1 \mathrm{H}, \mathrm{H}-1^{\prime}{ }_{\mathrm{eq}}$ ), 3.82 (dd, $\left.J=12.4,2.9 \mathrm{~Hz}, 1 \mathrm{H} \mathrm{H}-1^{\prime}{ }_{\mathrm{ax}}\right), 3.66-$ $3.53\left(\mathrm{~m}, 2 \mathrm{H}, \mathrm{H}-6^{\prime}\right.$ and $\left.\mathrm{H}-6^{\prime \prime}\right), 3.40-3.36\left(\mathrm{~m}, 1 \mathrm{H}, \mathrm{H}-5^{\prime}\right), 3.02(\mathrm{~d}, J=$ $\left.6.5 \mathrm{~Hz}, 1 \mathrm{H}, \mathrm{NH}-4^{\prime}\right), 2.79\left(\mathrm{~h}, J=6.9 \mathrm{~Hz}, 1 \mathrm{H}, \mathrm{CH}-{ }^{i} \mathrm{Pr}\right), 2.40-2.35(\mathrm{~m}$, $\left.1 \mathrm{H}, \mathrm{H}-4^{\prime}\right), 1.64-1.58\left(\mathrm{~m}, 1 \mathrm{H}, \mathrm{H}-3^{\prime}{ }_{\mathrm{eq}}\right), 1.46-1.42\left(\mathrm{~m}, 1 \mathrm{H}, \mathrm{H}-3^{\prime}{ }_{\mathrm{ax}}\right)$, $1.16,1.11\left(2 \mathrm{~d}, J=6.8 \mathrm{~Hz}, 6 \mathrm{H}, 2 \times \mathrm{CH}_{3}-{ }^{i} \mathrm{Pr}\right) ;{ }^{13} \mathrm{C}$ NMR $(125 \mathrm{MHz}$, DMSO- $\left.d_{6}\right) \delta 180.2\left(\mathrm{CO}-{ }^{i} \mathrm{Bu}\right), 155.0(\mathrm{C}-6), 148.2(\mathrm{C}-2), 147.6(\mathrm{C}-$ 4), 146.6 (ipso C-Trt), 138.2 (C-8), 128.5, 127.5, 126.2 (Ar C-Trt), 119.7 (C-5), 81.2 (C-5'), 70.1 (1C-Trt), $67.5\left(\mathrm{C}-1^{\prime}\right), 61.9$ (C-6'), $49.3\left(\mathrm{C}-2^{\prime}\right), 47.9\left(\mathrm{C}-4^{\prime}\right), 34.7\left(\mathrm{CH}-{ }^{i} \mathrm{Pr}\right), 34.4\left(\mathrm{C}-3^{\prime}\right), 19.0,18.9(2 \times$ $\mathrm{CH}_{3}-{ }^{i} \mathrm{Pr}$ ); HRMS (ESI-TOF) $\mathrm{m} / z$ : $[\mathrm{M}+\mathrm{H}]^{+}$calcd for $\mathrm{C}_{34} \mathrm{H}_{36} \mathrm{~N}_{6} \mathrm{O}_{4}$, 593.2871; found, 593.2873.

\section{ASSOCIATED CONTENT}

\section{Supporting Information}

The Supporting Information is available free of charge on the ACS Publications website at DOI: 10.1021/acs.joc.8b02444.

${ }^{1} \mathrm{H},{ }^{13} \mathrm{C}$, APT, COSY, HSQC, HMBC, and HRMS spectra of intermediates and final compounds (PDF)

\section{AUTHOR INFORMATION}

\section{Corresponding Author}

*E-mail: piet.herdewijn@kuleuven.be.

ORCID

Steven De Jonghe: 0000-0002-3872-6558

Piet Herdewijn: 0000-0003-3589-8503

\section{Notes}

The authors declare no competing financial interest.

\section{REFERENCES}

(1) Zamecnik, P. C.; Stephenson, M. L. Inhibition of Rous sarcoma virus replication and cell transformation by a specific oligodeoxynucleotide. Proc. Natl. Acad. Sci. U. S. A. 1978, 75 (1), 280-4.

(2) Stein, C. A.; Castanotto, D. FDA-Approved Oligonucleotide Therapies in 2017. Mol. Ther. 2017, 25 (5), 1069-1075.

(3) Shen, X.; Corey, D. R. Chemistry, mechanism and clinical status of antisense oligonucleotides and duplex RNAs. Nucleic Acids Res. 2018, 46 (4), 1584-1600.

(4) Herdewijn, P. Targeting RNA with Conformationally Restricted Oligonucleotides. Liebigs Ann. 1996, 1996, 1337-1348. 
(5) Roehr, B. Fomivirsen approved for CMV retinitis. J. Int. Assoc. Physicians AIDS Care 1998, 4, 14-6.

(6) Lundin, K. E.; Gissberg, O.; Edvard Smith, C. I. Oligonucleotide Therapies: The Past and the Present. Hum. Gene Ther. 2015, 26 (8), 475-485.

(7) Herdewijn, P. Nucleic acids with a six-membered 'carbohydrate' mimic in the backbone. Chem. Biodiversity 2010, 7 (1), 1-59.

(8) Egli, M.; Pallan, P. S.; Allerson, C. R.; Prakash, T. P.; Berdeja, A.; Yu, J.; Lee, S.; Watt, A.; Gaus, H.; Bhat, B.; Swayze, E. E.; Seth, P. P. Synthesis, Improved Antisense Activity and Structural Rationale for the Divergent RNA Affinities of 3'-Fluoro Hexitol Nucleic Acid (FHNA and Ara-FHNA) Modified Oligonucleotides. J. Am. Chem. Soc. 2011, 133 (41), 16642-16649.

(9) Hendrix, C.; Rosemeyer, H.; De Bouvere, B.; Van Aerschot, A.; Seela, F.; Herdewijn, P. 1', $5^{\prime}$-Anhydrohexitol Oligonucleotides: Hybridisation and Strand Displacement with Oligoribonucleotides, Interaction with RNase $\mathrm{H}$ and HIV Reverse Transcriptase. Chem. Eur. J. 1997, 3 (9), 1513-1520.

(10) Gryaznov, S.; Chen, J.-K. Oligodeoxyribonucleotide N3' $\rightarrow \mathrm{P5}^{\prime}$ Phosphoramidates: synthesis and Hybridization Properties. J. Am. Chem. Soc. 1994, 116 (7), 3143-3144.

(11) Verheggen, I.; Van Aerschot, A.; Toppet, S.; Snoeck, R.; Janssen, G.; Balzarini, J.; De Clercq, E.; Herdewijn, P. Synthesis and antiherpes virus activity of 1,5 -anhydrohexitol nucleosides. J. Med. Chem. 1993, 36 (14), 2033-2040.

(12) D’Alonzo, D.; Van Aerschot, A.; Guaragna, A.; Palumbo, G.; Schepers, G.; Capone, S.; Rozenski, J.; Herdewijn, P. Synthesis and Base Pairing Properties of 1',5'-Anhydro-L-Hexitol Nucleic Acids (LHNA). Chem. - Eur. J. 2009, 15, 10121-10131.

(13) De, S.; De Jonghe, S.; Herdewijn, P. Synthesis of a 3'-Fluoro-3' deoxytetrose Adenine Phosphonate. J. Org. Chem. 2017, 82 (18), 9464-9478.

(14) Mitsunobu, O. The Use of Diethyl Azodicarboxylate and Triphenylphosphine in Synthesis and Transformation of Natural Products. Synthesis 1981, 1981 (01), 1-28.

(15) Allart, B.; Busson, R.; Rozenski, J.; Van Aerschot, A.; Herdewijn, P. Synthesis of protected D-altritol nucleosides as building blocks for oligonucleotide synthesis. Tetrahedron 1999, 55 (21), 6527-6546.

(16) Katritzky, A. R.; Mokrosz, J. L.; Lopez-Rodriguez, M. L. Pyrylium-mediated transformations of natural products. Part 5. Reactions of gelatin and chymotrypsin with 4-(4-methoxy-3sulphophenyl)-2,6-bis-(4-sulphophenyl)pyrylium perchlorate. J. Chem. Soc., Perkin Trans. 2 1984, No. 0, 875-878.

(17) D’Alonzo, D.; Guaragna, A.; Van Aerschot, A.; Herdewijn, P.; Palumbo, G. De novo approach to L-anhydrohexitol nucleosides as building blocks for the synthesis of L-hexitol nucleic acids (L-HNA). Tetrahedron Lett. 2008, 49 (42), 6068-6070.

(18) Eleuteri, A.; Reese, C. B.; Song, Q. Synthesis of $3^{\prime}, 5^{\prime}$ dithiothymidine and related compounds. J. Chem. Soc., Perkin Trans. 1 1996, No. 0, 2237-2240.

(19) Krizmanić, I.; Višnjevac, A.; Luić, M.; Glavaš-Obrovac, L.; Žinić, M.; Žinić, B. Synthesis, structure, and biological evaluation of C-2 sulfonamido pyrimidine nucleosides. Tetrahedron 2003, 59 (23), $4047-4057$.

(20) Monger, S. J.; Parry, D. M.; Roberts, S. M. Selective removal of the methyldiphenylsilyl protecting group using azide ion. J. Chem. Soc., Chem. Commun. 1989, 0, 381-382.

(21) Obika, S.; Rahman, S. M. A.; Song, B.; Onoda, M.; Koizumi, M.; Morita, K.; Imanishi, T. Synthesis and properties of $3^{\prime}$-amino$2^{\prime}, 4^{\prime}$-BNA, a bridged nucleic acid with a $\mathrm{N} 3^{\prime} \rightarrow \mathrm{P}^{\prime}$ phosphoramidate linkage. Bioorg. Med. Chem. 2008, 16 (20), 9230-9237.

(22) Reese, C. B.; Ubasawa, A. Reaction between 1-arenesulphonyl3-nitro-1,2,4-triazoles and nucleoside base residues. Elucidation of the nature of side-reactions during oligonucleotide synthesis. Tetrahedron Lett. 1980, 21 (23), 2265-2268.

(23) Grugel, H.; Albrecht, F.; Minuth, T.; Boysen, M. M. K. Efficient Pseudo-enantiomeric Carbohydrate Olefin Ligands. Org. Lett. 2012, 14 (14), 3780-3783.
(24) Wolf, S.; Berrio, R. M.; Meier, C. Synthesis of Nonnatural Nucleoside Diphosphate Sugars. Eur. J. Org. Chem. 2011, 31, 63046313.

(25) Henbest, H. B.; Wilson, R. A. L. Aspects of stereochemistry. Part I. Stereospecificity in formation of epoxides from cyclic allylic alcohols. J. Chem. Soc. 1957, 0, 1958-1965.

(26) Fürst, A.; Plattner, P. A. Über Steroide und Sexualhormone. 160. Mitteilung. $2 \alpha, 3 \alpha$ - und $2 \beta$, $3 \beta$-Oxido-chlolestane; Konfiguration der 2-Oxy-cholestane. Helv. Chim. Acta 1949, 32 (1), 275-283.

(27) Thompson, A. S.; Humphrey, G. R.; DeMarco, A. M.; Mathre, D. J.; Grabowski, E. J. J. Direct conversion of activated alcohols to azides using diphenyl phosphorazidate. A practical alternative to Mitsunobu conditions. J. Org. Chem. 1993, 58 (22), 5886-5888.

(28) Abramov, M.; Marchand, A.; Calleja-Marchand, A.; Herdewijn, P. Synthesis of D-Altritol Nucleosides with a 3'-O-Tert-Butyldimethylsilyl Protecting Group. Nucleosides Nucleotides Nucleic Acids 2004, $23(1-2), 439-455$. 